\title{
ipen
}

AUTARQUIA ASSOCIADA À UNIVERSIDADE DE SÃO PAULO

\section{CARACTERIZAÇÃO FÍSICO-QUÍMICA DA CERÂMICA DO SÍTIO ARQUEOLÓGICO SÃO PAULO II}

\author{
ROGÉRIO BARIA RIBEIRO
}

Dissertação apresentada como parte dos requisitos para obtenção do Grau de Mestre em Ciências na Área de Tecnologia Nuclear - Aplicações

Orientador:

Prof. Dr. Casimiro Sepúlveda Munita 


\title{
INSTITUTO DE PESQUISAS ENERGÉTICAS E NUCLEARES
}

Autarquia associada à Universidade de São Paulo

\section{CARACTERIZAÇÃO FÍSICO-QUÍMICA DA CERÂMICA DO SÍTIO ARQUEOLÓGICO SÃO PAULO II}

\author{
ROGÉRIO BARIA RIBEIRO
}

\begin{abstract}
Dissertação apresentada como parte dos requisitos para obtenção do Grau de Mestre em Ciências na Área de Tecnologia Nuclear - Aplicações

Orientador:

Prof. Dr. Casimiro Sepúlveda Munita
\end{abstract}

Versão Corrigida

Versão Original disponível no IPEN

São Paulo

2013 
Aos meus pais: pela educação, valores e amor inaudito...

\author{
À minha irmã: pelo carinho e \\ compreensão...
}

\begin{abstract}
Aos amigos pelo apoio e suporte indispensável à realização deste.
\end{abstract}

Dedico

À Deus.

Ofereço 


\section{AGRADECIMENTOS}

AGRADEÇO...

... À Deus por guiar nossos caminhos...

... Ao Prof. Dr. Casimiro Sepúlveda Munita pela oportunidade, orientação e contribuição marcante para desenvolvimento deste...

... Ao Prof. Dr. Shigueo Watanabe pelo apoio, orientação e assistência durante o todo período deste...

... Ao Prof. Dr. Eduardo Góes Neves pelo suporte, incentivo e oportunidade de estudar a cerâmica Guarita...

... Ao Mestre Eduardo Tamanaha pelo suporte e oportunidade de estudar a cerâmica Guarita...

.. Á Profa. Dra. Sonia Hatsue Tatumi pela orientação e apoio para desenvolvimento deste...

... Ao Dr. Nilo Francisco Cano pelo apoio, incentivo e assistência durante todo período deste...

... À todos os colaboradores, colegas e amigos da Divisão de Radioquímica do IPEN... ... A
trabalho...

.. Á CNEN pelo aporte financeiro indispensável ao longo de todo 
... Á Universidade de São Paulo (USP) e ao IPEN pela oportunidade e por toda sua gloriosa história...

... Á todos aqueles que de forma direta ou indireta, contribuíram para concretização deste trabalho.

MUITO OBRIGADO! 


\title{
CARACTERIZAÇÃO FÍSICO-QUÍMICA DA CERÂMICA DO SÍTIO ARQUEOLÓGICO SÃO PAULO II
}

\author{
ROGÉRIO BARIA RIBEIRO
}

\begin{abstract}
RESUMO
A arqueometria é uma área consolidada, com ampla utilização de métodos analíticos nucleares destrutivos e não destrutivos para caracterização, proteção e restauração de peças arqueológicas. O presente projeto teve como objetivo estudar a composição química elementar de amostras de fragmentos cerâmicos encontradas no sítio arqueológico São Paulo II localizado na calha do rio Solimões, próximo ao município de Coari na Amazônia Brasileira. Realizou-se a caracterização das amostras pela determinação de Ce, Co, Cr, Cs, Eu, Fe, Hf, K, La, Lu, Na, Nd, Sb, Sm, Rb, Sc, Ta, Tb, Th, $\mathrm{U}, \mathrm{Yb}$ and $\mathrm{Zn}$ por meio da análise por ativação com nêutrons (NAA). A partir da composição química da cerâmica, foi possível definir o agrupamento de amostras em função da similaridade/dissimilaridade da composição química presente no material cerâmico. O agrupamento foi interpretado por métodos estatísticos multivariados como análise de cluster, análise de componentes principais e análise de discriminante. Foram selecionadas, a partir da formação dos grupos, 7 cerâmicas com o objetivo de elaborar o horizonte temporal do sítio, realizado por termoluminescência (TL) e ressonância paramagnética eletrônica (EPR). A temperatura de queima da cerâmica foi determinada em 6 fragmentos por meio da técnica de EPR. Os resultados apresentados neste trabalho podem contribuir com os estudos arqueológicos sobre a dinâmica da ocupação da Amazônia Central anterior à colonização Brasileira.
\end{abstract}




\title{
PHYSICAL AND CHEMICAL CHARACTERIZATION OF CERAMICS FROM ARCHAEOLOGICAL SITE SÃO PAULO II
}

\author{
ROGÉRIO BARIA RIBEIRO
}

\begin{abstract}
Archaeometry is currently a well established field in the archaeological sciences. The nuclear method for analysis of chemical elements is one of the important instruments for the characterization of the archaeological materials and has influences on the preservation and restoration. From the chemical and physical analyses it is possible to infer technical processes in ceramics manufacture and tools used by ancient people. Therefore, it contributes to the typology and to understand the roles of materials available in the archaeological sites, such as clays and lythic sources. Evidently, all the archaeological materials and sites are related to people that lived there a long time ago, and studies, as outlined above, reconstruct at least partially the history of such a population. This project aimed at studying the elementary chemical composition of 70 ceramic fragments samples from São Paulo II archaeological site, located along the Solimões River channel, next to Coari city, in Brazilian Amazon. The characterization of samples was performed by neutron activation analysis (NAA). By the determination of 22 elements in the ceramic fragments ( Ce, Co, Cr, Cs, Eu, Fe, Hf, K, La, Lu, Na, Nd, Sb, Sm, Rb, Sc, Ta, Tb, $\mathrm{Th}, \mathrm{U}, \mathrm{Yb}$ and $\mathrm{Zn}$ ), it was possible to define groups of samples regarding the similarity/dissimilarity in elementary chemical composition. For such a task, the multivariate statistical methods employed were cluster analysis (CA), principal component analysis (PCA) and discriminant analysis (DA). Afterwards, seven ceramic fragments have been selected to elaborate the site temporal horizon using thermoluminescence (TL) and electron paramagnetic resonance (EPR) dating results. The EPR technique was also used to find the average firing temperature to produce the ceramics. The results of this research may contribute to the study on the occupation dynamics in the pre-colonial Brazilian Amazon.
\end{abstract}




\section{SUMÁRIO}

Página

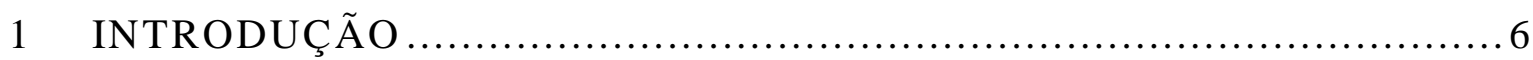

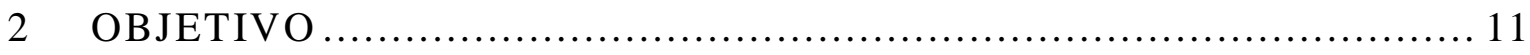

3 REVISÃO BIBLIOGRÁFICA A........................................... 12

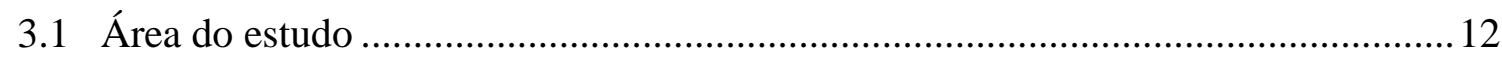

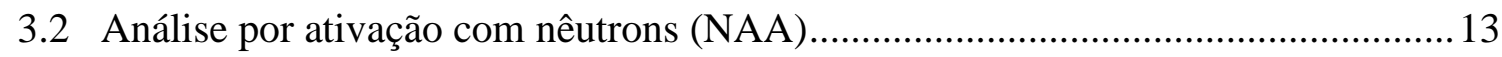

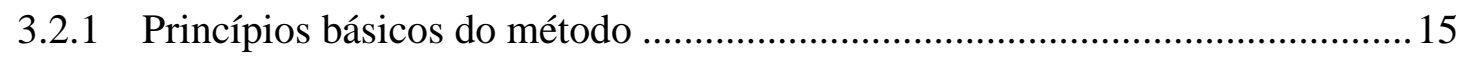

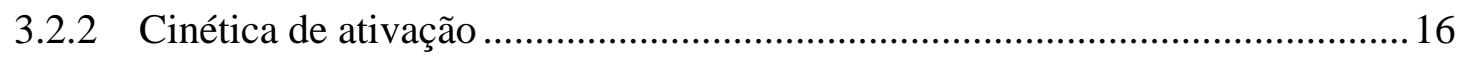

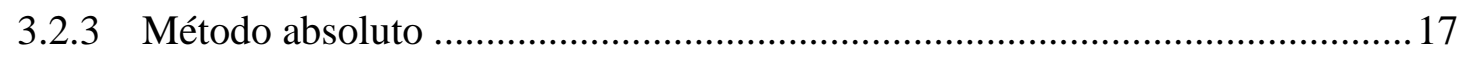

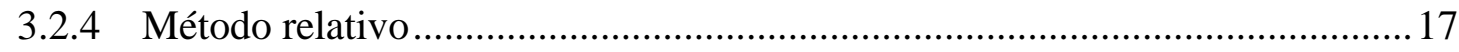

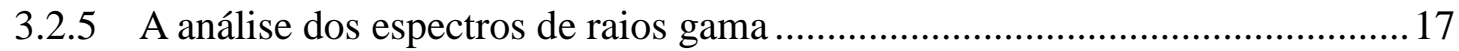

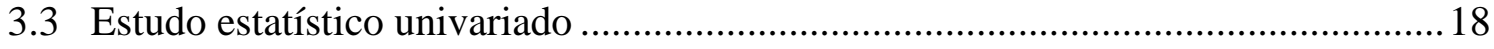

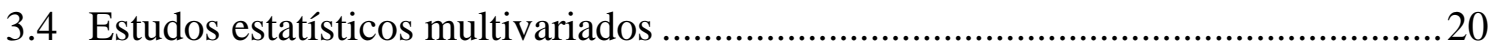

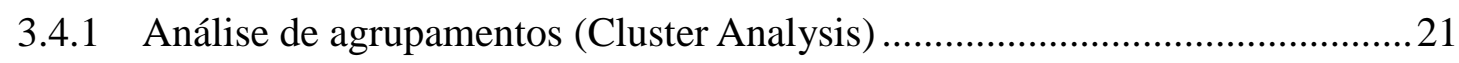

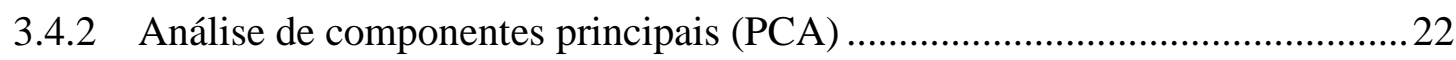

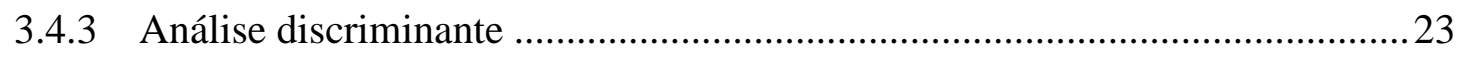

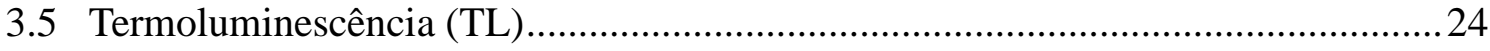

3.6 Ressonância paramagnética eletrônica (EPR) ….................................................25

4 MATERIAIS E MÉTODOS EXPERIMENTAIS ...........................29

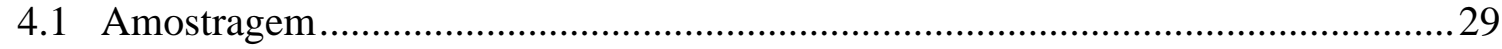

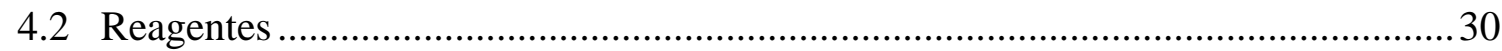

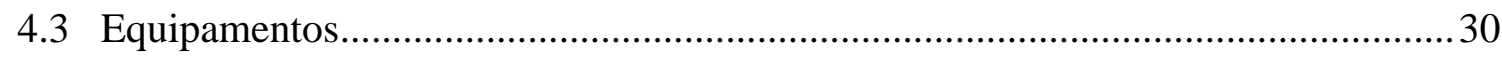

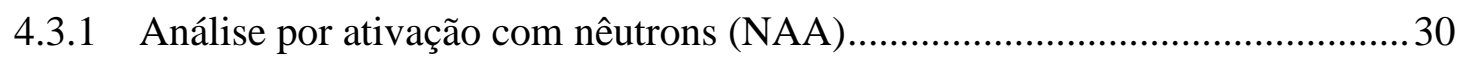

4.3.2 Datação por termoluminescência (TL) ......................................................... 31

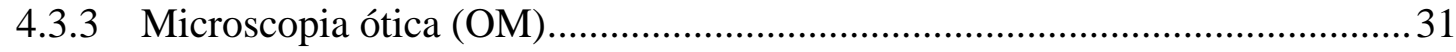

4.3.4 Ressonância paramagnética eletrônica (EPR) .............................................. 32

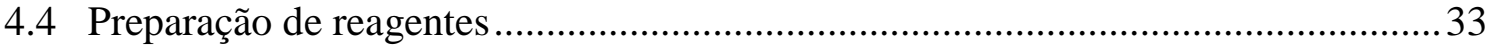

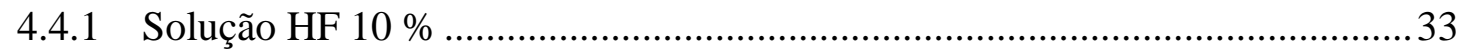

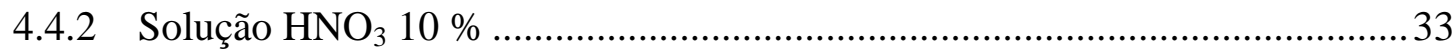




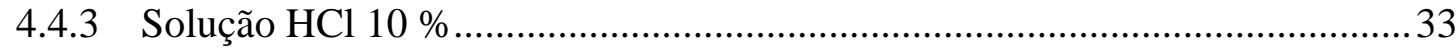

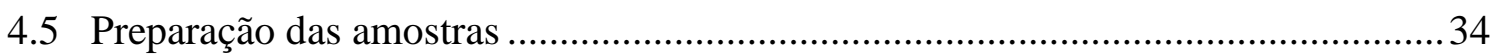

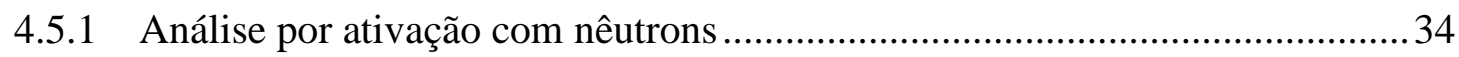

4.5.2 Procedimento para a obtenção do quartzo natural da amostra de cerâmica

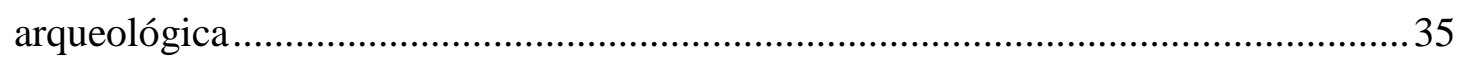

4.5.3 Temperatura de queima por ressonância paramagnética eletrônica..................36

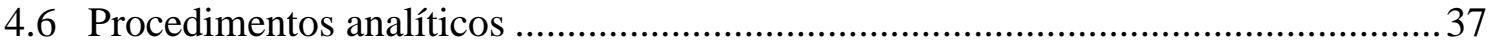

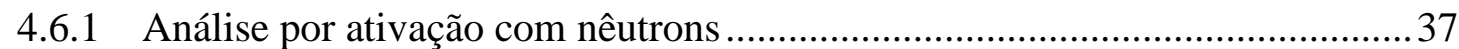

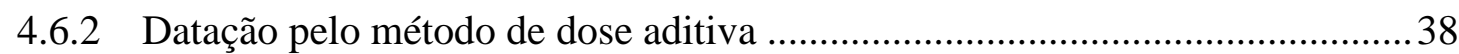

4.6.3 Temperatura de queima por ressonância paramagnética eletrônica.................. 39

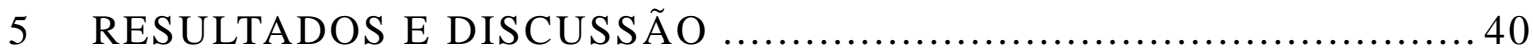

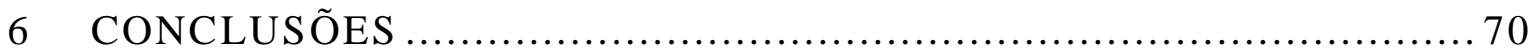

7 SUGESTÕES PARA TRABALHOS FUTUROS $\ldots \ldots \ldots \ldots \ldots \ldots \ldots \ldots \ldots \ldots \ldots$

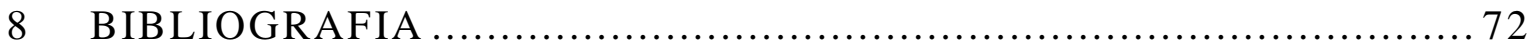




\section{LISTA DE FIGURAS}

FIGURA 1- Mapa com localização do sítio arqueológico São Paulo II. ............................ 12

FIGURA 2 - Representação do decaimento $(\mathrm{n}, \gamma)$ na ativação de um núcleo. 15

FIGURA 3 - (a) Níveis de energia do spin eletrônico em função de B. (b) Potência do microondas e a ressonância.

FIGURA 4 - O espectro EPR registrado, que é a derivada primeira $\mathrm{dP} / \mathrm{dH}$. ......................2 27

FIGURA 5 - Amostras de fragmentos cerâmicos do sítio São Paulo II...............................2 29

FIGURA 6 - Espectrômetro de radiação gama. ............................................................... 31

FIGURA 7 - Leitora TL Model Daybreak 1100 Automatic TL System............................ 31

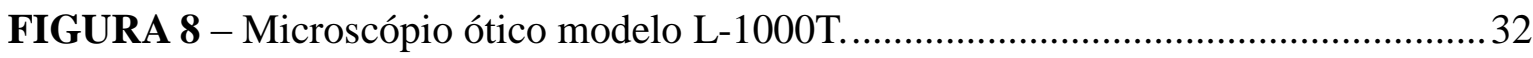

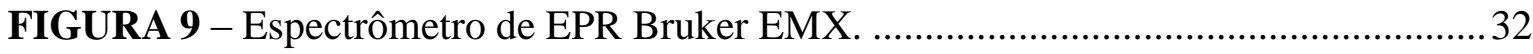

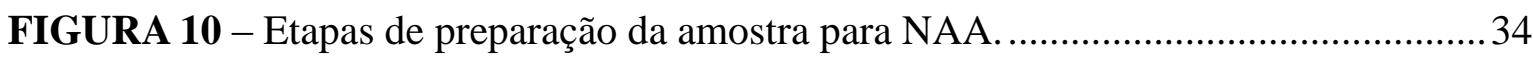

FIGURA 11 - Etapas de preparação da amostra para obtenção do quartzo. ....................... 36

FIGURA 12 - Etapas do preparo das amostras para o tratamento térmico. ..........................36

FIGURA 13 - Etapas para o processo de irradiação........................................................... 37

FIGURA 14 - Dendrograma da matriz de dados utilizando distância Euclideana quadrática

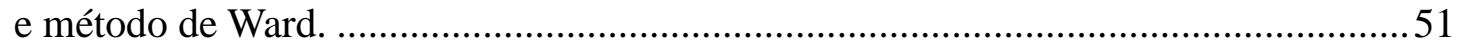

FIGURA 15 - Scores dos três primeiros componentes principais......................................53

FIGURA 16 - Análise discriminante dos grupos de cerâmicas do Sítio São Paulo II.........54

FIGURA 17 - Espículas encontradas na região da Amazônia.............................................55

FIGURA 18 - Grãos de quartzos encontrados nas amostras de cerâmicas utilizadas para

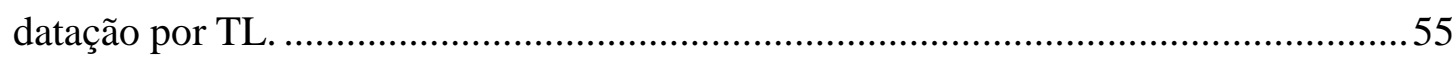

FIGURA 19 - Curva de emissão TL para a amostra 06, natural e adicional entre 0,5 Gy e 20 Gy. .56

FIGURA 20 - Curva de emissão TL para a amostra 11, natural e adicional entre 0,5 Gy e 20 Gy.

FIGURA 21 - Curva de emissão TL para a amostra 28, natural e adicional entre 0,5 Gy e 20 Gy.

FIGURA 22 - Curva de emissão TL para a amostra 49, natural e adicional entre 0,5 Gy e 20 Gy. 
FIGURA 23 - Intensidade TL contra doses adicionais entre 0,5 Gy e 20 Gy para a amostra 06.

FIGURA 24 - Intensidade TL contra doses adicionais entre 0,5 Gy e 20 Gy para a amostra 11 .

FIGURA 25 - Intensidade TL contra doses adicionais entre 0,5 Gy e 20 Gy para a amostra 28.

FIGURA 26 - Intensidade TL contra doses adicionais entre 0,5 Gy e 20 Gy para a amostra 49. 60

FIGURA 27 - Curva de comportamento das linhas de EPR em g=2.0092 para a amostra 05.

FIGURA 28 - Curva de comportamento das linhas de EPR em g=2.0092 para a amostra 30.

FIGURA 29 - Curva de comportamento das linhas de EPR em g=2.0092 para a amostra 56. 62

FIGURA 30 - Curva de calibração pelo método de dose aditiva para a amostra 05 63

FIGURA 31 - Curva de calibração usando o método de dose aditiva para a amostra 30 . 64

FIGURA 32 - Curva de calibração usando o método de dose aditiva para a amostra 56. .64

FIGURA 33 - Variação do fator g para o $\mathrm{Fe}^{3+}$ com a temperatura experimental realizada na amostra 02 . 66

FIGURA 34 - Variação do fator g para o $\mathrm{Fe}^{3+}$ com a temperatura experimental realizada na amostra 06. 66

FIGURA 35 - Variação do fator g para o $\mathrm{Fe}^{3+}$ com a temperatura experimental realizada na amostra 11 .

FIGURA 36 - Variação do fator g para o $\mathrm{Fe}^{3+}$ com a temperatura experimental realizada na amostra 47 .

FIGURA 37 - Variação do fator g para o $\mathrm{Fe}^{3+}$ com a temperatura experimental realizada na amostra 28.

FIGURA 38 - Variação do fator g para o $\mathrm{Fe}^{3+}$ com a temperatura experimental realizada na amostra 49 . 
LISTA DE TABELAS

Página

TABELA 1 - Limites de detecção para elementos em amostras de solo, em mg/kg.......... 14

TABELA 2 - Propriedades nucleares dos elementos determinados por NAA. .................. 18

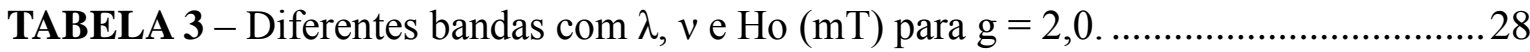

TABELA 4 - Resultados para o material de referências IAEA -Soil 7, valores em ppm a não ser quando indicado.

TABELA 5 - Resultados para o material de referências IAEA - Soil 7, valores em ppm a não ser quando indicado, $n=18$ e para $n=17$.

TABELA 6 - Resultado para 3 determinações na amostra 38. 43

TABELA 7 - Resultado para 3 determinações na amostra 01 44

TABELA 8 - Resultado para 3 determinações na amostra 39. 45

TABELA 9 - Resultados da concentra das amostras de cerâmicas, em $\mu \mathrm{g} / \mathrm{g}$ a não ser indicado, para $\mathrm{n}=70$ e distância de Mahalanobis (D).

TABELA 10 - Porcentagem da variança explicada para cada componente principal. .......52

TABELA 11 - Dose acumulada $\left(D_{a c}\right)$, Dose anual $\left(D_{a n}\right)$ e Idade $(I)$ das amostras, obtidas por TL.

TABELA 12 - Dose acumulada $\left(D_{a c}\right)$, Dose anual $\left(D_{a n}\right)$ e Idade $(I)$ das amostras obtidas por EPR 65

TABELA 13 - Resultado da temperatura de queima para as amostras analisadas. 69 


\section{INTRODUÇÃO}

A aplicação da química e da física à arqueologia não é um fato recente. Há publicações, em relatórios arqueológicos, do século XIX, que relatam ressultados apresentados por métodos físicos e químicos da época. Esses estudos foram realizados, como por exemplo, por Martin Heinrich Klaproth, farmacéutico, foi professor de química na universidade de Berlin em 1810. Klaproth dedicou-se à análise química de minerais e de materiais. A grande contribuição de Klaproth para arqueologia foi à determinação da composição de algumas moedas gregas e romanas, todas de cobre (Caley, 1949).

Outro nome importante é do químico inglês Humphry Davy, descobridor do óxido nitroso (NO). Davy, também, desempenhou um importante papel no desenvolvimento da química aplicada à arqueologia. Em 1815, escvreveu um relatório sobre a química de pigmentos de ruínas da Roma antiga. Michael Faraday, químico e físico inglês, também deixou sua contribuição à arqueologia. Faraday estudou uma grande variedade de materiais, incluindo moedas de cobre, bronze e vidros (Caley, 1951; Benedetto et. al., 1998; Chang, 2012).

Muitos outros químicos do século XIX, incluindo Kekulé, Berzelius e Berthelot contribuíram para o conhecimento da composição de materiais arqueológicos. Sem dúvida, a contribuição para arqueologia, destes e de outros cientistas, aqui não citados, foram menores quando comparada com a contribuição feita à química em geral. Mas, esses nomes deram os primeiros passos para o uso e desenvolvimento da ciência exata aplicada à investigação de materias arqueológicos (Peacock, 1970; Munita, 2010).

O desenvolvimento de técnicas instrumentais durante os anos de 1960 como a espectroscopia de emissão óptica (OES), análise por ativação com nêutrons (NAA), análise por raios-X (XRD) e espectrometria de massa (ICP) impulsionou os estudos de minerais e os estudos de materias arqueológicos. Atualmente, a análise físico-química de objetos arqueológicos é realizada por meio das ciências exatas (Física, Química e Petrografia) sob

a denominação de Arqueometria, termo apresentado em 1958. 
Um dos principais focos da Arqueometria é o estudo das cerâmicas. Esse material apresenta grande resistência, principalmente, ao intemperismos e podem ser encontrados em grandes quantidades nos sítios arqueológicos. O estudo deste importante material contribui para contextualização dos sítios (Latini et. al., 2001; Martini, 2004; Glascock et. al., 2004; Speakman e Glascock, 2007).

As cerâmicas são formadas de rochas sedimentares, nos quais os principais componentes são alumínios e silicatos. Também, são encontrados em menor quantidade os óxidos de $\mathrm{Na}, \mathrm{Mg}, \mathrm{K}$, e Fe. Os elementos estudados com mais frequência na arqueometria são os da ordem de traços, em concentrações inferiores a 0,01\% (Shepard, 1985).

A estrutura e a caracterização dos principais minerais que compõe a cerâmica foram estudadas durante as últimas décadas por uma grande variedade de técnicas. Essas foram desenvolvidas, como resultado dos avanços científicos e tecnológicos do pós-guerra. Estas técnicas incluem a análise de difração de raios-X (XDR), fluorescência de raios-X (XRF), espectrometria de massa (ICP), análise por ativação com nêutrons (NAA), termoluminescência (TL) e ressonância paramagnética eletrônica (EPR). O uso dessas tem como objetivo avaliar a composição química, a idade e a temperatura de queima utilizada na produção das cerâmicas (Speakman e Glascock, 2007; Lombardi, 2009; Stoltman, 2011; Knappett et. al., 2011; Rasmussen et. al., 2012; Farias e Watanabe, 2012).

A NAA é uma técnica nuclear não destrutiva que permite analisar de forma qualitativa e quantitativa elementos químicos presentes em diferentes tipos de matrizes. Esse método é considerado um dos mais confiáveis para a determinação de elementos inorgânicos em nível de traços e ultra-traços. Essa técnica consiste na produção de radioisótopos artificiais a partir de elementos estáveis. As amostras são irradiadas com um fluxo de nêutrons que interagem com os núcleos (ativáveis) dos isótopos dos elementos presentes na amostra formando os nuclídeos radioativos. O decaimento radioativo é caracterizado pela meia-vida $\left(\mathrm{T}_{1 / 2}\right)$ do radioisótopo, isto é, cada radioisótopo tem uma meia vida diferente de outros radionuclídeos. A identificação e quantificação das concentrações elementares são realizadas por meio da espectroscopia gama, que utiliza a intensidade da radiação emitida pelo elemento instável para determinar os componentes e suas concentrações (Glascock et. al., 2004; Hancock e Carter, 2010; Thorn e Glascock, 2010; Tandoh et. al., 2010).

Alguns materiais, quando aquecidos, após serem expostos à radiação ionizante apresentam a propriedade de emitir luz. Este fenômeno é conhecido como 
termoluminescência e o material que apresenta esta característica é denominado material termoluminescente (Aitken, 1978; Mckeever, 1985).

A TL é a luz emitida por cristais previamente aquecidos e expostos a algum tipo de radiação ionizante a baixas temperaturas (Kisrh, 1992). Em outras palavras, a termoluminescência é a emissão da energia que foi previamente armazenada no cristal durante o fluxo de radiação. Em geral, a termoluminescência presente nos grãos de quartzo, encontrados nas cerâmicas arqueológicas, está relacionada com o período de exposição à radiação natural, radiação proveniente dos elementos radioativos presentes no solo e na própria cerâmica. A termoluminescência resultante é proporcional ao tempo em que a amostra ficou exposta a essas radiações (Aitken, 1978; Aitken, 1985; Kisrh, 1992; Ikeya, 1993). A idade arqueológica da peça é definida quando ela é queimada (marco zero). Dessa forma, a datação do fragmento pode ser realizada a partir da medida de termoluminescência dos grãos de quartzo presentes na amostra (Aitken, 1985; Wintle, 1997; Ikeya, 1993).

A argila, principal constituinte dos materiais cerâmicos, apresenta espectro de ressonância paramagnética eletrônica. A EPR é uma técnica espectroscópica que mede a absorção de radiação de micro-ondas por espécies paramagnéticas, como os metais de transição quando submetidos a um campo magnético. Em materiais cerâmicos, os sinais são devido à absorção de micro-ondas e estão relacionados, essencialmente, à espécie paramagnética Fe ${ }^{3+}$ (Bensimon et. al., 1998; Mangueira et. al., 2011; Eaton e Eaton, 2012).

$\mathrm{Na}$ arqueometria, o uso da estatística avançada vem tonando-se mais frequente. Umas destas metodologias é a análise de grupos ou cluster analysis, uma técnica com conceitos matemáticos simples. O objetivo principal é agrupar amostras, de acordo com suas características, no caso, a composição química do material cerâmico. O resultado da análise de agrupamento é apresentado na forma de um dendrograma, uma representação gráfica de fácil visualização.

Outra ferramenta de análise multivariada, muito utilizada no estudo do comportamento de padrões químicos de materiais cerâmicos, é a análise de componentes principais (PCA). O conceito dessa técnica tem como base a redução da dimensão de um conjunto de variáveis correlacionadas. Essa redução é realizada a partir da transformação das variáveis originais em um novo conjunto de variáveis, chamados de componentes principais, não correlacionados e ordenados. A redução permite que um número reduzido de componentes retenha a maior parte das informações presentes na matriz original com a 
menor perda de informação (Jolliffe, 1989; Kaufman e Rousseeeuw, 1990; Jolliffe, et. al., 1995).

A análise discriminante ou discriminant analysis, a terceira técnica de agrupamento, é utilizada para discriminar populações e classificar amostras em grupos prédefinidos. Essa técnica permite determinar funções das variáveis originais, chamadas de funções discriminantes, com o objetivo de explicar as diferenças entre os grupos e, também, alocar novas amostras em grupos já definidos (Munita et. al., 2003; Hair et al., 2006).

O número de pesquisas arqueológicas na Amazônia Brasileira vem aumentando nos últimos anos. Isso tem ocorrido, principalmente, devido à implantação de obras de construções de grande porte, tais como barragens, hidrelétricas e gasodutos. Essas e outras obras deram início a projetos ligados à arqueologia preventiva, na Amazônia Brasileira, que inclui resgate e salvamento de materiais e sítios arqueológicos. A construção do gasoduto Coari-Manaus deu início ao projeto multidisciplinar PIATAM (Inteligência, Socioambiental Estratégica da Indústria do Petróleo na Amazônia). Esse projeto tem fornecido um número expressivo de material, datações e identificação de sítios arqueológicos da Tradição Polícroma da Amazônia (TPA). Um dos sítios estudados nesse projeto é o sítio São Paulo II. As cerâmicas resgatadas neste sítio foram catalogadas e classificadas como pertencente à fase Guarita (Tamanaha, 2012).

Esta dissertação visa à caracterização físico-química de 70 fragmentos cerâmicos coletados no sítio arqueológico São Paulo II, localizado no estado do Amazonas, as margens do rio Solimões. A caracterização química foi realizada por NAA e os resultados interpretados por métodos estatísticos multivariados. A caracterização física realizada por ressonância paramagnética eletrônica teve como finalidade obter informações sobre a temperatura de queima. Também, para complementar o estudo foi determinada a idade dos fragmentos cerâmicos por meio da técnica de datação por termoluminescência e por EPR. O conjunto destes resultados tem como objetivo contribuir com as discussões relacionadas à ocupação da região da Amazônia Central e com a preservação do Patrimônio Cultural Brasileiro.

Este trabalho foi realizado com a colaboração do Prof. ${ }^{\circ}$ Dr. Eduardo Góes Neves, do Museu de Arqueologia e Etnologia da USP (MAE-USP), que cedeu as amostras de fragmentos cerâmicos para o estudo. Contou com a colaboração do Laboratório de cristais iônicos, filmes finos e datação (LACIFID), localizado no Instituto de Física da USP 
São Paulo (IF-USP), com a pareceria do Prof. ${ }^{\circ}$ Dr. Shigueo Watanabe e do departamento de ciências do mar da Universidade Federal de São Paulo, Baixada Santista, SP, em parceria com a Prof(a). Dr(a). Sonia Tatumi. 


\section{OBJETIVO}

O trabalho teve como objetivo a caracterização físico-química de 70 fragmentos cerâmicos arqueológicos do sítio São Paulo II, estado Amazonas a $390 \mathrm{~km}$ da cidade de Manaus visando determinar os elementos químicos neles contidos, que são características dessas cerâmicas. Estudaram-se, também, pela técnica de ressonância magnética eletrônica, as temperaturas de queima na produção das cerâmicas. Para complementar este estudo, foram feitas datações de cerâmicas pelo método de termoluminescência e por ressonância paramagnética eletrônica; datas que, além de indicar a época em que os antigos habitantes ocuparam e viveram no sítio arqueológico mencionado podem contribuir para estabelecer a cronologia das sucessivas ocupações no decorrer dos tempos. Com o conhecimento de tudo que foi acima mencionado, não só o do sítio em estudo, mas de outros na vizinhança, os antropólogos podem reconstruir a história dos habitantes da região, no período pré-colonial. 


\section{REVISÃO BIBLIOGRÁFICA}

\section{1 Área do estudo}

O sítio São Paulo II está inserido na região da Bacia do Amazonas e ocupa uma área próxima à calha do rio Solimões, no município de Coari (AM) (FIG.1). O município de Coari está situado a $363 \mathrm{~km}$ de Manaus, o acesso é por via fluvial ou por via aérea. A cidade de Coari faz divisa com os municípios de Tapauá, Tefé, Codajas e Anori, sua área é de, aproximadamente, $57,3 \mathrm{~km}^{2}$ e população de 67 mil habitantes. As terras do sítio são utilizadas para pastagem, cultivo de banana, limão, mandioca e mamão. Podem-se observar, também, alterações da vegetação nativa, grande quantidade de fragmentos de cerâmica e terra preta (Tamanaha, 2012).

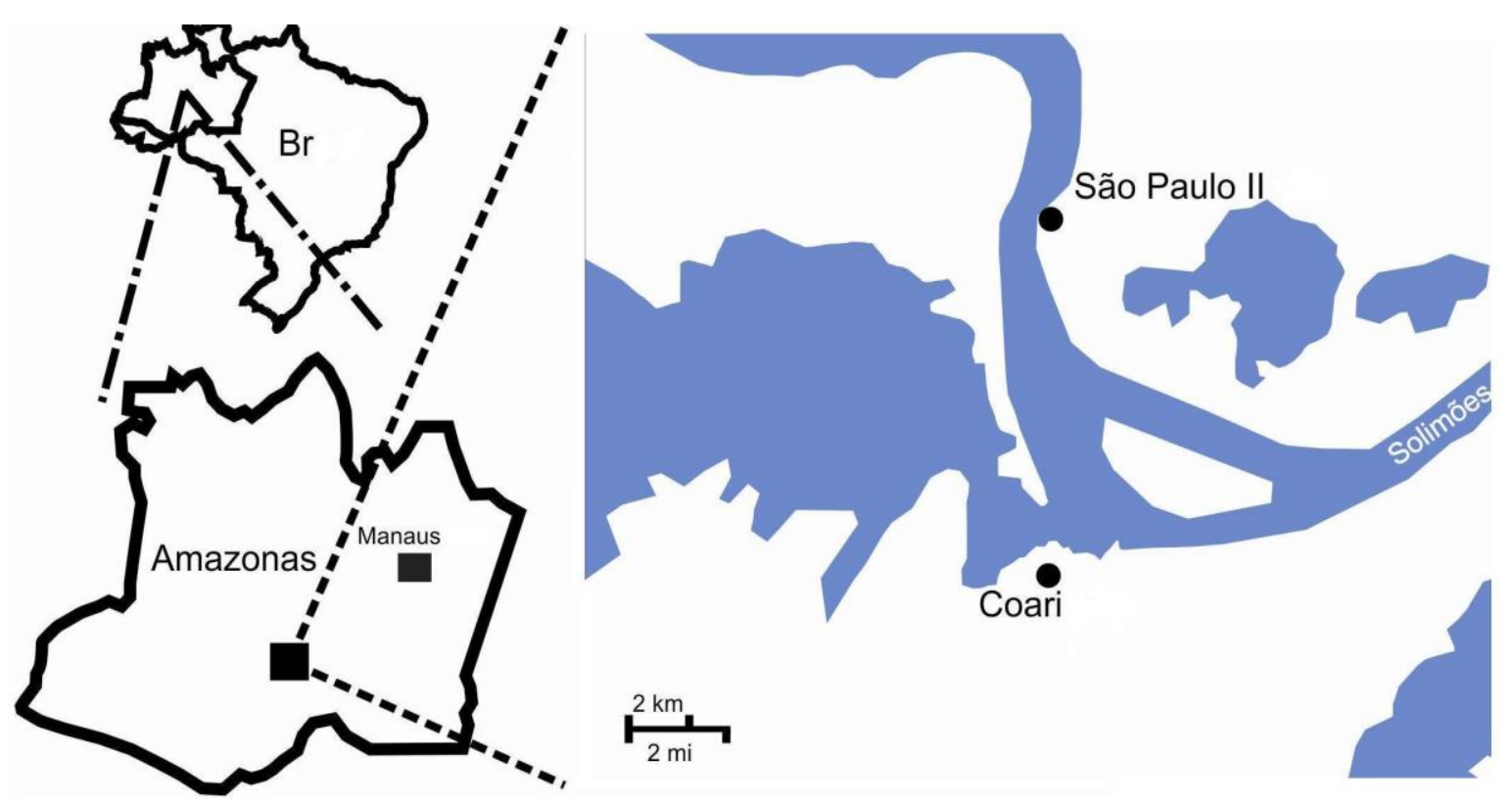

FIGURA 1- Mapa com localização do sítio arqueológico São Paulo II.

O relevo da região é formado, basicamente, por terras firmes e planícies fluviais. A terra firme compreende os planaltos de topografia plana e colinas com vertentes 
suaves e topo arredondados. As áreas dos planaltos são elevadas e fora do alcance das cheias dos rios. Na região, há um grande predomínio de rochas sedimentares da formação Içá, em geral, caracterizadas por processos erosivos. As planícies fluviais constituem terrenos aplanados e baixos, aptos à sedimentação aluviais, configurando áreas sazonalmente inundáveis, diques marginais, lagos, igarapés e ilhas (Costa, et. al., 1996; Bezzera, 2003; Rossetti et. al., 2005; Almeida-Filho e Miranda, 2007; Moita, 2008).

O clima da região da Amazônia Central é classificado como equatorial quente e úmido. Nessa região, o período mais chuvoso compreende os meses de dezembro a maio e o período de seca, os meses de julho a novembro. A vegetação que abrange a área do sítio é chamada de floresta densa tropical. Na região, as formações florestais são popularmente caracterizadas por matas de terra firme e matas de várzea. No município de Coari, há evidências da formação de florestas secundárias em diferentes etapas de desenvolvimento regenerativo, resultado da ação antrópica do desmatamento para a formação de pastos, extrativismo e desenvolvimento de outros cultivos (Tamanaha, 2012).

O solo da área do sítio é marcado pela presença de um horizonte antrópico, chamado popularmente de terra preta. Esse solo apresenta alta fertilidade, elevadas concentrações de matéria orgânica, Fósforo (P), Cálcio (Ca), Magnésio (Mg), Zinco ( $\mathrm{Zn})$, Manganês (Mn) e baixa concentração de Alumínio (Al) (Major et. al., 2005; Queiroz et. al., 2009).

\subsection{Análise por ativação com nêutrons (NAA)}

A análise de ativação com nêutrons é um método analítico quantitativo e qualitativo utilizado na determinação da concentração de uma grande variedade de elementos inorgânicos, na ordem de traços em diferentes tipos de matrizes. É um método nuclear baseado na atividade do radioisótopo formado através de reações nucleares entre o fluxo de nêutron incidente e o núcleo-alvo dos elementos que constitui a amostra (Dams, 1994; Roelandts, 2000).

A NAA foi utilizada pela primeira vez por Seaborg e Livingood para determinação de enxofre em amostras biológicas por meio do processo de (n, p) captura de nêutrons e emissão de prótons. Essa técnica, durante muitos anos, foi limitada ao uso acadêmico. Após a segunda guerra mundial e com o surgimento dos reatores com fluxos de nêutrons da ordem de $10^{11}$ a $10^{13} \mathrm{n} \mathrm{cm}^{-2} \mathrm{~s}^{-1}$, a NAA foi aperfeiçoada e assumiu um lugar de 
destaque entre as técnicas de instrumentação analítica (Seaborg e Livingood, 1938; Brown e Goldberg, 1948; Steinnes, 2004).

Apesar do crescimento e desenvolvimento de novas técnicas, a NAA ainda é a mais competitiva. A vantagem do método está na sua sensibilidade e precisão, especialmente na determinação de alguns elementos químicos inorgânicos. Na TAB. 1 são apresentados os dados de sensibilidade para determinação da composição elementar das amostras de solo irradiadas em um fluxo de nêutrons da ordem de $5 \times 10^{16} \mathrm{n} \mathrm{cm}^{-2} \mathrm{~s}^{-1}$. Além disso, o método permite a determinação simultânea de uma grande variedade de elementos (Bode e Coeij, 1998; Steinnes, 2004).

TABELA 1 - Limites de detecção para elementos em amostras de solo, em mg/kg. Fonte: Bode e Coeij (1998).

\begin{tabular}{|c|c|c|c|}
\hline Elemento & Solo & Elemento & Solo \\
\hline $\mathrm{Na}$ & 10 & $\mathrm{~K}$ & 1500 \\
\hline $\mathrm{Ca}$ & 4000 & $\mathrm{Sc}$ & 0,02 \\
\hline $\mathrm{Cr}$ & 1 & $\mathrm{Fe}$ & 100 \\
\hline Co & 0.3 & $\mathrm{Ni}$ & 30 \\
\hline $\mathrm{Zn}$ & 6 & $\mathrm{Ga}$ & 10 \\
\hline As & 0,8 & $\mathrm{Se}$ & 1 \\
\hline $\mathrm{Br}$ & 0,8 & $\mathrm{Rb}$ & 6 \\
\hline $\mathrm{Sr}$ & 60 & $\mathrm{Zr}$ & 80 \\
\hline Mo & 10 & $\mathrm{Ag}$ & 2 \\
\hline $\mathrm{Cd}$ & 8 & $\mathrm{Zn}$ & 20 \\
\hline $\mathrm{Sb}$ & 0,2 & $\mathrm{U}$ & 02 \\
\hline Cs & 0,3 & $\mathrm{Ba}$ & 40 \\
\hline $\mathrm{La}$ & 0,3 & $\mathrm{Ce}$ & 1 \\
\hline $\mathrm{Nd}$ & 8 & $\mathrm{Sm}$ & 0,03 \\
\hline $\mathrm{Eu}$ & 0,01 & $\mathrm{~Tb}$ & 0,1 \\
\hline $\mathrm{Yb}$ & 0,2 & $\mathrm{Lu}$ & 0,02 \\
\hline Hf & 0,1 & $\mathrm{Ta}$ & 0,2 \\
\hline
\end{tabular}




\subsubsection{Princípios básicos do método}

Depois da interação do nêutron com a matéria, as seguintes reações nucleares podem ocorrer: espalhamento elástico (n, n); espalhamento inelástico (n, n'); captura de nêutrons $(n, \gamma)$ : reações que produzem partículas, $(n, \alpha),(n, p)$, e $(n, 2 n)$, e fissão $(n, f)$ (Greenberg et. al., 2011; Frontasyeva, 2011).

A principal reação que ocorre durante a NAA é denominada captura radioativa de nêutrons (n, $\gamma$ ). Na FIG. 2 apresenta-se o processo de captura de nêutrons (n, $\gamma$ ). Nesse processo, o fluxo de nêutrons incidente interage com os isótopos estáveis do elemento alvo convertendo-os em radioativos. Posteriormente, o núcleo composto desses elementos emite radiação gama pronto para alcançar sua estabilidade (Bode e Coeij, 1998; Glascock e Neff, 2003; Greenberg et. al., 2011).

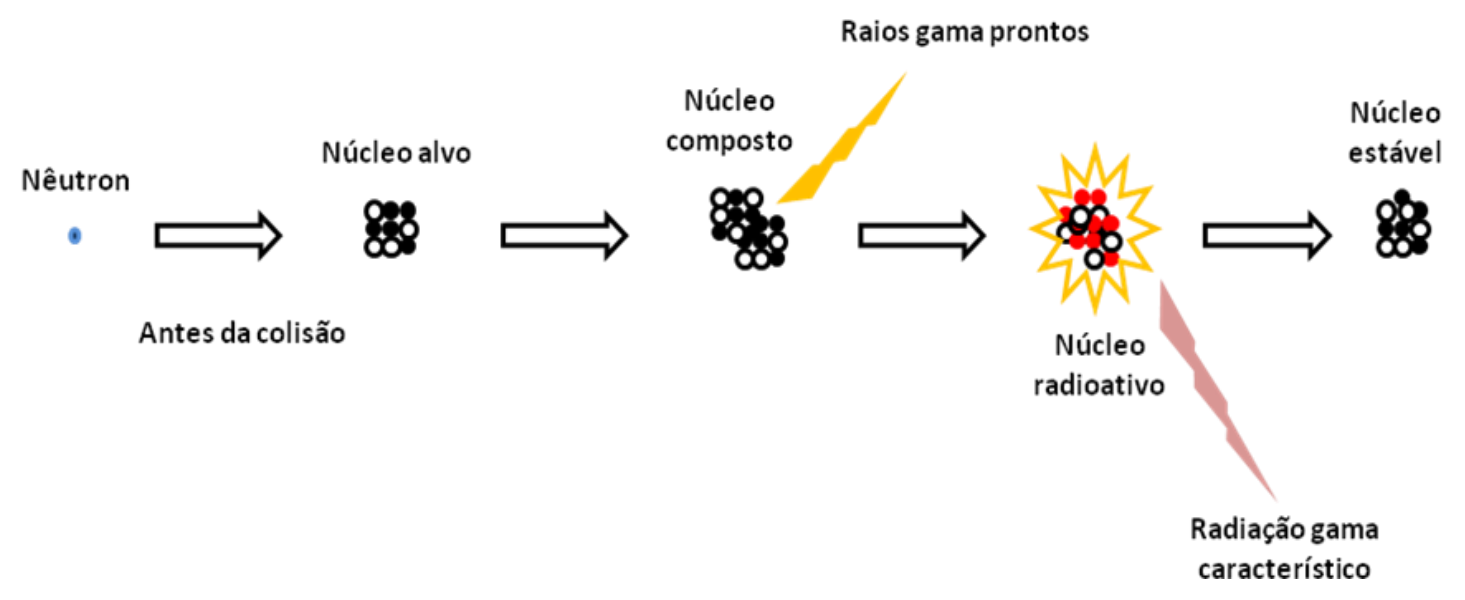

FIGURA 2 - Representação do decaimento (n, $\gamma$ ) na ativação de um núcleo. Fonte: Glascock e Neff (2003).

A quantidade de nuclídeos radioativos é determinada medindo a energia dos picos característicos desses radioisótopos (Parry, 1990). A reação que caracteriza o processo de captura de nêutrons apresenta-se na Equação 1:

$$
\mathbf{n}+{ }^{\mathrm{A}} \mathbf{Z} \rightarrow{ }^{\mathrm{A}+\mathbf{1}} \mathbf{Z}^{*} \rightarrow{ }^{\mathrm{A}+\mathbf{1}} \mathbf{Z}+\mathbf{Y} \quad \text { Equação } 1
$$

onde ${ }^{\mathrm{A}} \mathrm{Z}$ é o núcleo alvo; ${ }^{\mathrm{A}+1} \mathrm{Z}^{*}$ é o núcleo composto em estado excitado e $\gamma$ é a radiação gama característica. A radiação gama emitida pelo núcleo instável pode ser utilizada tanto 
para a análise qualitativa como quantitativa dos elementos presentes na amostra. Essa radiação pode ser medida por meio da técnica chamada de espectroscopia de raios gama (Frontasyeva, 2011).

O espectrômetro de raios gama é constituído, basicamente, de um detector e um semicondutor de germânio, ligados a um computador. Esse equipamento, ainda, pode ser acoplado a um analisador de canais múltiplos e dessa forma, capacitar à avaliação e os cálculos dos picos de energia emitidos pelo núcleo radioativo (Greenberg et. al., 2011).

\subsubsection{Cinética de ativação}

O fluxo de nêutrons $\phi\left(\mathrm{n} \mathrm{cm}^{-2} \mathrm{~s}^{-1}\right)$ interage com os elementos presentes na amostra, o resultado é uma série de reações nucleares e a formação de isótopos radioativos (radioisótopos). Após a irradiação, o elemento radioativo continua o processo de desintegração e, consequentemente, a sua atividade decrescerá exponencialmente com o tempo (Frontasyeva, 2011).

A atividade induzida (Equação 2) de um elemento, após irradiação, é proporcional ao número de átomos do nuclídeo alvo $\left(\mathrm{N}_{0}\right)$, fluxo de nêutrons $(\phi)$, tempo de exposição à irradiação $(\mathrm{t})$, meia vida característica do radionuclídeo $\left(\mathrm{T}_{1 / 2}\right)$, a secção de choque $(\sigma)$, eficiência do detector $(\mathrm{z})$, massa da amostra $(\mathrm{m})$, fração isotópica do elemento (f) e massa atômica do nuclídeo alvo (M) (Soete at. al., 1972).

$$
A=\frac{z N_{0} \phi \sigma \varphi m f}{M}\left(1-e^{\frac{-0,693 t}{T_{1 / 2}}}\right)
$$

A radioatividade induzida pode ser detectada por espectroscopia de raios gama, e assim, a partir dos picos de energia dos radioisótopos é possível determinar de forma simultânea, precisa e com boa sensibilidade a concentração do elemento que originou o radioisótopo (Glascock e Neff, 2003; Greenberg et. al., 2011). 


\subsubsection{Método absoluto}

O procedimento de normalização conhecido como "absoluto" pode ser aplicado para a determinação da concentração química dos elementos presentes na amostra. A quantificação pode ser efetuada baseada no fluxo de nêutrons incidentes. O cálculo é feito conhecendo-se algumas constantes físicas nucleares.

O método absoluto é trabalhoso, possui erros sistemáticos que podem ser consequência da incerteza dos dados nucleares retirados da literatura (abundância isotópica, secção de choque, fluxo de nêutrons, entre outras).

\subsubsection{Método relativo}

Neste trabalho, para determinar a concentração do elemento na amostra, foi adotado o método relativo. Esse método baseia-se na irradiação simultânea da amostra e padrões de concentrações conhecidas dos elementos investigados, seguida por medição da atividade induzida no padrão e na amostra (Balla et. al., 2004). A concentração do elemento de interesse $\left(\mathrm{C}_{\mathrm{a}}\right)$, na amostra, pode ser calculada a partir da Equação 3:

$$
\mathrm{C}_{\mathrm{a}}=\frac{\mathrm{m}_{\mathrm{p}} \mathrm{A}_{\mathrm{a}} \mathrm{e}^{0,693 \Delta \mathrm{t}_{\mathrm{T} / \mathrm{z}}}}{\mathrm{A}_{\mathrm{p}} \mathrm{M}_{\mathrm{a}}}
$$

onde $\Delta \mathbf{t}$ é diferença entre o tempo de decaimento da amostra e do padrão e $\mathrm{A}_{\mathrm{a}}, \mathrm{A}_{\mathrm{p}}$ são as atividades do radioisótopos de interesse na amostra e no padrão, $M_{a}$ é massa total da amostra, $\mathrm{m}_{\mathrm{p}}$ corresponde a massa do elemento no padrão e $\mathrm{T}_{1 / 2}$, meia vida do radioisótopo medido.

Os valores das constantes da secção de choque, eficiência do detector, fluxo de nêutrons e o tempo de irradiação são os mesmos. A precisão do método fica dependente, em grande parte, do processo de preparação do padrão e da amostra.

\subsubsection{A análise dos espectros de raios gama}

Os espectrômetros de medições para raios gama têm como objetivo a medida 
do número e da energia dos fótons emitidos por uma fonte. A localização do pico é uma medida da energia dos raios gama característico, enquanto que a área do pico é proporcional à taxa de emissão de fótons (Glascock, 1992). Na TAB. 2 são apresentados os parâmetros nucleares dos elementos determinados pela análise por ativação com nêutrons.

TABELA 2 - Propriedades nucleares dos elementos determinados por NAA. Fonte: Glascock (1992).

\begin{tabular}{ccccc}
\hline Elemento & Radioisótopo & $\mathbf{T}_{\mathbf{1} / \mathbf{2}}$ & $\begin{array}{c}\text { Seç̃ão de } \\
\text { choque }(\boldsymbol{\sigma})\end{array}$ & $\begin{array}{c}\text { Energia gama } \\
(\mathbf{k e V})\end{array}$ \\
\hline $\mathrm{Ce}$ & $\mathrm{Ce}-141$ & $32,50 \mathrm{~d}$ & 0,58 & 145,44 \\
$\mathrm{Co}$ & $\mathrm{Co}-60$ & $5,27 \mathrm{a}$ & 37,17 & 1332,50 \\
$\mathrm{Cs}$ & $\mathrm{Cs}-134$ & $2,06 \mathrm{a}$ & 29,00 & 795,84 \\
$\mathrm{Cr}$ & $\mathrm{Cr}-51$ & $27,70 \mathrm{~d}$ & 15,92 & 320,08 \\
$\mathrm{Eu}$ & $\mathrm{Eu}-152 \mathrm{~m}$ & $9,31 \mathrm{~h}$ & 9184,00 & 1408,01 \\
$\mathrm{Fe}$ & $\mathrm{Fe}-59$ & $44,50 \mathrm{~d}$ & 1,15 & 1099,25 \\
$\mathrm{Hf}$ & $\mathrm{Hf}-181$ & $42,39 \mathrm{~d}$ & 13,01 & 482,18 \\
$\mathrm{~K}$ & $\mathrm{~K}-42$ & $12,36 \mathrm{~h}$ & 1,46 & 1524,58 \\
$\mathrm{La}$ & $\mathrm{La}-140$ & $1,68 \mathrm{~d}$ & 9,04 & 1596,21 \\
$\mathrm{Lu}$ & $\mathrm{Lu}-177$ & $6,73 \mathrm{~d}$ & 2097,00 & 208,36 \\
$\mathrm{Na}$ & $\mathrm{Na}-24$ & $14,96 \mathrm{~h}$ & 0,53 & 1368,55 \\
$\mathrm{Nd}$ & $\mathrm{Nd}-147$ & $10,98 \mathrm{~d}$ & 1,49 & 531,02 \\
$\mathrm{Rb}$ & $\mathrm{Rb}-86$ & $18,63 \mathrm{~d}$ & 0,49 & 1077,00 \\
$\mathrm{Sm}$ & $\mathrm{Sm}-153$ & $46,27 \mathrm{~h}$ & 206,00 & 103,18 \\
$\mathrm{Sc}$ & $\mathrm{Sc}-46$ & $83,79 \mathrm{~d}$ & 27,16 & 889,28 \\
$\mathrm{Ta}$ & $\mathrm{Ta}-182$ & $114,43 \mathrm{~d}$ & 21,13 & 1221,41 \\
$\mathrm{~Tb}$ & $\mathrm{~Tb}-160$ & $72,30 \mathrm{~d}$ & 23,35 & 879,38 \\
$\mathrm{Th}$ & $\mathrm{Pa}-233$ & $26,96 \mathrm{~d}$ & 7,34 & 312,17 \\
$\mathrm{U}$ & $\mathrm{Np}-239$ & $2,35 \mathrm{~d}$ & 2,68 & 228,18 \\
$\mathrm{Yb}$ & $\mathrm{Yb}-175$ & $4,18 \mathrm{~d}$ & 63,2 & 396,32 \\
$\mathrm{Zn}$ & $\mathrm{Zn}-65$ & $244,26 \mathrm{~d}$ & 1,1 & 1115,55 \\
\hline
\end{tabular}

Para identificar a energia dos picos, os espectrômetros devem ser calibrados com fontes que emitem fótons de energias conhecidas. A área do pico pode ser calculada utilizando programas de computador combinados com funções matemáticas. Assim, vários elementos podem ser analisados simultaneamente.

\subsection{Estudo estatístico univariado}

Para interpretar uma série de resultados obtidos a partir de uma ou mais 
amostras, é necessário avaliar a existência de valores considerados discrepantes ou outliers, isto é valores que provavelmente não pertençam ao mesmo conjunto de resultados. Existem vários critérios utilizados para verificar se um ou mais valores são considerados discrepantes. Um desses critérios é conhecido como teste r. Nesse teste o valor de r é calculado por meio da Equação 4:

$$
r=\frac{|X i-\bar{X}|}{D P \sqrt{\frac{(n-1)}{n}}}
$$

Equação 4

onde $X i$ corresponde aos valores máximo e mínimos do conjunto de dados, $\bar{X}$ é a média dos resultados e DP é o desvio padrão. O cálculo de $\mathrm{r}$ depende do desvio-padrão do resultado para um ensaio. Os valores com $r_{\text {máximo }}$ e $r_{\text {mínimo }}$ maiores que $r_{\text {tabelado no nível de }}$ significância adotado, são eliminados da base de dados (Nalimov, 1963).

O DP é denominado um parâmetro de dispersão da distribuição dos resultados de uma análise e pode ser obtido a partir da Equação 5:

$$
\mathrm{DP}=\sqrt{\frac{\sum_{\mathrm{i}-1}^{\mathrm{n}}(\mathrm{Xi}-\overline{\mathrm{X}})^{2}}{(\mathrm{n}-1)}}
$$

onde DP é o desvio padrão, $X i$ corresponde aos valores do conjunto de dados e $\bar{X}$ é a média dos resultados.

A precisão é uma medida da proximidade dos resultados obtidos em um conjunto de medidas de uma mesma amostra. A precisão pode ser obtida por meio do desvio padrão relativo (DPR), dado em porcentagem pela Equação 6:

$$
\mathrm{DPR}=\frac{\mathrm{DP}}{\overline{\mathrm{X}}} \times 100 \%
$$

Equação 6

onde DP é o desvio padrão e $\bar{X}$ é a média das medidas.

Outro método que pode ser usado para identificar valores discrepantes em um conjunto de medidas é o cálculo da distância de Mahalanobis. A distância de Mahalanobis é uma medida que indica que a determinação está a vários desvios padrões do centro e, 
desta forma, a medida é considerada um outlier. A distância de Mahalanobis $\left(\mathrm{D}_{\mathrm{i}}\right)$ depende da matriz transposta $(T)$ e da matriz de covariância $(S)$. Para calcular $D_{i}$, usa-se a Equação 7 e 8 :

$$
D_{i}=\sqrt{(\mathrm{Xi}-\overline{\mathrm{X}})^{\mathrm{T}} \mathrm{S}^{-1}(\mathrm{Xi}-\overline{\mathrm{X}})}
$$

e,

$$
S=\sum_{i=1}^{n} \frac{(X i-\bar{X})(X i-\bar{X})^{T}}{(n-1)}
$$

onde $(\mathrm{Xi}-\overline{\mathrm{X}})$ representa o vetor da diferença entre os valores da medida e a média dos valores do grupo (Mahalanobis, 1936).

O valor crítico é utilizado como medida de parâmetro comparativo para o uso da distância de Mahalanobis. Os valores encontrados para o $\mathrm{D}_{\mathrm{i}}$ são comparados com o valor crítico. $\mathrm{O}$ valor de $\mathrm{D}_{\mathrm{i}}$ acima do valor crítico, no nível de significância adotado, é considerado outliers. O critério usado, neste trabalho, como valor crítico foi o de lambda Wilks, definido pela Equação 9:

$$
\frac{p(n-1)^{2}}{n\left(n-p-1+p F_{p, n-p-1, \alpha / n}\right)}
$$

onde $\mathrm{n}$ é o número de amostras, $\mathrm{p}$ o número de variáveis, $\mathrm{F}$ o distribuição de Fischer e $\alpha \mathrm{o}$ nível de significância. Neste trabalho foi adotado o nível de significância de 0,05 (Wilks, 1963).

\subsection{Estudos estatísticos multivariados}

A estatística multivariada é definida como um conjunto de métodos estatísticos com a finalidade de medir, simultaneamente, mais de uma variável (Hair et. at., 2006). Neste trabalho, a análise multivariada, por meio de uma abordagem gráfica, teve como objetivo, apresentar os grupos formados pelo conjunto de dados das concentrações elementares das cerâmicas do sítio São Paulo II. 
As técnicas utilizadas no tratamento multivariado dos dados foram à análise de grupamento, também conhecida por cluster analysis, análise de componentes principais e análise discriminante.

\subsubsection{Análise de agrupamentos (Cluster Analysis)}

A análise de agrupamento, também conhecida na literatura como cluster analysis, pertence a um conjunto de técnicas multivariadas que têm como objetivo agrupar um conjunto de dados em grupos homogêneos com base em critérios preestabelecidos. Essa técnica baseia-se em métodos simples de similaridade (Morrison, 1976; Hair et. al., 2006).

Para realizar a análise de agrupamento, primeiramente, deve-se obter a matriz de dados reunidos em uma tabela com $m$ colunas (variáveis) e $n$ linhas (amostras). O próximo passo é o cálculo da matriz de distância de similaridade. Por fim, deve-se escolher o algoritmo que será utilizado para formar os grupos. Os resultados do agrupamento são apresentados na forma de um gráfico bidimensional, conhecido como dendrograma. $\mathrm{O}$ gráfico facilita a interpretação, sendo assim uma ferramenta de grande utilidade para a classificação, comparação e discussão do agrupamento (Kaufman e Rousseeuw, 1990).

Em resumo, na análise de cluster existe diversas maneira de determinar a distância entre elementos de uma matriz de dados. As mais utilizadas são distância Euclideana e suas componentes, distância absoluta, distância de Minkowski e distância de Mahalanobis (Jobson, 1992).

Neste trabalho, foi utilizada a distância Euclideana ao quadrado. A expressão matemática, desta distância, pode ser vista na Equação 10. Esta distância é calculada entre duas amostras i e j, na qual representa o somatório dos quadrados das diferenças entre os valores de i e j para todas as variáveis:

$$
d_{i j}^{2}=\sum_{k=1}^{p}\left(X_{i k}-X_{j k}^{r}\right)^{2}
$$

onde X é a j-ésima característica da i-ésima amostra e X' é a j-ésima característica da i'ésima amostra. Quanto mais próximo de zero for o quadrado da distância Euclidiana, mais similares são os objetos comparados (Manly, 1986).

Por fim, na análise de agrupamento, é necessário estimar a distância entre os 
grupos pré-definidos e entre outros grupos ou amostras ainda não formados. Os critérios de agregação mais utilizados são o critério do vizinho mais próximo (single linkage), critério do vizinho mais afastado (complete linkage), critério da média dos grupos (average linkage), critério do centroide e o critério de Ward (Kaufman e Rousseeuw, 1990).

Neste trabalho, foi utilizado o critério de Ward, um método hierárquico que utiliza a comparação entre a soma dos quadrados dos desvios das amostras em relação à média dos grupos (Hair et al., 2006).

Dessa forma, a análise de agrupamento deve desencadear uma série de procedimentos matemáticos, onde critérios de similaridade/dissimilaridade podem ser usados para agrupar as amostras. Assim, os métodos utilizados nessa análise têm por objetivo a formação de grupos compostos por amostras, cujos resultados são posteriormente avaliados por outros métodos estatísticos multivariados como a análise de componentes principais e a análise discriminante.

\subsubsection{Análise de componentes principais (PCA)}

A análise de componentes principais (PCA) faz parte de um conjunto de técnicas estatística multivariada. O objetivo é a redução dos dados contidos nas variáveis de uma matriz de dados. Essa análise permite abordar aspectos como a geração, a seleção e a interpretação das variáveis investigadas.

A primeira pessoa que chamou este método de Principal Component Analysis foi Hotelling. Os conceitos matemáticos utilizados no método são simples e bem conhecidos. Mas, somente após o desenvolvimento da computação foi possível utilizar os autovalores e autovetores com o intuito de analisar matrizes de dados com um número muito grande de variáveis correlacionadas (Bouroche e Sporta, 1982).

$\mathrm{Na}$ prática, o PC é formado a partir de algoritmos baseados nas informações extraídas da matriz de variância-covariância. Para gerar o PC, é necessário, primeiramente, calcular a matriz de variância-covariância e encontrar os autovalores/autovetores. Cada componente principal é gerado fazendo-se o produto do fator (autovalor ou autovetor) por todas as variáveis da matriz, ou seja, uma combinação linear das variáveis originais. Os PCs gerados são, então, dispostos em ordem decrescente por suas variâncias, isto é, variância explicada pelo PC1 é maior que variância explicada pelo PC2 e assim, sucessivamente até a variância explicada pelo PCn (Hair et al., 2006). 
A PCA, assim como a análise de agrupamento, também permite agrupar os objetos a partir de critérios de similaridade/dissimilaridade. Como resultado, são formados grupos que podem ser visualizados por meio de um gráfico de dispersão de pontos. Este gráfico pode ter a forma bi ou tri dimensional. Desta forma, a visualização gráfica destes pontos permite uma melhor interpretação dos dados gerados pela PCA (Hair et al., 2006).

Segundo Davis (1986), as técnicas multivariadas permitem manipular um grande número de variáveis e consequentemente extrair informações de uma complexa base de dados. Vale ressaltar que, a análise envolve um conjunto complexo de fatores atuando simultaneamente. Por isso, para complementar o estudo multivariado, deve-se utilizar outras técnicas, como por exemplo, o método de análise discriminante.

\subsubsection{Análise discriminante}

A análise discriminante é uma técnica estatística multivariada utilizada para diferenciar grupos ou classes de amostras e, também, prever a probabilidade de certa amostra pertencer a uma determinada população (Hair et al., 2006).

O processo de discriminação parte do pressuposto de que $n$ amostras conhecidas pertencem a diversos subgrupos e procura determinar combinações lineares, chamadas de funções discriminantes, que melhor permitam alocar essas amostras. Dessa forma, essas funções têm a propriedade de minimizar a probabilidade de classificar de forma incorreta uma amostra em uma dada população ou grupo pré-definido.

A discriminação é a primeira fase dessa técnica e procura características capazes de serem utilizadas para alocar as amostras nos respectivos grupos (Johnson e Nichern, 2002). Segundo Hair et al. (2006), a função discriminante, apresenta a seguinte forma:

$$
\mathrm{Z}_{\mathrm{k}}=\mathrm{a}+\mathrm{U}_{1} \mathrm{X}_{1 \mathrm{k}}+\mathrm{U}_{2} \mathrm{X}_{2 \mathrm{k}}+\ldots+\mathrm{U}_{\mathrm{n}} \mathrm{X}_{\mathrm{nk}} \quad \text { Equação } 11
$$

onde $Z_{k}$, $Z$ é o escore para o objeto $\mathrm{k}$, a é a constante, $\mathrm{U}_{\mathrm{i}} \mathrm{o}$ coeficiente para a variável independente i e $\mathrm{X}_{\mathrm{ik}}$ é a variável independente i para o objeto k. Ainda segundo Hair et al. (2006), as técnicas multivariadas podem ser utilizadas para resolver muitos problemas práticos nas diversas áreas das ciências exatas, humanas e biológicas. 
$\mathrm{Na}$ maioria das vezes, os objetivos destes problemas só são resolvidos mediante aplicação em sequência de mais de uma técnica multivariada. Portanto, é interessante ter uma visão global de quase todas as técnicas multivariadas.

No tratamento multivariado de dados arqueológicos, as técnicas multivariadas mais utilizadas são a análise de agrupamentos, análise de componentes principais e análise discriminante. A análise multivariada foi utilizada com o objetivo de extrair o máximo de informações da matriz de dados, com a menor perda de informação.

\subsection{Termoluminescência (TL)}

Um parâmetro muito importante em arqueometria é a idade de objetos arqueológicos. Na década de 1970, com o desenvolvimento da tecnologia, o uso da datação por meio do método da luminescência térmica estendeu-se para matérias como a cerâmica arqueológica. Por este motivo, no início do ano de 1971, no Brasil, foram realizadas as primeiras datações por termoluminescência Estas medidas foram realizadas, no Instituto de Pesquisas Energéticas e Nucleares, IPEN/CNEN por Szmuk e Watanabe ( Szmuk e Watanabe, 1971).

A determinação das idades, que é a função principal da datação, os métodos usados são predominantemente físicos; excetuando o paleomagnetismo, em todos outros a radiação natural ou artificial tem um papel central. No conhecido método de carbono-14 (ou de radiocarbono) e nos de isótopos radioativos, a lei da radioatividade é a chave da datação, mas, nos métodos de luminescência térmica (TL) ou oticamente estimulada (LOE) e no de EPR, a radiação natural e artificial são usadas. Qualquer que seja o método usado, a idade dos objetos encontrados num sítio arqueológico, está intimamente ligada ao povo que viveu naquela época. Se houver mais de um sítio na região, as idades determinadas podem ajudar na reconstrução da relação cronológica desses povos. De uma forma geral, esse aspecto permite localizar, temporalmente, o objeto em uma cultura e também permite reconstruir o contexto arqueológico do sítio e da região de estudo (Aitken, 1978; Ikeya, 1993; Velde e Druc, 1999; Munita et. al., 2003; Pavia, 2006; Tite, 2008; Wintle, 2008)

Os cristais iônicos, como o quartzo, previamente irradiados com radiação ionizante, emitem luz quando aquecidos. Este fenômeno é conhecido como termoluminescência (TL). A radiação natural do solo é formada de raios $\alpha, \beta$ e $\gamma$ emitidos pelos radionuclídeos das séries de U-238 e Th-232. Existem tabelas que fornecem as doses 
da radiação natural de um lugar, desde que, por NAA ou ICP-MS, as concentrações de U238 e Th-232 sejam determinadas. É frequentemente usada a Tabela 4.5 da página 112 de Ikeya, 1993, mas existem outras para serem consultadas. Há na natureza, radioisótopos como o K-40, que contribuem para a dose anual. Na tabela citada acima, a dose devido K40 é obtida determinando a $\%$ em peso de $\mathrm{K}_{2} \mathrm{O}$. Esses elementos $\mathrm{U}$, Th e o $\mathrm{K}$ têm meiavida característica, em torno de $10^{9}$ anos, dessa forma, o fluxo de radiação é praticamente constante e a TL resultante é proporcional ao tempo em que a amostra ficou exposta a essas radiações. O "marco zero" da idade arqueológica da peça é definido quando ela é queimada, porque a queima elimina todo o sinal TL que a amostra acumulou no período anterior a sua coleta para a datação (Aitken, 1985; Ikeya, 1993; Wintle, 1997; Oliveira et.al., 2006; Wintle, 2008; Farias e Watanabe, 2012).

Para obter a idade do fragmento por termoluminescência, é necessário realizar medidas da dose acumulada, conhecida como $\mathrm{D}_{\mathrm{ac}}$ em Gray, nos cristais de quartzo. Posteriormente, deve-se obter a taxa de dose anual $D_{a n}$ em Gy/ano do local em que a cerâmica foi retirada. Por fim, são consideradas as contribuições da radioatividade natural. Para obter a idade do fragmento utiliza-se a Equação 12 (Ikeya, 1993):

$$
\mathrm{I}=\mathrm{D}_{\mathrm{ac}} / \mathrm{D}_{\mathrm{an}}
$$

onde, $D_{a c}$ é a dose acumulada e $D_{a n}$ a taxa de dose anual.

\subsection{Ressonância paramagnética eletrônica (EPR)}

A ressonância paramagnética eletrônica foi observada em 1945 pelo físico russo Zavoisky em $\mathrm{CuCl}_{2} \cdot \mathrm{H}_{2} \mathrm{O}$ a $133 \mathrm{MHz}$. Os resultados foram interpretados por Frenkel (Weil e Bolton, 2007).

Um elétron, classicamente, é considerado uma esfera negativamente carregada e em rotação (spin do elétron). Uma carga em rotação produz um campo magnético equivalente ao de um pequeno imã. Como a carga do elétron é negativa, o sentido da corrente elétrica equivalente é o oposto do spin (da rotação) (Atherton, 1993).

Da mesma forma que um imã, o elétron tem um momento magnético. Numa substância, a tendência é a de dois elétrons formarem um par com spins opostos, isto é, com momentos magnéticos opostos, portanto, com momento magnético total zero. Fazem 
exceções alguns átomos e moléculas que tem spins paralelos. Os elementos de transição e de terras raras são casos interessantes e importantes do ponto de vista de EPR. Outro caso importante é aquele em que um elétron é capturado por um defeito pontual. Em termos de bandas de energia, esse elétron é um elétron armadilhado (Atherton, 1993; Ikeya, 1993).

$\mathrm{O}$ elétron de momento magnético $\mu$, colocado num campo magnético $\mathrm{B}$ interage com a energia:

$$
\mathrm{E}=-\vec{\mu} \overrightarrow{\mathrm{B}}
$$

Equação 13

e é chamada de energia de Zeeman. Sendo $\vec{S}$ spin do elétron, o momento magnético do elétron pode ser escrito pela Equação 14:

$$
\vec{\mu}=\operatorname{g\beta } \vec{S}
$$

Equação 14

onde g é chamado fator de separação espectroscópico e vale $g=2,0023, \beta$ é o magnéton de Bohr. Quanticamente, S em relação a uma direção (que pode ser o do campo magnético) pode ter duas projeções $M=+1 / 2$ e $M=-1 / 2$, onde $M$ é chamado de número quântico magnético. Assim, a energia de Zeeman pode ser escrita como:

$$
\mathrm{E}_{\mathrm{z}}=\mathrm{g} \beta \mathrm{B} \mathrm{M}
$$

Equação 15

isto é, $E_{z}$ pode ser $-1 / 2 \mathrm{~g} \beta \mathrm{B}$ ou $+1 / 2 \mathrm{~g} \beta \mathrm{B}$, E' é o efeito Zeeman quântico. Isto significa que o momento magnético dos elétrons que estão orientados, aleatoriamente, na ausência de um campo magnético externo, na presença deste se orientam ou paralelamente ou antiparalelamente ao campo magnético. $\mathrm{O}$ estado de $\mathrm{E}_{\mathrm{z}}=-1 / 2 \mathrm{~g} \beta \mathrm{B}$ de $\mathrm{M}=-1 / 2$ é de energia mais baixa que o de $E_{z}=+1 / 2 g \beta$ B (Atherton, 1993; Ikeya, 1993). A FIG. 3 (a) mostra como a energia $E_{z}$ varia com $B$.

Para B= B', a energia de um estado a outro é:

$$
\Delta \mathrm{E}=\mathrm{g} \beta \mathrm{B}
$$

Quando ao sistema de momentos magnéticos de elétrons no campo magnético $\mathrm{B}$, incide uma microonda, quando a frequência $v$ desta for igual a g $\beta$ B'/h, é possível, por absorção 
de energia $\Delta \mathrm{E}$ de microonda, os spins dos elétrons do estado $\mathrm{M}=-1 / 2$ passar para o estado de $\mathrm{M}=+1 / 2$. A condição de ressonância é $h v=\mathrm{g} \beta \mathrm{B}$ '.

(a)

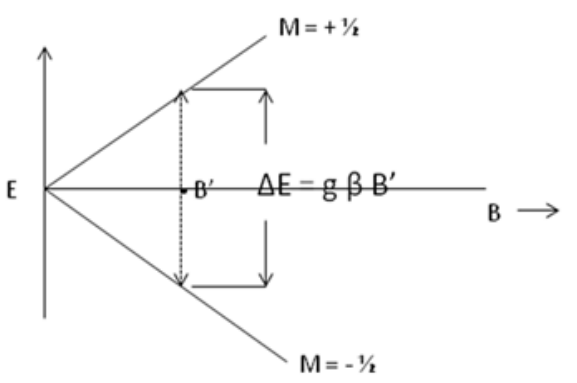

(b) $\mathrm{P}$

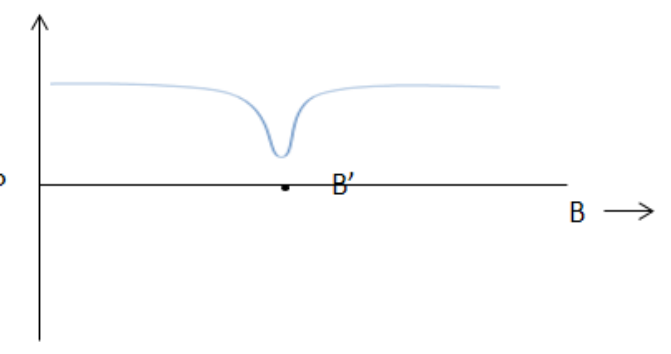

FIGURA 3 - (a) Níveis de energia do spin eletrônico em função de B. (b) Potência do microondas e a ressonância. Fonte: Ikeya (1993).

Na FIG. 3 (b) têm-se a potência de microonada e a absorção de energia h $\nu=g \beta$ B' na ressonância. Na prática, um espectrômetro de EPR é feito de modo que, ele detecta e registra não só a banda de absorção, mas, a sua derivada primeira da curva de absorção (Ikeya, 1993).

A frequência (ou o campo magnético) de ressonância é dada pela banda de absorção da FIG. 3 (b). Mas, na prática, devido à modulação da absorção de microonda por uma frequência alta de $100 \mathrm{kHz}$ e amplificação eletrônica, a curva que o espectrômetro fornece é a derivada primeira $\mathrm{dP} / \mathrm{dH}$ da potência. A FIG. 4 mostra o tipo de espectro fornecido pela EPR (Ikeya, 1993).

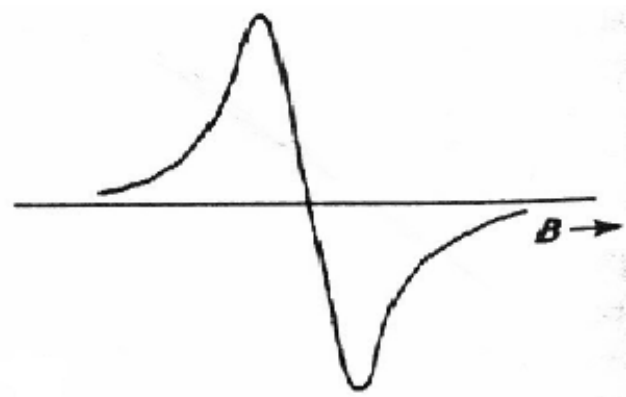

FIGURA 4 - O espectro EPR registrado, que é a derivada primeira dP/dH. Fonte: Ikeya (1993)

O fator de separação espectroscópico, o fator-g de um sinal EPR, como o da FIG. 4, é um parâmetro muito importante, pois, enquanto seu valor é 2,0023 quando não está sobre a ação de um campo, como já foi visto, quando se encontra num ambiente, em 
geral poliédrico ou capturado num defeito, assume valores ligeiramente diferentes. Há situações em que o valor de $\mathrm{g}$ pode ser grande como no sinal do $\mathrm{Fe}^{3+}$ em magnetita, com $\mathrm{g}$ $\sim 9.0$, em hematita com $\mathrm{g} \sim 6.0$, etc (Ikeya, 1993).

Como já foi visto sendo $v_{\mathrm{s}}$ a frequência de ressonância da microonda e $\mathrm{B}_{\mathrm{s}} \mathrm{a}$ intensidade do campo magnético, temos:

$$
\mathrm{h} v_{\mathrm{s}}=\mathrm{g} \beta \mathrm{B}_{\mathrm{s}}
$$

Equação 17

Como é mais fácil construir um espectrômetro com campo magnético variável, fixa-se a frequência e varia o campo magnético.

Encontram-se no mercado, 5 espectrômetros, cada um, caracterizado pela frequência fixa, chamada banda. A TAB. 3 mostra, para 5 bandas, os respectivos comprimento de onda, frequência e o campo magnético $B_{o}$ em mT para $g=2,0$.

TABELA 3 - Diferentes bandas com $\lambda$, v e Ho (mT) para g = 2,0. Fonte: Ikeya (1993).

\begin{tabular}{cccc}
\hline Banda & Comp. de onda $(\mathbf{c m})$ & Freq. $\left(\mathbf{G H}_{\mathbf{z}}\right)$ & $\mathbf{H}_{\mathbf{o}}(\mathbf{m T})$ \\
\hline $\mathrm{L}$ & 20 & 1,5 & 53,5 \\
$\mathrm{~S}$ & 9,4 & 3,2 & 114 \\
$\mathrm{X}$ & 3,2 & 9,5 & 339 \\
$\mathrm{~K}$ & 1,2 & 25 & 892 \\
$\mathrm{Q}$ & 0,85 & 35 & 1250 \\
\hline
\end{tabular}

A ressonância paramagnética eletrônica é uma técnica poderosa no estudo das propriedades, em geral, de sólidos em física e em química. Em consequência, muitos materiais são estudados com EPR. Pelo fato de sinais EPR dependerem da irradiação do material em estudo, e da intensidade EPR variar com a dose da radiação, a EPR assim como a TL é usada na dosimetria da radiação. Pelo mesmo motivo, é usada, também, nas datações arqueológicas e geológicas. 


\section{MATERIAIS E MÉTODOS EXPERIMENTAIS}

\subsection{Amostragem}

Os fragmentos cerâmicos, estudados neste trabalho, foram coletados no sítio arqueológico São Paulo II localizado na Amazônia Central. As amostras foram estudadas e cedidas pelo grupo do professor Eduardo Góes Neves do Museu de Arqueologia e Etnologia da USP (MAE-USP). Na FIG. 5 apresentam-se alguns desses fragmentos cerâmicos.

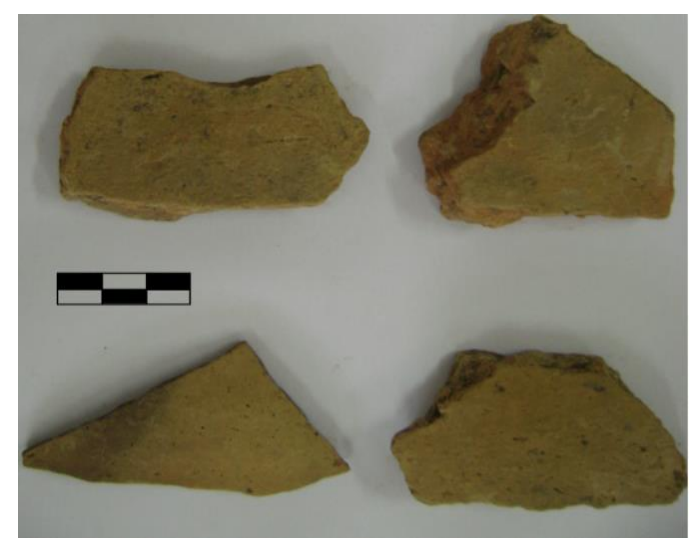

FIGURA 5 - Amostras de fragmentos cerâmicos do sítio São Paulo II.

Para o desenvolvimento deste projeto, foram selecionadas 70 amostras de fragmentos cerâmicos. Os fragmentos foram coletados, por arqueólogos, da equipe do Professor Eduardo Goes Neves, no sítio São Paulo II. Os pontos de escavação foram chamados de unidades básicas, formadas a partir da divisão do sítio arqueológico em quadras de $1 \mathrm{~m}^{2}$. Os fragmentos cerâmicos estavam dispersos de forma irregular em determinados pontos do sítio. A incidência de terra preta e quantidade de fragmentos cerâmicos foram utilizados como critério para delimitar a área onde se localizam os pontos de unidades de escavações. Ao todo foram abertas oito unidades de $1 \mathrm{~m}^{2}$, variando a profundidade de $10 \mathrm{~cm}$ até $60 \mathrm{~cm}$. As cerâmicas foram catalogadas e receberam um 
código de identificação representando o número de proveniência, ou seja, a localização geográfica da quadra e o número de identificação da peça arqueológica (Tamanaha, 2012).

Desta forma, para que o espaço amostral, deste trabalho, represente a população das amostras do sítio, escolheram-se fragmentos de todos os pontos de escavação e diferentes níveis de profundidade, seguindo a orientação do código de identificação da amostra para que mais de um fragmento por peça não seja analisado. A seguir, são apresentados os métodos de preparo das amostras para NAA, TL, EPR, OM e $\mathrm{XRD}$, os materiais, os reagentes e, também, as características de todos os equipamentos utilizados.

\subsection{Reagentes}

Todos os reagentes usados foram de grau analítico.

- Ácido fluorídrico $37 \%$ p/p

- Ácido clorídrico $35 \%$ p/p

- Ácido nítrico $65 \% \mathrm{p} / \mathrm{p}$

- Peróxido de hidrogênio $30 \%$ v/v

\subsection{Equipamentos}

\subsubsection{Análise por ativação com nêutrons (NAA)}

Em um detector de Ge hiperpuro modelo GX 2519, com resolução de 1,90 keV no pico de $1332 \mathrm{keV}$ do ${ }^{60} \mathrm{Co}$, placa S-100 MCA, ambos da Canberra, com 8192 canais (FIG. 6), realizaram-se as medidas da atividade gama induzida nas amostras.

Os espectros de raios gamas, assim como a determinação das concentrações foram obtidos por meio do programa Genie-2000 NAA Processing Procedure desenvolvido pela Canberra. 


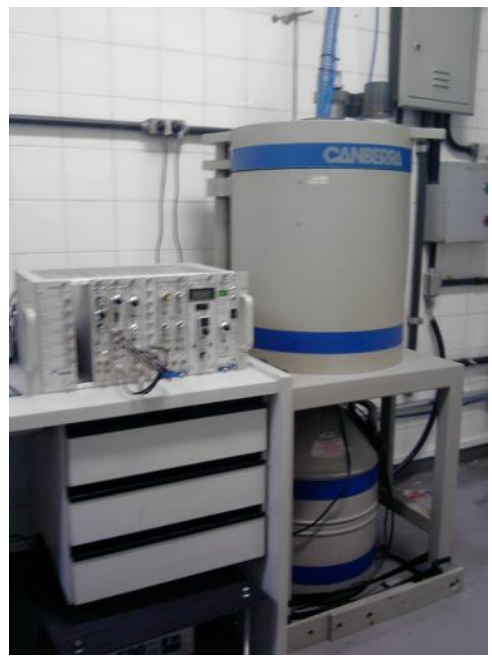

FIGURA 6 - Espectrômetro de radiação gama.

\subsubsection{Datação por termoluminescência (TL)}

Foi utilizado um leitor automático tipo Daybreak modelo 1100 Automated TL System, fabricado por Systems Inc., operando no Laboratório LACIFID do Instituto de Física da Universidade de São Paulo para obter as curvas de emissão TL. Na FIG. 7 é apresentado o leitor do tipo Daybreak.

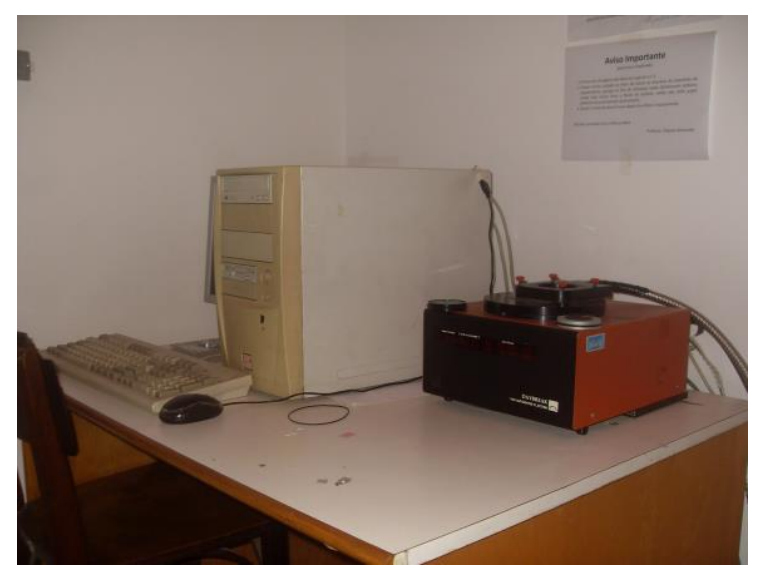

FIGURA 7 - Leitora TL Model Daybreak 1100 Automatic TL System.

\subsubsection{Microscopia ótica (OM)}

Para estudar a presença dos grãos de material amorfo utilizou-se um microscópio ótico da marca Bioval, modelo L-1000T, na versão trilocular, com capacidade de aumento de 40 a 1600x (FIG. 8). 


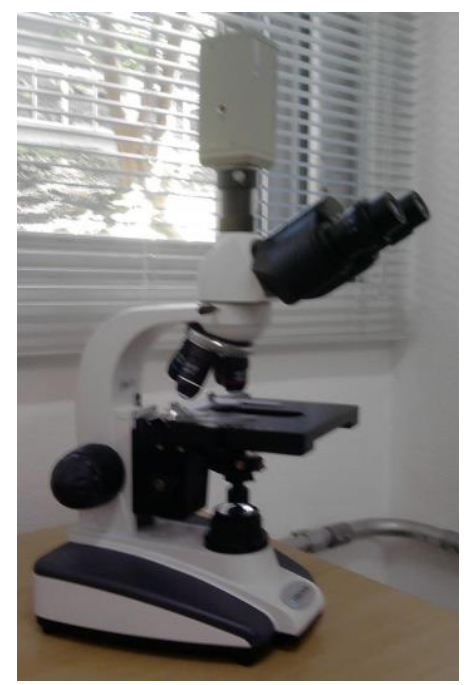

FIGURA 8 - Microscópio ótico modelo L-1000T.

A imagem dos grãos das amostras analisadas foi obtida com uma câmera 1/4" CCD modelo VI 6631 acoplada ao microscópio ótico com aumento de 64x.

\subsubsection{Ressonância paramagnética eletrônica (EPR)}

Utilizou-se o espectrômetro Bruker EMX, modelo ER 4102ST que opera na banda-X (9,75 Ghz), do Instituto de Física da Universidade de São Paulo (FIG. 9).
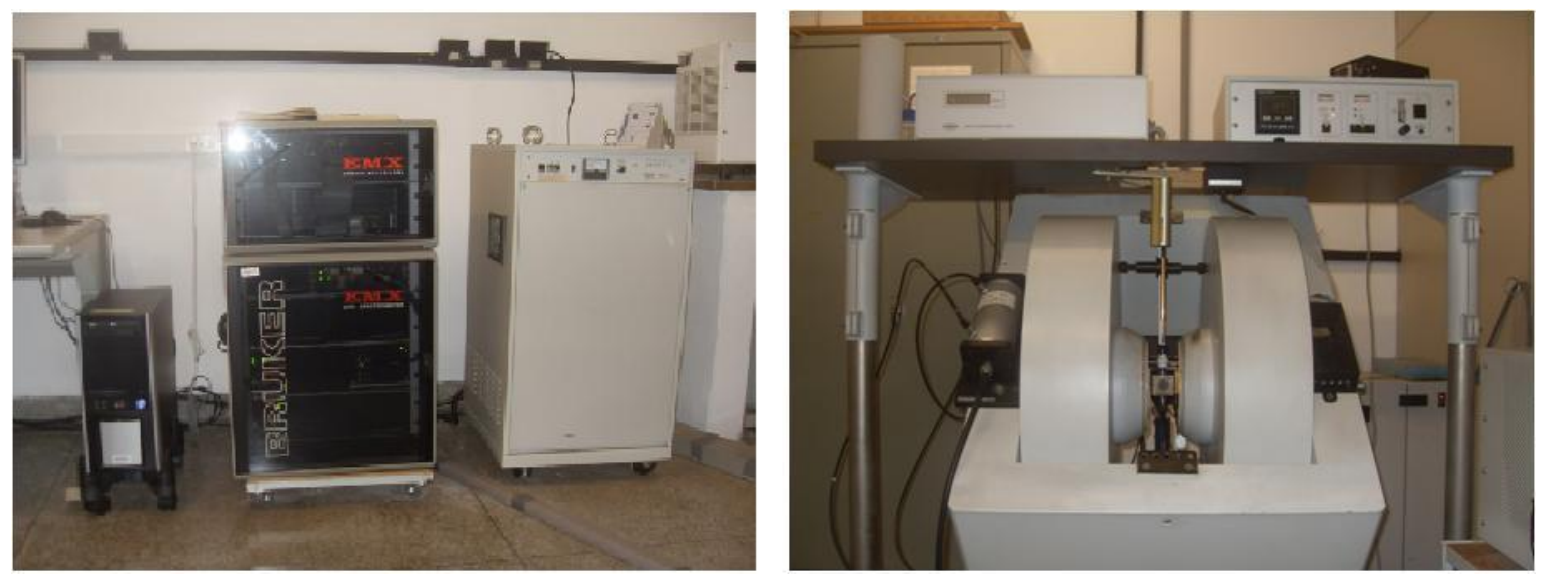

FIGURA 9 - Espectrômetro de EPR Bruker EMX.

Os parâmetros experimentais utilizados para a obtenção do espectro de EPR foram frequência de modulação de $100 \mathrm{kHz}$ a temperatura ambiente, potência de $20 \mathrm{~mW}$ de micro-ondas, amplitude de $1 \mathrm{G}$ e intervalo de varredura de 500 a 6500 gauss. 


\subsection{Preparação de reagentes}

\subsubsection{Solução HF $10 \%$}

No interior de uma capela, pipetaram-se $19.8 \mathrm{~mL}$ de ácido fluorídrico concentrado em um béquer de teflon e adicionaram-se $25 \mathrm{~mL}$ de água destilada, misturando-se a solução com um bastão de vidro até homogeneização. Posteriormente, adicionou-se água destilada até completar $100 \mathrm{~mL}$ de solução. Por fim, transferiu-se, a solução, a um recipiente para armazenagem e o mesmo foi devidamente rotulado.

\subsubsection{Solução HNO3 $10 \%$}

Primeiramente, pipetaram-se 10,0 mL de ácido nítrico p.a. em um béquer e adicionaram-se $25 \mathrm{~mL}$ de água destilada misturando-se com um bastão de vidro para homogeneização.

A solução foi transferida para um balão volumétrico de $100 \mathrm{~mL}$, por meio de um funil e adicionou-se água destilada até completar o volume do balão. Posteriormente, fechou-se, com rolha, invertendo-o vinte vezes. Transferiu-se a solução estoque para um recipiente de armazenagem e a mesmo foi rotulada.

\subsubsection{Solução $\mathrm{HCl} 10 \%$}

No interior de uma capela, munido de pêra de borracha e uma pipeta de 10,0 mL, pipetaram-se $23,8 \mathrm{~mL}$ de ácido clorídrico p.a. em um béquer de vidro e adicionaram-se 25 $\mathrm{mL}$ de água destilada, misturando-se com um bastão de vidro até a homogeneização da solução.

Por fim, adicionaram-se ao béquer água destilada até completar o volume do balão $(100 \mathrm{~mL})$. A seguir, a solução foi transferida para um recipiente de armazenagem. 


\subsection{Preparação das amostras}

\subsubsection{Análise por ativação com nêutrons}

Inicialmente, catalogaram-se, de acordo com o critério do grupo de estudos arqueométricos do Instituto de Pesquisas Energéticas e Nucleares (IPEN-CNEN/SP), as amostras de fragmentos recebidas, e posteriormente, as mesmas foram armazenadas em recipientes de polietileno com tampa. A seguir, os fragmentos cerâmicos foram lavados com água Milli-Q e escovados com uma escova de cerdas finas. Posteriormente, colocaram-se os fragmentos em estufa a $100,4{ }^{\circ} \mathrm{C}$ por $2 \mathrm{~h}$. Com o objetivo de eliminar qualquer tipo de contaminação, removeram-se com lima rotativa de carbeto de tungstênio adaptada a uma furadeira com velocidade variável e em baixa rotação a superfície lateral dos fragmentos cerâmicos Posteriormente, $500 \mathrm{mg}$ da amostra, na forma de pó, com granulometria menor que 100 mesh, foram obtidos fazendo-se 3 a 5 orifícios na parte lateral do fragmento, evitando que a broca atravesse as paredes das cerâmicas. Esse pó foi então recolhido, seco em estufa a $100,4{ }^{\circ} \mathrm{C}$ por $24 \mathrm{~h}$, armazenado em potes de polietileno e guardado em dissecador (Munita et. al., 2003). Na FIG. 10 apresenta-se a preparação das amostras para NAA.
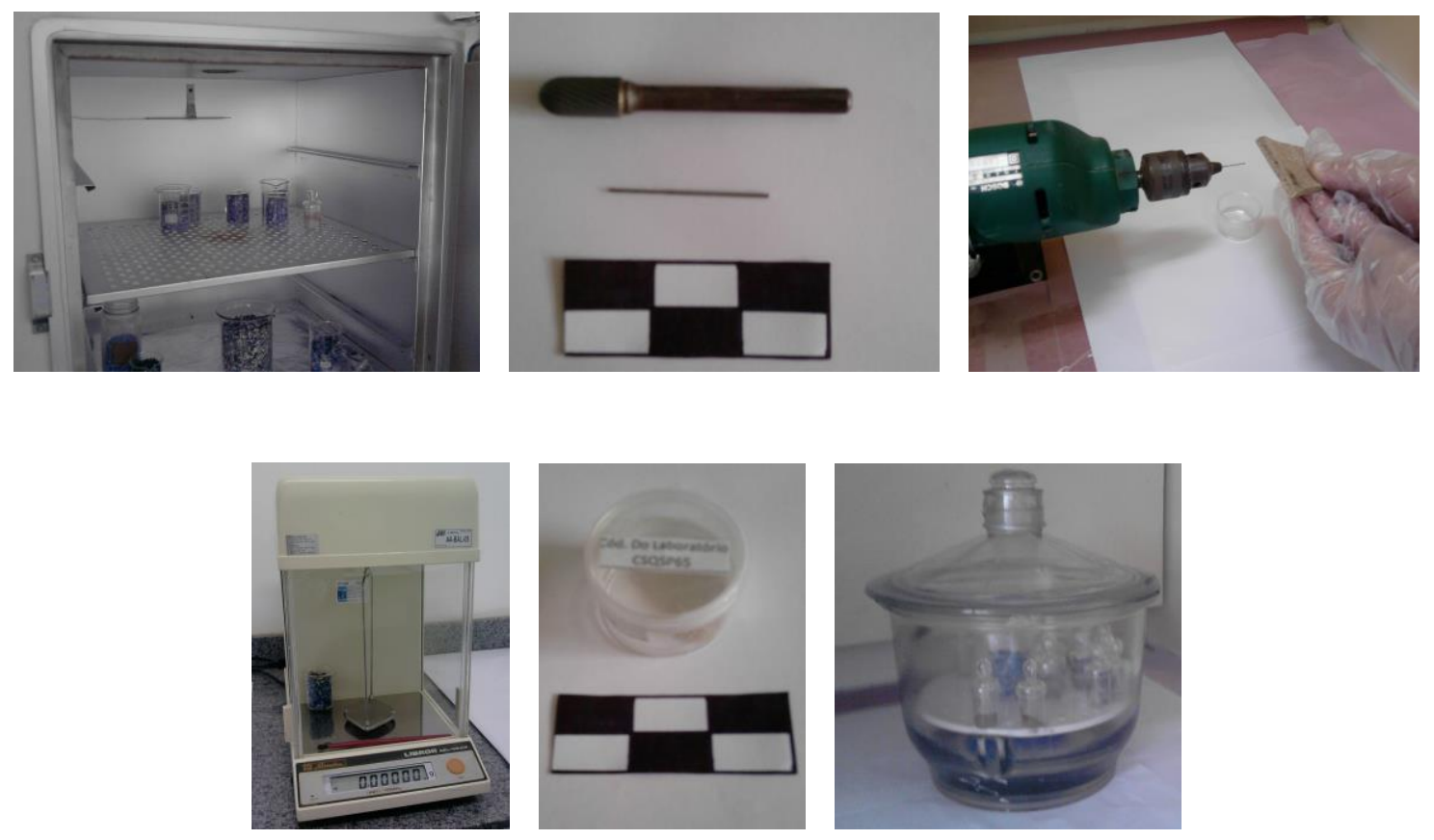

FIGURA 10 - Etapas de preparação da amostra para NAA. 
4.5.2 Procedimento para a obtenção do quartzo natural da amostra de cerâmica arqueológica

Todo o processo para obtenção dos grãos de quartzo foi realizado em sala escura (com lâmpada LED de luz vermelha). Inicialmente, retirou-se uma fina camada da parede externa do fragmento cerâmico com o auxílio de uma lixa fina, removeram-se cerca de $3 \mathrm{~mm}$ de espessura das faces de cada cerâmica selecionada. Essa etapa do processo tem como objetivo eliminar a fração da amostra que esteve exposta a luz branca. A seguir, o fragmento foi cuidadosamente pulverizado em um almofariz com auxílio de um pistilo, ambos de ágata. Posteriormente, peneirou-se o pó para obter uma granulometria de 80 mesh.

O pó, devidamente selecionado, foi submetido ao seguinte tratamento químico. Inicialmente, em um béquer de teflon, adicionou-se o pó da amostra e $15 \mathrm{ml}$ de $\mathrm{H}_{2} \mathrm{O}_{2} 30 \%$ v/v, no qual permaneceu em repouso por 3 horas. O peróxido de hidrogênio tem como objetivo eliminar toda a matéria orgânica presente na amostra. A seguir, lavou-se o material com água Milli-Q a fim de retirar todo o peróxido de hidrogênio por meio de processo de decantação.

A seguir, transferiu-se a amostra para um béquer de teflon e adicionaram-se 15 $\mathrm{ml}$ de $\mathrm{HF} 10 \%$. O béquer permaneceu em repouso por $45 \mathrm{~min}$. A adição do ácido fluorídrico tem como objetivo eliminar os carbonetos presentes na amostra, retirar uma fina camada da superfície do quartzo para eliminar toda a radiação $\alpha$ incidente no quartzo. O procedimento de enxague com água Milli-Q foi repetido até a retirada total do ácido. $\mathrm{Na}$ terceira etapa, adicionaram-se $15 \mathrm{ml}$ de $\mathrm{HCl} 10 \%$ mantendo-o em repouso por 1 hora.

Desta forma eliminaram-se os fluoretos formados pela reação do material com o HF. Por fim, lavou-se, novamente, a amostra com água Milli-Q até a retirada de todo o ácido e a limpeza total da amostra em pó. Finalmente, secou-se a amostra em estufa a $100,4^{\circ} \mathrm{C}$ durante 30 min e, posteriormente, submeteu-se a mesma à separação magnética, usando ímã de Nd para remover todo material de caráter magnético presente.

Na FIG. 11 apresentam-se as principais etapas do preparo da amostra para a obtenção do quartzo. 

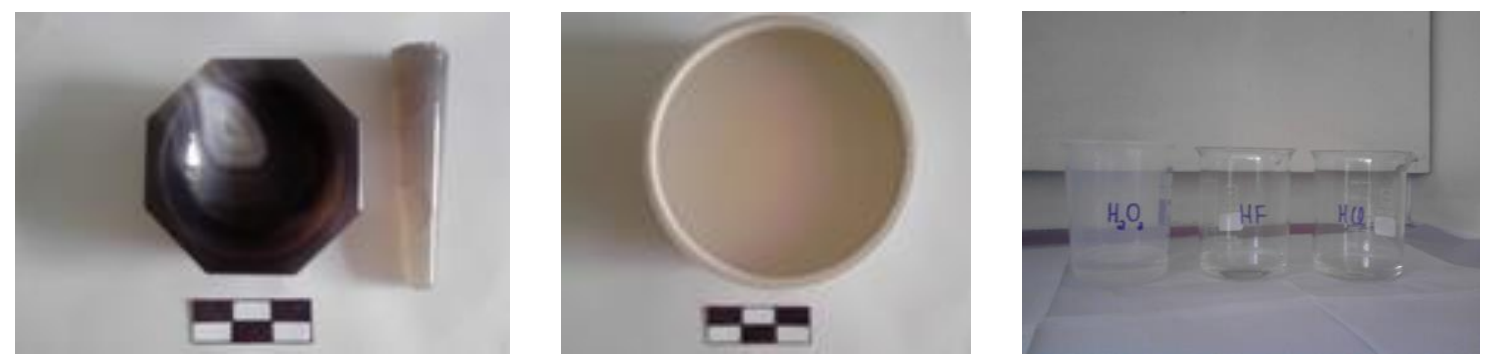

FIGURA 11 - Etapas de preparação da amostra para obtenção do quartzo.

\subsubsection{Temperatura de queima por ressonância paramagnética eletrônica}

Para a determinação da temperatura de queima por EPR, inicialmente, trituraram-se os fragmentos cerâmicos com almofariz e pistilo, ambos de ágata. Peneirouse o pó das amostras para obter grãos de forma homogênea e com granulometria de 200 mesh.

A seguir, pesou-se em cápsulas de polietileno, cerca de $200 \mathrm{mg}$ para cada amostra. Posteriormente, foram separadas 09 alíquotas para cada amostra. A seguir transferiram-se, para cadinhos de porcelana 08 alíquotas de cada amostra e as mesmas foram submetidas a tratamento térmico em mufla. A temperatura do tratamento iniciou-se a $450{ }^{\circ} \mathrm{C}$, com incrementos de $50{ }^{\circ} \mathrm{C}$, até $850{ }^{\circ} \mathrm{C}$ por um período de tempo de 30 min por cada incremento de temperatura. Na FIG. 12 apresentam-se as principais etapas do preparo das amostras para o tratamento térmico.

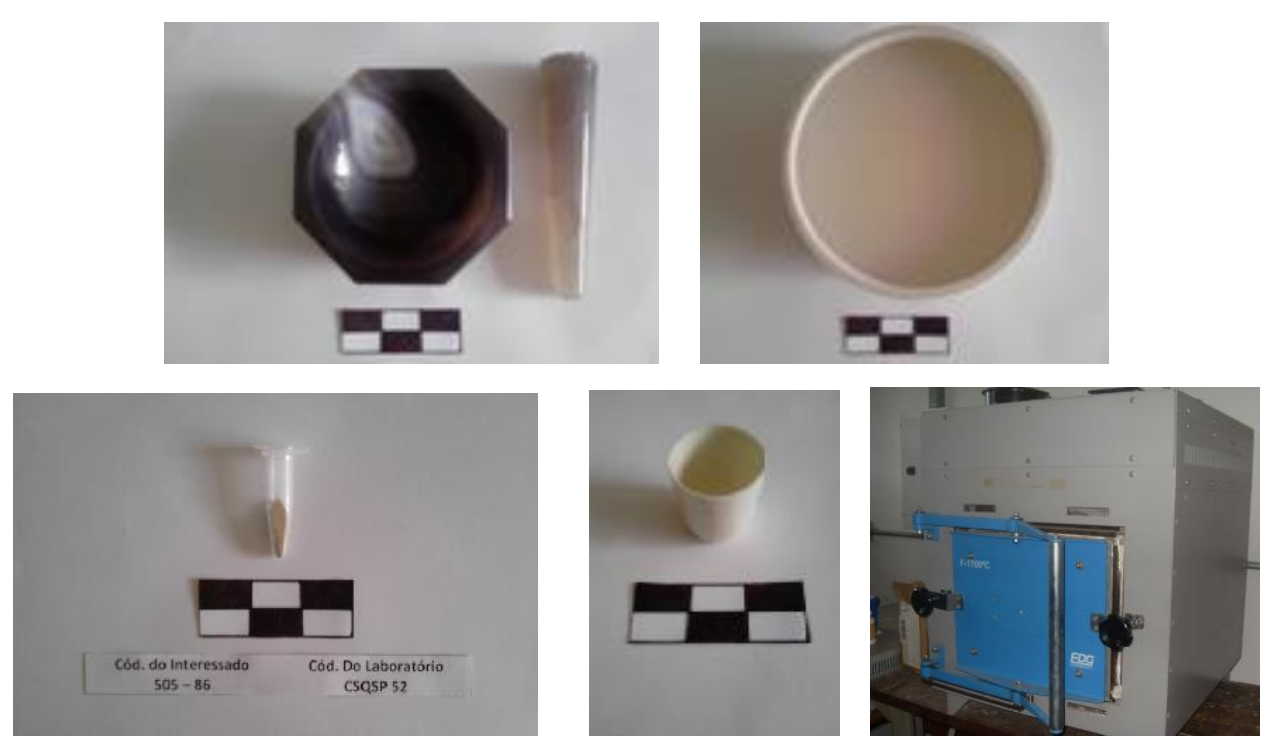

FIGURA 12 - Etapas do preparo das amostras para o tratamento térmico. 


\subsection{Procedimentos analíticos}

\subsubsection{Análise por ativação com nêutrons}

Para determinação da concentração química dos fragmentos cerâmicos, cerca de $120 \mathrm{mg}$ de cada amostra, na forma de pó, foram pesados em um invólucro de polietileno e selado com ferro para solda. A seguir, $120 \mathrm{mg}$ do material de referência Standard Reference Material - NIST-SRM 1633b (Constituent Elements in Coal Fly Ash), utilizado como padrão e do material de referência IAEA Soil-7 (Trace Elements in Soil), utilizado como amostra desconhecida, foram pesados e selados em um invólucro, também, de polietileno. Cada invólucro foi envolto em folha de alumínio e catalogado com o seu respectivo código do laboratório.

Uma série de 08 amostras, juntamente com o padrão foram postos em um suporte de alumínio, conhecido como coelho, este foi devidamente selado e submetido à irradiação por 8h no núcleo do Reator IEA-R1 do IPEN-CNEN/SP, sob um fluxo de nêutrons térmicos da ordem de $10^{12} \mathrm{n} \mathrm{cm}^{-2} \mathrm{~s}^{-1}$ (FIG. 13).
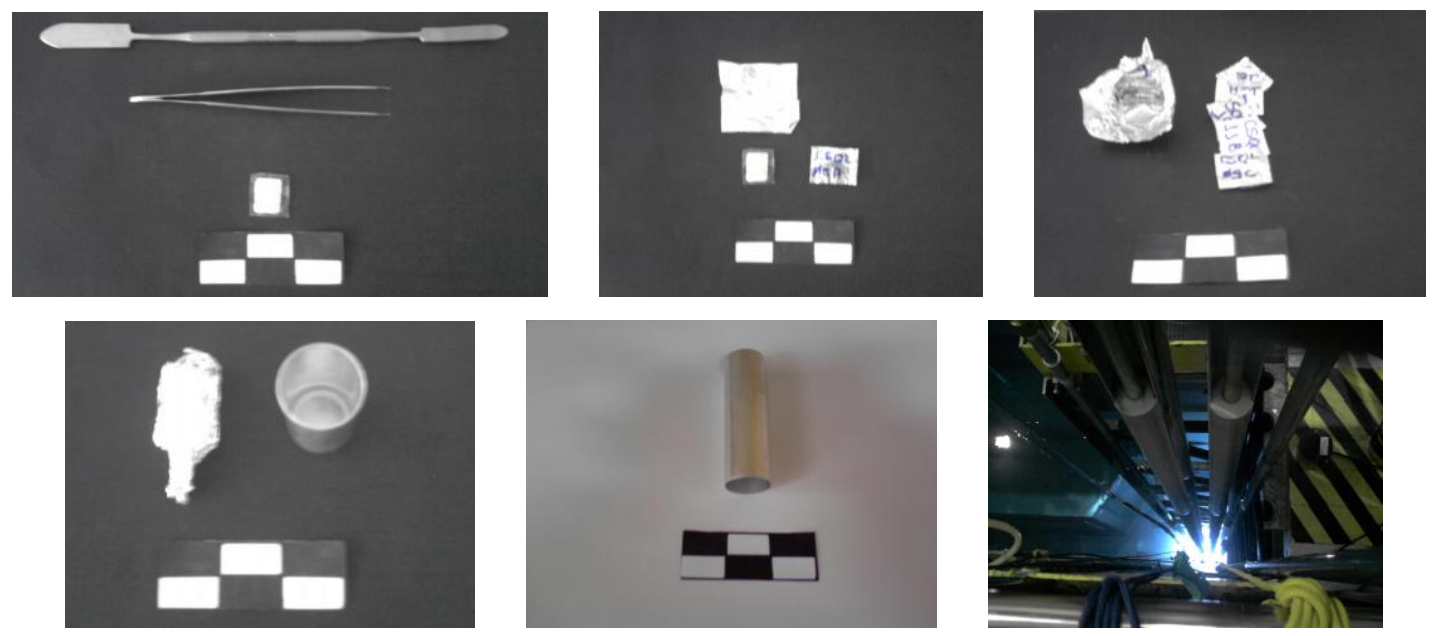

FIGURA 13 - Etapas para o processo de irradiação.

Após a irradiação, o coelho foi aberto na capela de chumbo e as amostras foram acomodadas em pequenos pratos de alumínio e, posteriormente, foram medidas as atividades no espectrômetro de raios gama.

Realizou-se para cada amostra 02 medidas, sendo determinado após sete dias de decaimento os elementos K, La, Lu, Na, Nd, Sb, Sm, U e Yb e após 25 a 30 dias os 
elementos Ce, Co, Cr, Cs, Eu, Fe, Hf, Rb, Sc, Ta, Tb, Th e Zn.

Para estudar a precisão, exatidão e a sensibilidade do método de NAA, determinaram-se concentrações de K, La, Lu, Na, Nd, Sm, U, Yb, Ce, Co, Cr, Cs, Eu, Sb, Fe, Hf, Rb, Sc, Ta, Tb, Th e Zn no material de referência IAEA-Soil 7 (Trace Elements in Soil) e, também, analisaram-se 05 amostras em triplicatas.

\subsubsection{Datação pelo método de dose aditiva}

Para determinar a dose acumulada pelo método de dose aditiva, todo o processo foi realizado em um ambiente escuro, utilizando apenas lâmpada LED de luz vermelha para a iluminação.

Inicialmente, a amostra foi dividida em 08 alíquotas com aproximadamente 30 mg cada. Uma alíquota foi utilizada para obter a TL referente à leitura da intensidade da curva TL da amostra natural e as outras sete foram irradiadas, respectivamente, com doses de 0,$5 ; 1,0 ; 1,5 ; 2,5 ; 5,0 ; 10,0$ e 20,0 Gy. As alíquotas foram submetidas à radiação $\gamma$ em fonte de ${ }^{60}$ Co no Centro de Tecnologia das Radiações do IPEN-CNEN/SP.

Para cada alíquota irradiada e a natural utilizaram-se exatamente $4 \mathrm{mg}$ de quartzo. A alíquota foi posta na bandeja da leitora com o auxílio de uma espátula de alumínio, aqueceu-se a bandeja a uma taxa constante de $4{ }^{\circ} \mathrm{C} / \mathrm{s}$ e as medidas de TL foram realizadas fazendo uma varredura entre 50 a $500{ }^{\circ} \mathrm{C}$ a uma vazão constante de nitrogênio $\left(\mathrm{N}_{2}\right)$. Este procedimento foi repetido cinco vezes, de modo a obter o valor médio da leitura da TL correspondente ao valor de cada dose de radiação e o seu respectivo desvio em cada amostra.

Realizadas as leituras de TL, construiu-se a curva de calibração utilizando-se as intensidades dos picos TL do quartzo de $325^{\circ} \mathrm{C}$ a $375^{\circ} \mathrm{C}$ e os valores das áreas dos picos de $365^{\circ} \mathrm{C}$ a $395^{\circ} \mathrm{C}$, pois nestas faixas de temperaturas, os picos TL são considerados estáveis. Para obter o melhor ajuste da curva aos pontos utilizou-se a função matemática exponencial assintótica. Por fim, estimou-se o valor da dose acumulada usando-se a curva de calibração e extrapolando a curva até o eixo do gráfico.

Para a determinação da dose acumulada $\left(\mathrm{D}_{\mathrm{ac}}\right)$ por EPR, também, utilizou-se o método de dose aditiva. Para isso, cada amostra foi dividida em 05 alíquotas. Para cada alíquota, inicialmente, foi medida a intensidade do sinal EPR da amostra natural. Em seguida a mesma alíquota foi irradiada, a temperatura ambiente, com radiação $\gamma$ de 0,5 ; 
1,0; 2,0 e 4,0 Gy, respectivamente na fonte de ${ }^{60}$ Co do Centro de Tecnologia das Radiações do IPEN-CNEN/SP e, posteriormente, foi realizada a medida da intensidade do sinal de EPR para as doses adicionais em cada amostra.

Para calcular a dose anual $\left(\mathrm{D}_{\mathrm{an}}\right)$, é necessária a soma da dose interna, expressa na radiação proveniente do próprio material, da dose externa que consiste na radiação ambiental oriunda da radioatividade presente no solo e, também, da radiação cósmica. As concentrações de $\mathrm{U}$, Th e K, presentes na argila do material, foram determinadas por NAA e utilizadas para o cálculo da dose anual.

4.6.3 Temperatura de queima por ressonância paramagnética eletrônica

Inicialmente, 70mg de cada amostra, na forma de pó, foram postas em tubos de quartzo de $4 \mathrm{~mm}$ de diâmetro, por meio de um funil de polietileno. Em seguida, acomodou-se o tubo no suporte do equipamento e realizou-se a leitura de EPR.

Analisaram-se por EPR 08 alíquotas submetidas ao tratamento térmico e uma alíquota natural, sem tratamento térmico, totalizando 09 medidas de EPR para cada amostra. 


\section{RESULTADOS E DISCUSSÃO}

Um dos principais focos da Arqueometria desde a década de 1960 tem sido o estudo de cerâmicas por meio da determinação de suas concentrações elementares. $\mathrm{O}$ objetivo principal da caracterização de cerâmicas é identificar os centros de produção de cerâmica por meio da identificação das fontes de matérias-primas.

Para isso, torna-se imprescindível o uso de uma técnica analítica que apresente boa precisão para realizar a caracterização química de cerâmicas arqueológicas. A análise por ativação com nêutrons é um dos métodos analíticos mais utilizados para essa finalidade, porque apresenta várias vantagens em relação aos outros métodos. Esse método vem sendo utilizado e aperfeiçoado pelo grupo de estudos arqueométricos da Supervisão de Radioquímica do IPEN há vários anos.

As medidas de precisão têm sido utilizadas para estudar a variabilidade de métodos analíticos. A precisão é definida como a dispersão dos resultados obtidos em torno da média. Este procedimento tem como objetivo identificar e eliminar elementos que ocasionem variabilidade no conjunto de dados das concentrações e, consequentemente, provocar uma distorção na intrpretação dos resultados da análise estístico (Neto, 2002).

Com o objetivo de avaliar a repetitividade do método empregado, foram determinadas as concentrações elementares de $\mathrm{Ce}, \mathrm{Co}, \mathrm{Cr}, \mathrm{Cs}, \mathrm{Eu}, \mathrm{Fe}, \mathrm{Hf}, \mathrm{K}, \mathrm{La}, \mathrm{Lu}, \mathrm{Na}$, $\mathrm{Nd}, \mathrm{Rb}, \mathrm{Sb}, \mathrm{Sc}, \mathrm{Sm}, \mathrm{Ta}, \mathrm{Tb}, \mathrm{Th}, \mathrm{U}, \mathrm{Yb}$ e Zn, em 18 amostras do material de referência IAEA -Soil 7, Trace Elements in Soil. Os valores encontrados foram comparados com os valores do certificado. Na TAB. 4 apresentam-se valores determinados experimentalmente e os valores certificados.

Um problema que frequentemente surge após a obtenção de uma série de medidas é decidir se a diferença entre as várias análises de uma mesma amostra é significante para um nível de confiança adotado. Desse modo, para que a rejeição não assuma um caráter subjetivo, foi adotado o teste da distribuição do r. Nesse critério, comparam-se os valores de $r_{\text {máximo }} r_{\text {mínimo, }}$ experimentais, com valores de $r_{\text {tabelado }}$ para $o$ 
nível de significância de 0,05 com n-2 graus de liberdade, onde n é o número de medidas.

TABELA 4 - Resultados para o material de referências IAEA -Soil 7, valores em ppm a não ser quando indicado.

\begin{tabular}{|c|c|c|c|}
\hline Elemento & Valor encontrado \pm DP & Valor certificado & $\begin{array}{c}\text { Intervalo de conf., } \\
95 \%\end{array}$ \\
\hline $\mathrm{Na}, \%$ & $0,24 \pm 0,02$ & $(0,24)$ & $0,23-0,24$ \\
\hline $\mathrm{K}, \%$ & $1,37 \pm 0,30$ & $(1,21)$ & $1,13-1,27$ \\
\hline $\mathrm{La}$ & $30,85 \pm 1,85$ & 28 & $27-29$ \\
\hline $\mathrm{Nd}$ & $28,89 \pm 11,76$ & 30 & $22-34$ \\
\hline $\mathrm{Sm}$ & $4,12 \pm 1,47$ & 5,1 & $4,8-5,5$ \\
\hline $\mathrm{Yb}$ & $2,31 \pm 0,15$ & 2,4 & $1,9-2,6$ \\
\hline $\mathrm{Lu}$ & $0,37 \pm 0,03$ & $(0,3)$ & $0,1-0,4$ \\
\hline $\mathrm{U}$ & $2,43 \pm 0,54$ & 2,6 & $2,2-3,3$ \\
\hline $\mathrm{Sc}$ & $8,63 \pm 0,43$ & 8,3 & $6,9-9,0$ \\
\hline $\mathrm{Cr}$ & $69,67 \pm 5,01$ & 60 & $49-74$ \\
\hline $\mathrm{Fe}, \%$ & $2,66 \pm 0,14$ & $(2,57)$ & $2,52-2,63$ \\
\hline Co & $9,07 \pm 0,47$ & 8,9 & $8,4-10,1$ \\
\hline $\mathrm{Zn}$ & $106,69 \pm 14,18$ & 104 & $101-113$ \\
\hline $\mathrm{Rb}$ & $47,20 \pm 13,39$ & 51 & $47-56$ \\
\hline $\mathrm{Sb}$ & $2,22 \pm 0,52$ & 1,7 & $1,4-1,8$ \\
\hline Cs & $5,84 \pm 0,73$ & 5,4 & $4,9-6,4$ \\
\hline $\mathrm{Ce}$ & $59,02 \pm 3,06$ & 61 & $50-63$ \\
\hline $\mathrm{Eu}$ & $1,07 \pm 0,13$ & 1 & $0,9-1,3$ \\
\hline $\mathrm{Tb}$ & $0,71 \pm 0,30$ & 0,6 & $0,5-0,9$ \\
\hline $\mathrm{Hf}$ & $5,16 \pm 0,48$ & 5,1 & $4,8-5,5$ \\
\hline $\mathrm{Ta}$ & $0,76 \pm 0,17$ & 0,8 & $0,6-1,0$ \\
\hline Th & $8,13 \pm 0,45$ & 8,2 & $6,5-8,7$ \\
\hline
\end{tabular}

média e desvio padrão DP para $n=18$;

(..) valor informado.

O estudo da homogeneidade do conjunto de dados mostrou que os elementos $\mathrm{Na}, \mathrm{La}, \mathrm{Sm}, \mathrm{Yb}, \mathrm{Lu}, \mathrm{U}, \mathrm{Sc}, \mathrm{Cr}, \mathrm{Fe}, \mathrm{Co}, \mathrm{Cs}, \mathrm{Ce}, \mathrm{Hf}$, Th, não apresentaram medidas experimentais discrepantes, uma vez que o valor encontrado tanto para $r_{\text {máximo }}$ e $r_{\text {mínimo }}$ foi 
menor que o $r_{\text {tabelado, }}$ isto é, menor que 2,57. Para os elementos em que o $r_{\text {tabelado }}$ foi menor que o encontrado, a determinação foi eliminada e, novamente, o $r_{\text {máximo }}$ e $r_{\text {mínimo }}$ foram recalculados.

Os elementos $\mathrm{K}, \mathrm{Nd}, \mathrm{Co}, \mathrm{Rb}, \mathrm{Sb}, \mathrm{Eu}, \mathrm{Tb}$ e Ta, após a primeira eliminação, apresentaram valor de $\mathrm{r}$ foi menor que 2,55 que é o valor tabelado de $\mathrm{r}$ com 15 graus de liberdade no nível de significância de 0,05. Nesse caso, todas as determinações apresentaram valores de $r_{\text {máximo }}$ e $r_{\text {mínimo menores que }}$ o $r_{\text {tabelado. }}$ Na TAB. 5 são apresentados os valores experimentais obtidos no material IAEA - Soil 7 após a aplicação do critério do $r_{\text {máximo }}$ e $r_{\text {mínimo. }}$

TABELA 5 - Resultados para o material de referências IAEA - Soil 7, valores em ppm a não ser quando indicado, $\mathrm{n}=18$ e para $\mathrm{n}=17$.

\begin{tabular}{ccccc}
\hline Elemento & Valor encontrado & $\begin{array}{c}\text { Valor } \\
\text { certificado }\end{array}$ & $\begin{array}{c}\text { Intervalor de } \\
\text { conf., 95\% }\end{array}$ & $\begin{array}{c}\text { DPR } \\
(\boldsymbol{\%})\end{array}$ \\
\hline $\mathrm{Na}, \%$ & $0,24 \pm 0,02$ & $(0,24)$ & $0,23-0,24$ & 6,91 \\
$\mathrm{~K}, \%$ & $1,30 \pm 0,14^{*}$ & $(1,21)$ & $1,13-1,27$ & 10,41 \\
$\mathrm{La}$ & $30,85 \pm 1,85$ & 28 & $27-29$ & 6,01 \\
$\mathrm{Nd}$ & $26,46 \pm 5,79^{*}$ & 30 & $22-34$ & 21,89 \\
$\mathrm{Sm}$ & $4,12 \pm 1,47$ & 5,1 & $4,8-5,5$ & 35,67 \\
$\mathrm{Yb}$ & $2,31 \pm 0,15$ & 2,4 & $1,9-2,6$ & 6,47 \\
$\mathrm{Lu}$ & $0,37 \pm 0,03$ & $(0,3)$ & $0,1-0,4$ & 7,67 \\
$\mathrm{U}$ & $2,43 \pm 0,54$ & 2,6 & $2,2-3,3$ & 22,29 \\
$\mathrm{Sc}$ & $8,63 \pm 0,43$ & 8,3 & $6,9-9,0$ & 4,95 \\
$\mathrm{Cr}$ & $69,67 \pm 5,01$ & 60 & $49-74$ & 7,19 \\
$\mathrm{Fe}, \%$ & $2,66 \pm 0,14$ & $(2,57)$ & $2,52-2,63$ & 5,13 \\
$\mathrm{Co}$ & $9,07 \pm 0,47^{*}$ & 8,9 & $8,4-10,1$ & 5,17 \\
$\mathrm{Zn}$ & $103,68 \pm 6,36$ & 104 & $101-113$ & 6,14 \\
$\mathrm{Rb}$ & $45,03 \pm 10,04^{*}$ & 51 & $47-56$ & 22,30 \\
$\mathrm{Sb}$ & $2,14 \pm 0,38^{*}$ & 1,7 & $1,4-1,8$ & 17,71 \\
$\mathrm{Cs}$ & $5,84 \pm 0,73$ & 5,4 & $4,9-6,4$ & 12,54 \\
$\mathrm{Ce}$ & $59,02 \pm 3,06$ & 61 & $50-63$ & 5,18 \\
$\mathrm{Eu}$ & $1,04 \pm 0,09^{*}$ & 1 & $0,9-1,3$ & 8,96 \\
$\mathrm{~Tb}$ & $0,65 \pm 0,15^{*}$ & 0,6 & $0,5-0,9$ & 22,95 \\
$\mathrm{Hf}$ & $5,16 \pm 0,48$ & 5,1 & $4,8-5,5$ & 9,30 \\
$\mathrm{Ta}$ & $0,73 \pm 0,13^{*}$ & 0,8 & $0,6-1,0$ & 17,64 \\
$\mathrm{Th}$ & $8,13 \pm 0,45$ & 8,2 & $6,5-8,7$ & 5,55 \\
\hline
\end{tabular}

*média e desvio padrão para $\mathrm{n}=17$;

(..) valor informado. 
Além do estudo da repetitividade, realizado no material de referência, avaliouse a reprodutibilidade por meio da determinação da concentração química elementar em um conjunto de amostras de cerâmicas avaliando-se DP e o DPR. A repetitividade e reprodutibilidade podem ser dependentes da concentração do analito e deste modo diferentes números de medidas de concentrações devem ser determinadas para estabelecer a relação entre precisão e concentração do analito investigado na amostra. Desta forma, foram realizadas 03 determinações das concentrações dos elementos $\mathrm{Ce}, \mathrm{Co}, \mathrm{Cr}, \mathrm{Cs}, \mathrm{Eu}$, Fe, Hf, K, La, Lu, Na, Nd, Rb, Sb, Sc, Sm, Ta, Tb, Th, U, Yb e Zn, em 5 amostras (1, 17, 18, 38 e 39) do conjunto de 70 amostras de fragmentos cerâmicos. Nas TABs. 6, 7 e 8 apresentam-se os resultados das 03 determinações para cada amostra.

O resultado da análise é considerado adequado, em estudos de caracterização elementar de cerâmicas arqueológicas, quando o valor do seu DPR for $\leq 10 \%$ (Bishop et.al., 1990). Constata-se, por meio das TABs. 5, 6, 7 e 8 que o valor do desvio padrão relativo para os elementos $\mathrm{Na}, \mathrm{La}, \mathrm{Yb}, \mathrm{Lu}, \mathrm{Sc}, \mathrm{Cr}, \mathrm{Fe}, \mathrm{Co}, \mathrm{Zn}, \mathrm{Ce}, \mathrm{Eu}, \mathrm{Hf}$ e Th, é $\leq 10 \%$ e, portanto, esses elementos satisfazem o critério escolhido para a seleção das variáveis.

TABELA 6 - Resultado para 3 determinações na amostra 38.

\begin{tabular}{|c|c|c|c|c|c|c|}
\hline \multirow[t]{2}{*}{ Elemento } & \multicolumn{3}{|c|}{ Amostra } & \multirow[t]{2}{*}{ Média } & \multirow[t]{2}{*}{ DP } & \multirow[t]{2}{*}{ DPR } \\
\hline & 38A & 38B & $38 \mathrm{C}$ & & & \\
\hline $\mathrm{Na}, \%$ & 0,08 & 0,07 & 0,08 & 0,08 & 0,01 & 6,71 \\
\hline $\mathrm{K}, \%$ & 1,31 & 1,01 & 1,05 & 1,12 & 0,16 & 14,48 \\
\hline $\mathrm{La}$ & 54,06 & 52,83 & 61,35 & 56,08 & 4,60 & 8,21 \\
\hline $\mathrm{Nd}$ & 48,44 & 31,27 & 49,29 & 43,00 & 10,17 & 23,64 \\
\hline $\mathrm{Sm}$ & 5,25 & 6,70 & 8,36 & 6,77 & 1,56 & 23,00 \\
\hline $\mathrm{Yb}$ & 3,45 & 3,99 & 3,97 & 3,80 & 0,30 & 7,98 \\
\hline $\mathrm{Lu}$ & 0,56 & 0,62 & 0,62 & 0,60 & 0,03 & 5,65 \\
\hline $\mathrm{U}$ & 3,83 & 3,74 & 4,62 & 4,06 & 0,48 & 11,90 \\
\hline Sc & 16,75 & 16,95 & 18,62 & 17,44 & 1,03 & 5,91 \\
\hline $\mathrm{Cr}$ & 81,88 & 76,94 & 84,69 & 81,17 & 3,93 & 4,84 \\
\hline $\mathrm{Fe}, \%$ & 3,02 & 3,07 & 3,33 & 3,14 & 0,16 & 5,19 \\
\hline $\mathrm{Co}$ & 4,67 & 4,74 & 4,95 & 4,79 & 0,15 & 3,09 \\
\hline
\end{tabular}


TABELA 6 - (Cont.).

\begin{tabular}{|c|c|c|c|c|c|c|}
\hline \multirow[t]{2}{*}{ Elemento } & \multicolumn{3}{|c|}{ Amostra } & \multirow[t]{2}{*}{ Média } & \multirow[t]{2}{*}{ DP } & \multirow[t]{2}{*}{ DPR } \\
\hline & 38A & $38 B$ & $38 \mathrm{C}$ & & & \\
\hline $\mathrm{Zn}$ & 134,37 & 150,53 & 144,59 & 143,16 & 8,17 & 5,71 \\
\hline $\mathrm{Rb}$ & 62,37 & 86,67 & 100,78 & 83,27 & 19,43 & 23,33 \\
\hline $\mathrm{Sb}$ & 1,19 & 1,56 & 1,37 & 1,37 & 0,19 & 13,46 \\
\hline Cs & 7,66 & 6,76 & 9,32 & 7,91 & 1,30 & 16,41 \\
\hline $\mathrm{Ce}$ & 96,72 & 109,25 & 94,42 & 100,13 & 7,98 & 7,97 \\
\hline $\mathrm{Eu}$ & 1,38 & 1,35 & 1,54 & 1,42 & 0,10 & 7,08 \\
\hline $\mathrm{Tb}$ & 0,91 & 1,12 & 0,90 & 0,98 & 0,12 & 12,72 \\
\hline $\mathrm{Hf}$ & 7,05 & 8,20 & 8,50 & 7,92 & 0,77 & 9,67 \\
\hline $\mathrm{Ta}$ & 1,46 & 2,02 & 1,67 & 1,72 & 0,29 & 16,62 \\
\hline Th & 15,32 & 15,71 & 16,69 & 15,91 & 0,70 & 4,42 \\
\hline
\end{tabular}

TABELA 7 - Resultado para 3 determinações na amostra 01

\begin{tabular}{ccccccc}
\hline Elemento & & Amostra & & Média & DP & DPR \\
& $\mathbf{0 1 A}$ & $\mathbf{0 1 B}$ & $\mathbf{0 1 C}$ & & & \\
\hline $\mathrm{Na}, \%$ & 0,05 & 0,04 & 0,04 & 0,05 & 0,00 & 8,29 \\
$\mathrm{~K}, \%$ & 0,97 & 0,90 & 0,78 & 0,88 & 0,10 & 10,88 \\
$\mathrm{La}$ & 39,38 & 38,83 & 37,00 & 38,40 & 1,25 & 3,24 \\
$\mathrm{Nd}$ & 33,97 & 28,96 & 23,95 & 28,96 & 5,01 & 17,30 \\
$\mathrm{Sm}$ & 6,83 & 13,64 & 6,16 & 8,88 & 4,14 & 46,64 \\
$\mathrm{Yb}$ & 3,34 & 3,28 & 3,12 & 3,25 & 0,11 & 3,43 \\
$\mathrm{Lu}$ & 0,56 & 0,47 & 0,56 & 0,53 & 0,05 & 9,80 \\
$\mathrm{~Np}$ & 3,34 & 3,12 & 3,13 & 3,20 & 0,12 & 3,90 \\
$\mathrm{Sc}$ & 17,40 & 17,22 & 17,39 & 17,34 & 0,10 & 0,58 \\
$\mathrm{Cr}$ & 84,00 & 72,99 & 81,22 & 79,40 & 5,73 & 7,21 \\
$\mathrm{Fe}, \%$ & 3,87 & 3,80 & 3,93 & 3,87 & 0,07 & 1,68 \\
$\mathrm{Co}$ & 7,57 & 7,05 & 7,06 & 7,23 & 0,30 & 4,12 \\
$\mathrm{Zn}$ & 99,59 & 100,55 & 101,50 & 100,55 & 0,96 & 0,95 \\
$\mathrm{Rb}$ & 73,57 & 75,89 & 94,30 & 81,25 & 11,36 & 13,98 \\
$\mathrm{Sb}$ & 1,26 & 1,31 & 1,35 & 1,31 & 0,05 & 3,45 \\
$\mathrm{Cs}$ & 8,87 & 7,43 & 9,37 & 8,56 & 1,01 & 11,77 \\
\hline & & & & & &
\end{tabular}


TABELA 7 - (Cont.).

\begin{tabular}{|c|c|c|c|c|c|c|}
\hline \multirow[t]{2}{*}{ Elemento } & \multicolumn{3}{|c|}{ Amostra } & \multirow[t]{2}{*}{ Média } & \multirow[t]{2}{*}{ DP } & \multirow[t]{2}{*}{ DPR } \\
\hline & $01 \mathrm{~A}$ & 01B & $01 C$ & & & \\
\hline $\mathrm{Ce}$ & 71,32 & 65,72 & 69,81 & 68,95 & 2,90 & 4,20 \\
\hline $\mathrm{Eu}$ & 1,23 & 1,09 & 1,11 & 1,14 & 0,08 & 6,63 \\
\hline $\mathrm{Tb}$ & 0,99 & 0,85 & 0,43 & 0,76 & 0,29 & 38,52 \\
\hline $\mathrm{Hf}$ & 8,59 & 7,04 & 8,00 & 7,88 & 0,78 & 9,93 \\
\hline $\mathrm{Ta}$ & 1,11 & 1,00 & 1,31 & 1,14 & 0,16 & 13,79 \\
\hline $\mathrm{Th}$ & 14,25 & 13,49 & 14,25 & 14,00 & 0,44 & 3,13 \\
\hline
\end{tabular}

TABELA 8 - Resultado para 3 determinações na amostra 39.

\begin{tabular}{|c|c|c|c|c|c|c|}
\hline \multirow[t]{2}{*}{ Elemento } & \multicolumn{3}{|c|}{ Amostra } & \multirow[t]{2}{*}{ Média } & \multirow[t]{2}{*}{ DP } & \multirow[t]{2}{*}{ DPR } \\
\hline & 39A & 39B & $39 \mathrm{C}$ & & & \\
\hline $\mathrm{Na}, \%$ & 0,06 & 0,05 & 0,06 & 0,06 & 0,00 & 1,83 \\
\hline $\mathrm{K}, \%$ & 2,03 & 1,41 & 2,05 & 1,83 & 0,36 & 19,91 \\
\hline $\mathrm{La}$ & 49,53 & 48,03 & 49,52 & 49,03 & 0,86 & 1,76 \\
\hline $\mathrm{Nd}$ & 30,94 & 39,87 & 46,46 & 39,09 & 7,79 & 19,93 \\
\hline $\mathrm{Sm}$ & 8,50 & 7,94 & 8,62 & 8,35 & 0,36 & 4,35 \\
\hline $\mathrm{Yb}$ & 3,83 & 3,63 & 3,70 & 3,72 & 0,10 & 2,73 \\
\hline $\mathrm{Lu}$ & 0,56 & 0,58 & 0,52 & 0,55 & 0,03 & 6,12 \\
\hline $\mathrm{Np}$ & 4,88 & 3,57 & 3,73 & 4,06 & 0,71 & 17,60 \\
\hline $\mathrm{Sc}$ & 18,31 & 17,87 & 18,93 & 18,37 & 0,53 & 2,89 \\
\hline $\mathrm{Cr}$ & 73,52 & 74,42 & 76,02 & 74,65 & 1,26 & 1,69 \\
\hline $\mathrm{Fe}, \%$ & 3,86 & 3,72 & 3,99 & 3,85 & 0,13 & 3,47 \\
\hline $\mathrm{Co}$ & 12,38 & 11,85 & 11,63 & 11,95 & 0,39 & 3,23 \\
\hline $\mathrm{Zn}$ & 174,20 & 167,26 & 184,31 & 175,26 & 8,57 & 4,89 \\
\hline $\mathrm{Rb}$ & 94,07 & 95,31 & 47,28 & 78,89 & 27,38 & 34,70 \\
\hline $\mathrm{Sb}$ & 0,51 & 1,11 & 1,72 & 1,11 & 0,61 & 54,42 \\
\hline Cs & 7,12 & 6,35 & 7,77 & 7,08 & 0,71 & 10,01 \\
\hline $\mathrm{Ce}$ & 93,15 & 90,76 & 97,47 & 93,79 & 3,40 & 3,62 \\
\hline $\mathrm{Eu}$ & 1,64 & 1,53 & 1,60 & 1,59 & 0,06 & 3,60 \\
\hline $\mathrm{Tb}$ & 0,91 & 1,26 & 1,60 & 1,26 & 0,35 & 27,52 \\
\hline Hf & 6,40 & 6,54 & 7,11 & 6,68 & 0,38 & 5,65 \\
\hline $\mathrm{Ta}$ & 1,32 & 1,44 & 1,56 & 1,44 & 0,12 & 8,29 \\
\hline $\mathrm{Th}$ & 14,58 & 14,12 & 15,11 & 14,61 & 0,50 & 3,40 \\
\hline
\end{tabular}


O elemento Co, embora tenha apresentado DPR $\leq 10 \%$, foi eliminado, por que existem evidências da contaminação com a broca de carboneto de tungsténio durante a preparação das amostras (Attas et al., 1958). A determinação de Zn, no pico de raios $\gamma$ de 1115,55 keV mostrou que esse elemento não é confiável, em virtude da interferência do raio $\gamma$ de ${ }^{46} \mathrm{Sc}$ com pico em $1120,3 \mathrm{keV}$ e ${ }^{182}$ Ta com pico em 1121,41 keV (Perlman \& Asaro, 1969). Dessa forma, eliminou-se o elemento Zn da base de dados.

Após o estudo da precisão, selecionaram-se os elementos $\mathrm{Na}, \mathrm{La}, \mathrm{Yb}, \mathrm{Lu}, \mathrm{Sc}$, $\mathrm{Cr}, \mathrm{Fe}, \mathrm{Ce}, \mathrm{Eu}, \mathrm{Hf}$ e Th, e esses foram utilizados como variáveis da base de dados na interpretação por meio da análise multivariada. Na TAB. 9 apresentam-se os valores experimentais das concentrações dos 11 elementos determinados para as 70 amostras de cerâmicas.

Inicialmente, os dados das concentrações elementares foram normalizados por meio da transformação logarítmica base 10. A normalização das concentrações, anterior à aplicação de métodos estatísticos multivariados, é um procedimento usual em estudos arqueométricos (Glascock \& Neff, 2003).

Uma das razões para usar a transformação logarítmica, é conciderar que os elementos químicos no solo seguem uma distribuição normal logarítmica (Ahrens, 1954), senão que a normalização tende estabilizar a variância das concentrações dos elementos, causada, principalemente, pela diferença de magnitude entre os elementos determinados em \% e os que estão no nível de ppm.

Vários estudos mostram que em uma base de dados, os valores discrepantes (outliers) são resultados inconsistentes e diferem significativamente da maioria das amostras. Inúmeras causas estão associadas ao surgimento dos outliers. As mais prováveis dar-se-á por erros de equipamento de medida e erro na preparação da amostra (Beckman \& Cook, 1983; Mahalanobis, 1936).

Neste trabalho, o estudo dos valores anômalos no conjunto de dados das concentrações das amostras foi realizado por meio da distância de Mahalanobis (D) associado, como valor crítico, ao critério lambda Wilks. Nas três últimas colunas da TAB. 8 (colunas 13, 14 e 15), estão apresentados os dados para a distância de Mahalanobis. 
TABELA 9 - Resultados da concentração das amostras de cerâmicas, em $\mu \mathrm{g} / \mathrm{g}$ a não ser indicado, para n=70 e distância de Mahalanobis (D).

\begin{tabular}{|c|c|c|c|c|c|c|c|c|c|c|c|c|c|c|}
\hline Amostra & $\mathrm{Na}, \%$ & $\mathbf{L a}$ & $\mathbf{Y b}$ & $\mathbf{L u}$ & Sc & $\mathrm{Cr}$ & $\mathrm{Fe}, \%$ & $\mathrm{Ce}$ & $\mathbf{E u}$ & Hf & Th & $\mathbf{D}_{1}$ & $\mathbf{D}_{2}$ & $\mathbf{D}_{3}$ \\
\hline 1 & 0,05 & 39,38 & 3,34 & 0,56 & 17,40 & 84,00 & 3,87 & 71,32 & 1,23 & 8,59 & 14,25 & 8,22 & 9,10 & 8,99 \\
\hline 2 & 0,08 & 36,12 & 2,65 & 0,44 & 19,60 & 84,23 & 3,40 & 69,88 & 1,01 & 5,26 & 14,88 & 6,40 & 6,67 & 6,91 \\
\hline 3 & 0,32 & 34,62 & 2,82 & 0,44 & 16,10 & 62,41 & 3,59 & 72,93 & 1,23 & 5,35 & 13,70 & 3,63 & 3,57 & 3,45 \\
\hline 4 & 0,13 & 30,65 & 2,27 & 0,39 & 16,16 & 66,66 & 4,14 & 56,24 & 0,83 & 4,35 & 14,28 & 5,20 & 5,82 & 5,79 \\
\hline 5 & 0,04 & 17,88 & 1,67 & 0,28 & 10,33 & 52,22 & 2,53 & 35,59 & 0,62 & 3,73 & 10,47 & 20,74 & 21,53 & 24,85 \\
\hline 6 & 0,20 & 41,62 & 2,55 & 0,39 & 17,66 & 71,30 & 3,90 & 75,45 & 1,18 & 3,40 & 14,45 & 6,15 & 6,05 & 6,14 \\
\hline 7 & 0,05 & 34,35 & 2,70 & 0,45 & 13,46 & 54,54 & 3,75 & 65,11 & 1,13 & 5,87 & 11,95 & 7,11 & 7,12 & 6,99 \\
\hline 8 & 0,10 & 39,72 & 2,66 & 0,43 & 13,54 & 56,45 & 2,44 & 79,57 & 1,32 & 5,49 & 11,06 & 5,62 & 5,90 & 7,19 \\
\hline 9 & 0,11 & 36,19 & 2,95 & 0,38 & 13,85 & 64,26 & 2,48 & 75,40 & 1,22 & 5,83 & 11,70 & 15,79 & 15,79 & 15,50 \\
\hline 10 & 0,14 & 34,57 & 2,54 & 0,38 & 11,93 & 64,30 & 2,18 & 58,01 & 0,98 & 7,78 & 10,72 & 16,30 & 16,73 & 16,54 \\
\hline 11 & 0,14 & 41,76 & 3,16 & 0,54 & 13,31 & 64,13 & 2,44 & 91,41 & 1,74 & 6,73 & 11,67 & 12,45 & 12,76 & 12,88 \\
\hline 12 & 0,37 & 30,18 & 2,23 & 0,40 & 15,80 & 62,45 & 4,36 & 57,14 & 0,98 & 5,21 & 13,04 & 8,87 & 8,73 & 9,96 \\
\hline 13 & 0,22 & 32,07 & 3,07 & 0,51 & 15,44 & 76,74 & 2,84 & 69,90 & 1,29 & 10,06 & 14,12 & 7,51 & 7,75 & 8,15 \\
\hline 14 & 0,11 & 29,70 & 2,76 & 0,46 & 14,08 & 59,44 & 2,26 & 58,48 & 0,93 & 8,69 & 12,06 & 5,84 & 5,97 & 5,77 \\
\hline 15 & 0,32 & 43,64 & 2,93 & 0,45 & 16,98 & 68,78 & 4,60 & 77,07 & 1,26 & 4,59 & 14,54 & 4,29 & 4,24 & 4,17 \\
\hline 16 & 0,49 & 51,22 & 3,56 & 0,55 & 18,99 & 77,62 & 4,11 & 95,67 & 1,44 & 5,77 & 16,00 & 3,39 & 3,33 & 3,53 \\
\hline 17 & 0,15 & 35,93 & 2,69 & 0,42 & 13,00 & 71,07 & 2,70 & 62,05 & 0,89 & 5,56 & 12,79 & 10,74 & 11,29 & 14,33 \\
\hline 18 & 0,40 & 52,56 & 3,68 & 0,59 & 19,11 & 74,11 & 4,15 & 96,49 & 1,69 & 4,73 & 16,23 & 5,70 & 5,61 & 5,57 \\
\hline 19 & 0,32 & 44,96 & 3,00 & 0,49 & 16,64 & 63,28 & 3,46 & 84,09 & 1,41 & 3,25 & 14,12 & 11,31 & 11,15 & 11,52 \\
\hline 20 & 0,41 & 45,17 & 2,75 & 0,44 & 17,26 & 66,41 & 3,53 & 73,65 & 1,21 & 4,51 & 14,30 & 3,78 & 3,73 & 3,97 \\
\hline 21 & 0,34 & 52,05 & 3,17 & 0,54 & 18,54 & 76,86 & 4,56 & 84,27 & 1,43 & 4,53 & 16,22 & 8,90 & 8,86 & 8,97 \\
\hline 22 & 0,17 & 25,87 & 2,50 & 0,39 & 13,95 & 60,50 & 2,69 & 52,22 & 1,04 & 5,17 & 11,67 & 11,30 & 11,36 & 11,30 \\
\hline 23 & 0,10 & 34,04 & 2,88 & 0,50 & 15,50 & 67,68 & 1,91 & 54,76 & 0,80 & 7,71 & 12,86 & 9,28 & 9,14 & 9,42 \\
\hline 24 & 0,06 & 36,91 & 2,87 & 0,47 & 18,23 & 81,75 & 2,01 & 56,85 & 0,65 & 6,33 & 14,67 & 18,60 & 18,52 & 19,91 \\
\hline 25 & 0,11 & 32,54 & 2,61 & 0,40 & 14,41 & 61,97 & 2,48 & 56,57 & 0,99 & 4,93 & 11,52 & 3,19 & 3,42 & 5,11 \\
\hline
\end{tabular}


TABELA 9 - (Cont.).

\begin{tabular}{|c|c|c|c|c|c|c|c|c|c|c|c|c|c|c|}
\hline Amostra & $\mathrm{Na} \%$ & $\mathbf{L a}$ & $\mathbf{Y b}$ & Lu & Sc & $\mathrm{Cr}$ & $\mathrm{Fe} \%$ & $\mathrm{Ce}$ & $\mathbf{E u}$ & Hf & Th & $\mathbf{D}_{1}$ & $\mathbf{D}_{2}$ & $\mathbf{D}_{3}$ \\
\hline 26 & 0,14 & 40,17 & 2,79 & 0,45 & 16,17 & 69,65 & 3,76 & 79,07 & 1,12 & 6,02 & 13,67 & 3,22 & 3,56 & 3,44 \\
\hline 27 & 0,12 & 36,90 & 2,47 & 0,38 & 15,69 & 63,62 & 2,55 & 67,84 & 1,01 & 5,08 & 12,82 & 5,39 & 5,34 & 5,65 \\
\hline 28 & 0,17 & 46,70 & 3,29 & 0,56 & 19,00 & 73,58 & 3,26 & 88,20 & 1,40 & 6,98 & 15,49 & 4,30 & 4,46 & 5,01 \\
\hline 29 & 0,15 & 41,03 & 2,89 & 0,46 & 16,69 & 70,30 & 2,84 & 76,77 & 1,22 & 5,89 & 14,36 & 1,73 & 1,96 & 2,04 \\
\hline 30 & 0,05 & 48,92 & 3,36 & 0,51 & 15,62 & 75,50 & 2,32 & 94,03 & 1,42 & 6,43 & 14,15 & 9,06 & 8,92 & 9,17 \\
\hline 31 & 0,05 & 37,20 & 3,00 & 0,51 & 17,88 & 81,12 & 4,29 & 68,49 & 0,95 & 8,50 & 14,89 & 8,75 & 10,49 & 10,43 \\
\hline 32 & 0,12 & 42,77 & 3,68 & 0,63 & 17,62 & 81,43 & 3,47 & 88,51 & 1,50 & 9,31 & 15,16 & 5,94 & 5,84 & 5,85 \\
\hline 33 & 0,17 & 44,60 & 3,01 & 0,51 & 19,72 & 73,20 & 4,80 & 76,24 & 1,02 & 5,74 & 16,45 & 10,45 & 11,88 & 11,63 \\
\hline 34 & 0,08 & 30,21 & 2,43 & 0,40 & 14,10 & 56,47 & 2,17 & 58,68 & 0,91 & 6,32 & 11,55 & 4,52 & 4,53 & 4,92 \\
\hline 35 & 0,25 & 37,64 & 2,66 & 0,47 & 14,88 & 59,06 & 3,08 & 69,29 & 0,96 & 5,04 & 12,14 & 7,24 & 7,78 & 8,79 \\
\hline 36 & 0,31 & 43,17 & 2,91 & 0,45 & 18,45 & 75,82 & 4,20 & 77,27 & 1,24 & 4,87 & 15,41 & 3,71 & 4,02 & 3,88 \\
\hline 37 & 0,05 & 52,07 & 3,74 & 0,63 & 17,48 & 79,16 & 4,74 & 90,29 & 1,56 & 8,70 & 14,68 & 13,72 & 13,53 & 14,26 \\
\hline 38 & 0,08 & 54,06 & 3,45 & 0,56 & 16,75 & 81,88 & 3,02 & 96,72 & 1,38 & 7,05 & 15,32 & 7,67 & 7,57 & 7,88 \\
\hline 39 & 0,55 & 49,53 & 3,83 & 0,56 & 18,31 & 73,52 & 3,86 & 93,15 & 1,64 & 6,40 & 14,58 & 7,53 & 7,41 & 7,21 \\
\hline 40 & 0,27 & 48,15 & 2,99 & 0,47 & 19,06 & 72,05 & 3,56 & 86,94 & 1,34 & 4,45 & 16,35 & 5,69 & 5,82 & 5,92 \\
\hline 41 & 0,09 & 25,27 & 2,39 & 0,40 & 14,33 & 73,68 & 3,65 & 41,31 & 0,45 & 4,65 & 12,48 & 27,96 & - & - \\
\hline 42 & 0,03 & 28,41 & 2,63 & 0,48 & 20,37 & 97,68 & 3,60 & 84,32 & 1,20 & 4,22 & 17,21 & 21,28 & 21,00 & 20,69 \\
\hline 43 & 0,03 & 34,38 & 2,78 & 0,48 & 16,93 & 77,62 & 3,90 & 94,23 & 1,28 & 6,63 & 17,11 & 10,75 & 10,82 & 11,93 \\
\hline 44 & 0,13 & 32,06 & 2,78 & 0,48 & 17,63 & 68,90 & 3,54 & 89,64 & 1,61 & 4,42 & 16,86 & 15,03 & 16,00 & 15,75 \\
\hline 45 & 0,44 & 49,96 & 3,42 & 0,50 & 17,65 & 75,03 & 3,54 & 100,46 & 1,52 & 4,96 & 15,51 & 3,91 & 3,84 & 4,01 \\
\hline 46 & 0,40 & 46,78 & 3,16 & 0,51 & 17,59 & 60,20 & 3,52 & 99,13 & 1,63 & 5,30 & 15,11 & 9,55 & 10,01 & 10,50 \\
\hline 47 & 0,15 & 28,04 & 2,55 & 0,45 & 16,04 & 74,44 & 4,36 & 75,99 & 1,13 & 5,78 & 14,84 & 7,80 & 7,71 & 7,54 \\
\hline 48 & 0,06 & 29,47 & 3,49 & 0,59 & 17,53 & 74,79 & 3,75 & 80,73 & 1,46 & 7,91 & 16,84 & 15,88 & 15,66 & 16,85 \\
\hline 49 & 0,04 & 23,52 & 2,63 & 0,48 & 11,66 & 48,79 & 1,64 & 47,11 & 0,80 & 7,57 & 9,97 & 18,42 & 18,56 & 23,54 \\
\hline
\end{tabular}


TABELA 9 - (Cont.).

\begin{tabular}{|c|c|c|c|c|c|c|c|c|c|c|c|c|c|c|}
\hline Amostra & $\mathrm{Na} \%$ & $\mathbf{L a}$ & $\mathbf{Y b}$ & $\mathbf{L u}$ & Sc & $\mathrm{Cr}$ & $\mathrm{Fe} \%$ & $\mathrm{Ce}$ & Eu & Hf & Th & $\mathbf{D}_{1}$ & $\mathbf{D}_{2}$ & $\mathbf{D}_{3}$ \\
\hline 50 & 0,05 & 21,75 & 2,29 & 0,38 & 14,30 & 63,89 & 2,03 & 61,73 & 0,94 & 7,97 & 11,90 & 11,77 & 12,29 & 12,59 \\
\hline 51 & 0,57 & 47,24 & 3,36 & 0,59 & 17,50 & 75,63 & 4,96 & 88,89 & 1,38 & 6,40 & 16,55 & 8,84 & 8,70 & 9,73 \\
\hline 52 & 0,16 & 33,04 & 2,32 & 0,36 & 13,45 & 59,58 & 2,60 & 62,49 & 1,01 & 6,10 & 10,88 & 8,42 & 8,29 & 9,22 \\
\hline 53 & 0,03 & 43,94 & 2,86 & 0,42 & 13,29 & 69,12 & 1,58 & 84,01 & 1,33 & 5,04 & 10,09 & 16,79 & 16,62 & 18,86 \\
\hline 54 & 0,10 & 36,38 & 3,96 & 0,61 & 14,90 & 80,84 & 3,09 & 63,66 & 0,84 & 9,36 & 16,59 & 25,21 & 28,08 & - \\
\hline 55 & 0,05 & 18,63 & 1,82 & $\mathbf{0 , 3 0}$ & 9,67 & 47,33 & 1,07 & 38,17 & $\mathbf{0 , 5 1}$ & 3,44 & $\mathbf{7 , 5 8}$ & 25,26 & 28,75 & - \\
\hline 56 & 0,11 & 40,69 & 3,54 & 0,56 & 13,42 & 65,00 & 2,50 & 70,87 & 1,10 & 10,91 & 13,59 & 13,82 & 13,93 & 17,29 \\
\hline 57 & 0,04 & 49,49 & 4,13 & 0,58 & 17,63 & 76,57 & 4,47 & 99,60 & 1,99 & 7,12 & 14,22 & 15,00 & 14,91 & 14,60 \\
\hline 58 & 0,07 & 55,71 & 3,96 & 0,59 & 22,20 & 104,69 & 3,85 & 112,15 & 1,91 & 6,51 & 17,35 & 15,60 & 15,71 & 15,23 \\
\hline 59 & 0,07 & 29,12 & 2,55 & 0,45 & 16,08 & 75,63 & 1,63 & 53,26 & 0,70 & 6,44 & 13,31 & 12,41 & 12,23 & 13,25 \\
\hline 60 & 0,13 & 33,59 & 2,70 & 0,43 & 17,12 & 75,11 & 2,37 & 64,64 & 0,86 & 8,35 & 14,04 & 7,79 & 7,72 & 7,67 \\
\hline 61 & 0,32 & 46,53 & 3,11 & 0,48 & 18,63 & 73,73 & 4,23 & 87,79 & 1,41 & 5,43 & 15,16 & 3,03 & 3,08 & 3,73 \\
\hline 62 & 0,17 & 41,85 & 3,22 & 0,49 & 19,99 & 84,53 & 4,33 & 79,91 & 1,18 & 5,78 & 17,94 & 7,18 & 7,47 & 8,49 \\
\hline 63 & 0,08 & 36,93 & 2,61 & 0,48 & 20,61 & 93,71 & 3,68 & 75,23 & 1,11 & 5,25 & 16,01 & 12,27 & 12,23 & 12,79 \\
\hline 64 & 0,47 & 51,74 & 3,58 & 0,54 & 19,42 & 82,16 & 4,68 & 96,86 & 1,38 & 5,38 & 17,71 & 6,23 & 6,15 & 7,72 \\
\hline 65 & 0,10 & 44,26 & 3,52 & 0,56 & 15,43 & 67,70 & 2,29 & 89,30 & 1,31 & 8,25 & 14,32 & 6,22 & 6,82 & 7,38 \\
\hline 66 & 0,14 & 31,21 & 2,86 & 0,43 & 14,88 & 64,63 & 2,45 & 61,98 & 0,96 & 10,90 & 12,75 & 12,21 & 12,51 & 13,09 \\
\hline 67 & 0,16 & 73,64 & 4,65 & 0,71 & 18,16 & 77,19 & 2,65 & 153,24 & 2,95 & 6,62 & 15,67 & 20,24 & 20,74 & 20,24 \\
\hline 68 & 0,14 & 33,91 & 2,56 & 0,39 & 14,34 & 66,24 & 2,46 & 64,78 & 0,93 & 5,49 & 11,79 & 3,48 & 3,89 & 4,85 \\
\hline 69 & 0,10 & 31,75 & 2,39 & 0,41 & 15,35 & 63,73 & 2,76 & 61,97 & 0,85 & 5,49 & 12,76 & 3,46 & 3,40 & 3,44 \\
\hline 70 & 0,39 & 36,30 & 2,74 & 0,41 & 14,94 & 64,81 & 3,92 & 66,45 & 1,05 & 4,97 & 12,64 & 4,97 & 5,64 & 6,02 \\
\hline Valor Críticc & & & & & & & & & & & & 27,46 & 27.36 & 27,18 \\
\hline
\end{tabular}


Conforme sugerido por Penny (1996), a amostra discrepante é aquela que apresenta valor calculado para distância de Mahalanobis acima do valor crítico no nível de confiança adotado. Esta amostra, portanto, deve ser eliminada do conjunto de dados. Este procedimento é finalizado quando o valor da distância de Mahalanobis, encontrado, é menor que o valor crítico.

Para o conjunto das 70 amostras (TAB. 9), o valor crítico calculado no nível de significância de 0,05 foi de 27,46. A amostra 41 apresentou o valor da distância de Mahalanobis de 27,96 que é superior ao valor crítico. Portanto, essa amostra foi eliminada do conjunto de dados. Após a eliminação, a distância de Mahalanobis foi calculada novamente. Para o novo conjunto de 69 amostras, o novo valor crítico calculado foi de 27,36. As amostras 54 e 55 apresentaram valores para a distância de Mahalanobis de 28,08 e 28,75, respectivamente, e foram eliminadas da base de dados. Após a exclusão das duas amostras, a distância de Mahalanobis foi calculada novamente e os valores da distância em todos os casos foram menores que e o valor crítico de 27,18. Desta forma, o processo de identificação de valores anômalos na base de dados foi finalizado. A base de dados utilizada para o estudo de análise estatístico constou de 67 amostras e 11 elementos químicos.

Em virtude da quantidade de elementos e do número de amostras analisadas, isto é uma matriz de 11 x 67 o que resulta em 737 resultados, torna-se quase impossível lidar, manualmente, com essa quantidade de dados. Por isso, foram desenvolvidos métodos estatísticos avançados que facilitam a interpretação desses dados (Beier \& Mommsen, 1994). Neste trabalho, a base de dados foi submetida à análise de cluster, componentes principais e análise de discriminante.

Todos os estudos estatísticos multivariados foram realizados utilizando o programa estatístico $R$ (R Development Core Team, 2012).

Inicialmente, a unidade das variáveis deve estar na mesma unidade de medida, caso contrário a matriz deve ser padronizada, ou seja, possuir média 0 e desvio igual a 1. Posteriormente, foi aplicada a análise de agrupamento. O propósito dessa análise é realizar uma classificação preliminar por meio da interligação da similaridade/dissimilaridade entre as amostras (Hair et al., 2006; Legendre \& Legender, 1998). Para que a análise de agrupamento possa alcançar o resultado desejado, selecionou-se um modelo matemático que se aproxima da realidade do estudo.

As medidas de parecença têm como finalidade avaliar a menor distância entre 
duas amostras e, consequentemente, determinar se pertencem ao mesmo grupo. Segundo Johnson \& Nichern (2002), No presente trabalho, a distância Euclidiana ao quadrado foi escolhida como medida de dissimilaridade.

Segundo Hair et al. (2006), o método mais adequado para diferenciar resultados experimentais com menor perda de informação é o método de Ward. Ainda segundo Hair et. al (2006) esse método é ideal para representar o agrupamento quando a distância Euclidiana e suas derivadas são utilizadas.

Desse modo, o modelo matemático escolhido gerou o gráfico do tipo árvore ou dendrograma (FIG. 14). No dendrograma a escala vertical indica o nível de similaridade e no eixo horizontal são alocadas as amostras.

Ao observar a FIG. 14, nota-se que a maior distância entre os grupos encontrase, aproximadamente, entre as alturas próximas do valor da distância 100 até 500. Essa altura representa a melhor distância de ligação entre as amostras de cada grupo (Borcard et al., 2011). Um corte nesta altura de ligação mostra a formação de 3 grupos.

Os grupos formados foram chamados de grupo 01 cor preta, grupo 02 cor vermelha e o grupo 03 representado pela cor verde. O grupo 01 constitui 16 amostras (11, $13,56,65,01,31,43,48,37,57,30,38,28,32,58$ e 67$)$.

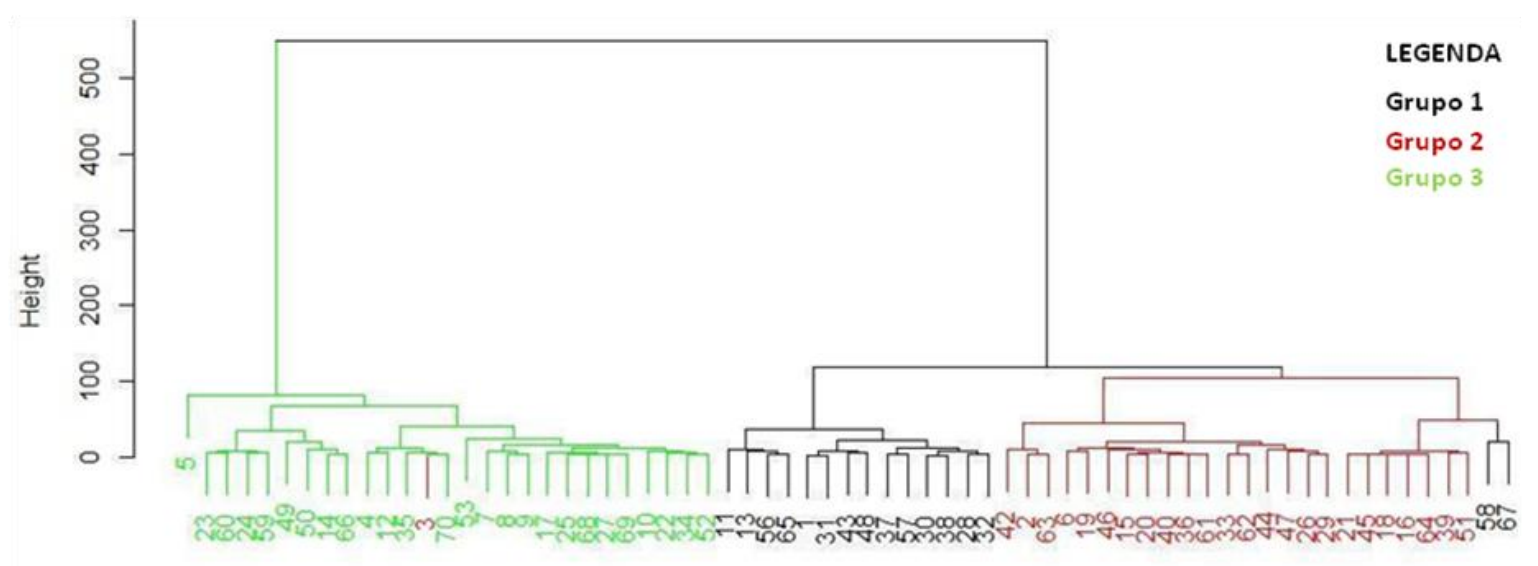

FIGURA 14 - Dendrograma da matriz de dados utilizando distância Euclideana quadrática e método de Ward.

O grupo 02 está formado por 25 amostras $(03,42,02,63,06,19,46,15,20$, $40,36,61,33,62,44,47,26,29,21,45,18,16,64,39$ e 51). O grupo 03 por 26 amostras $(05,23,60,24,59,49,50,14,66,4,12,35,70,53,07,08,09,17,25,68,27,69,10,22$, 
$34,52)$.

Na FIG. 14 o grupo formado pelas amostras (eixo horizontal), também, mostra que a diferença na composição química das amostras aumenta da posição inicial ( esquerda do gráfico) para a direita nos grupos. Podes-se notar também que o número de grupos aumenta quando o eixo vertical (distância) aproxima-se do valor zero.

A seguir a matriz de dados foi estudada por meio da análise de componentes principais. O primeiro objetivo desta análise é investigar o número total de componentes que expliquem a variância acumulada do sistema. O segundo objetivo, e principal, é confirmar o número de grupos. De forma resumida, a análise de componentes principais consiste na transformação de um conjunto de variáveis originais e correlacionadas em um novo conjunto de variáveis não correlacionadas, chamadas de componentes principais e dispostas em ordem decrescente de variância (Stearns et al., 2005).

Para iniciar a análise, alguns critérios devem ser investigados, com o objetivo de selecionar os componentes que melhor expliquem a variância total do sistema. Segundo Reis (1997), existe dois importantes critérios. O primeiro sugere que os componentes escolhidos devem possuir desvio padrão $\geq 1$. Na TAB. 10 são apresentados os valores da variância para cada componente. Pode-se notar na segunda coluna, da TAB. 10, o valor do desvio padrão. Esse valor para o componente 1 é 2,45, componente 2 é 1,34 e para o componente 3 de 1,12. A partir do componente 4 o valor do desvio padrão é menor que 1.

TABELA 10 - Porcentagem da variança explicada para cada componente principal.

\begin{tabular}{cccc}
\hline Componente & $\begin{array}{c}\text { Desvio } \\
\text { Padrão }\end{array}$ & $\begin{array}{c}\text { Variância } \\
\text { Explicada (\%) }\end{array}$ & $\begin{array}{c}\text { Variância } \\
\text { Acumulada (\%) }\end{array}$ \\
\hline 1 & 2,45 & 55,5 & 55,5 \\
2 & 1,34 & 16,4 & 71,9 \\
3 & 1,12 & 11,6 & 83,5 \\
4 & 0,81 & 6,1 & 89,6 \\
5 & 0,65 & 4 & 93,6 \\
6 & 0,46 & 2 & 95,6 \\
7 & 0,45 & 2 & 97,6 \\
8 & 0,33 & 1 & 98,6 \\
9 & 0,29 & 1 & 99,6 \\
10 & 0,22 & 0,38 & 99,98 \\
11 & 0,15 & 0,02 & 100 \\
\hline
\end{tabular}


O segundo critério baseia-se na soma da variância dos três primeiros componentes. Para Reis (1997), os três primeiros componentes são suficientes para explicar a variância total do sistema e deve estar entre $70 \%$ e 90 \% Na TAB. 10 mostrase, também, a distribuição da variância explicada e acumulada. Pode-se notar que a variância acumulada para os três primeiros componente explicam 83,5 \% da variância total do sistema. Dessa forma, os dois critérios utilizados, concomitantemente, corroboram entre sim, sendo os três primeiros componentes suficientes para explicar a variância do sistema.

Após a seleção dos componentes, foi construído o gráfico em 3 dimensões formado pelos scores dos componentes principais 1, componente principal 2 e componente principal 3. Na FIG. 15 apresenta-se o gráfico em 3 dimensões dos scores dos três primeiros componentes. Podem-se observar na FIG. 15, três grupos, em que cada grupo está formado por amostras com concentração química similar. É possível, também, observar a dispersão das amostras em cada grupo.

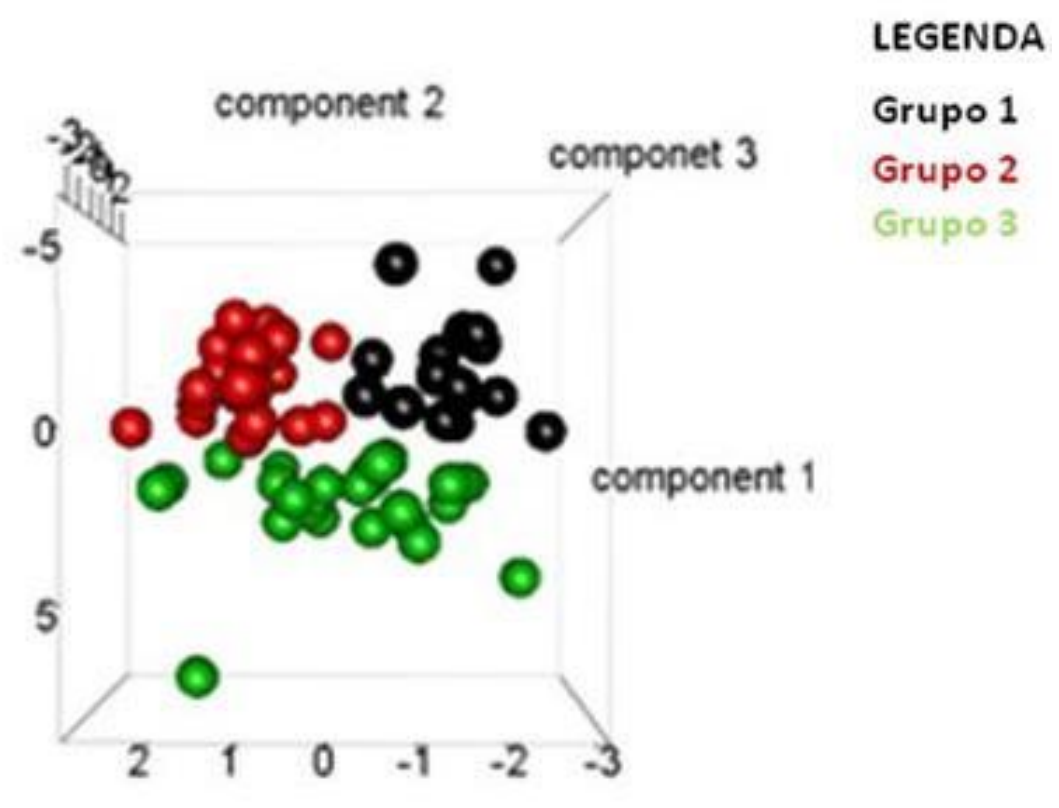

FIGURA 15 - Scores dos três primeiros componentes principais.

A seguir, com o objetivo de validar os resultados apresentados na análise de cluster e componentes principais, foi aplicada a análise discriminante. Este método baseiase na substituição do conjunto das variáveis por uma única medida, formada pela combinação linear de todas as variáveis. Esta medida é chamada de função linear. Na FIG. 
16 mostra-se o gráfico da função discriminante 1 contra a função discriminante 2 .

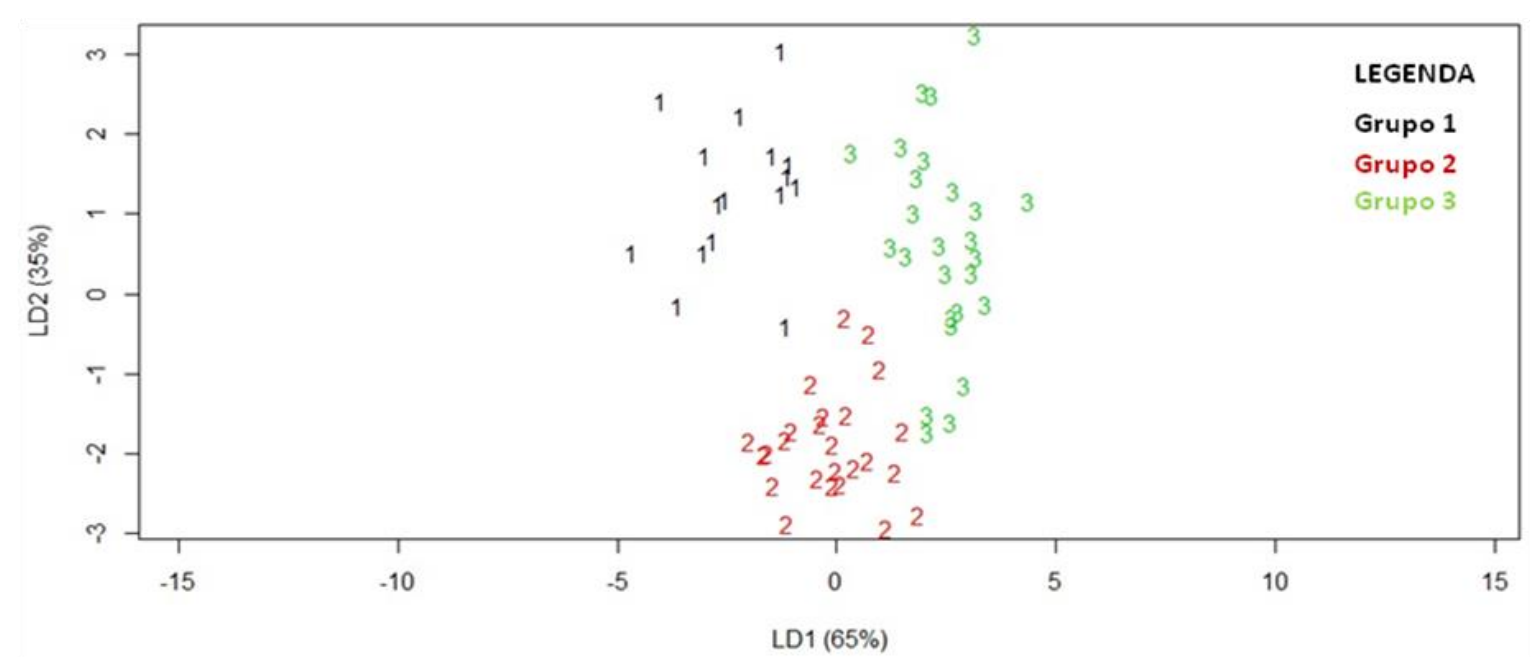

FIGURA 16 - Análise discriminante dos grupos de cerâmicas do Sítio São Paulo II.

O critério utilizado para a escolha dos fragmentos utilizados no estudo da temperatura de queima e da idade dos fragmentos cerâmicos teve como base o agrupamento formado após a análise de cluster, componentes principais e análise discriminante.

Primeiramente, as amostras de quartzo selecionadas foram analisadas por microscopia óptica. Esse estudo teve como objetivo avaliar a presença da espícula. As estruturas das espículas são formadas por carbonato de cálcio ou sílica, possuem a forma cilíndrica de um cone e constituem o esqueleto das esponjas de água doce e salgada encontradas nos rios e mares. Esse material é facilmente encontrado nos rios da região da Amazônia (Jensen et. al., 2011). As espículas eram, frequentemente, utilizadas com o tempero para a manufatura das cerâmicas. Na FIG. 17 apresenta-se a microestrutura das espículas encontradas nos rios da Amazônia e retirada do trabalho de Jensen e colaboradores.

Segundo Nunes (2009) as cerâmicas que apresentam espículas mostram grande imprecisão nos resultados da datação por TL. Em razão da presença das espículas, o material emite sinal luminescente de comportamento irregular com a dose de irradiação na região do pico de $440{ }^{\circ} \mathrm{C}$. 


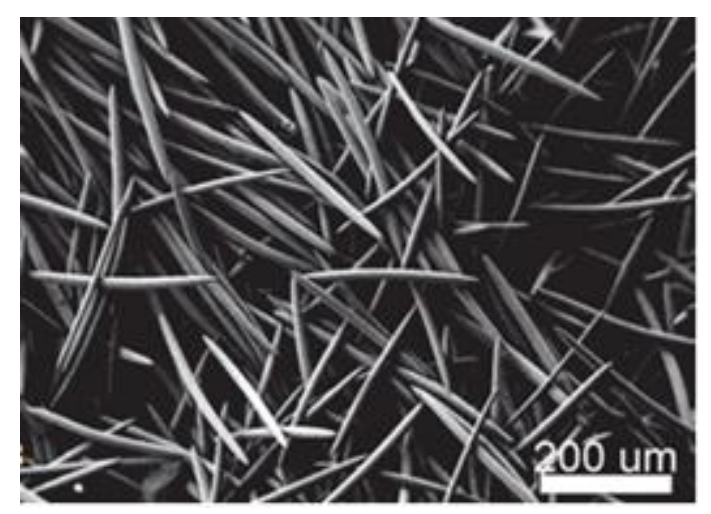

FIGURA 17 - Espículas encontradas na região da Amazônia. Fonte: Jensen et al. (2011).

Para a análise por microscopia óptica, foram selecionadas quatro amostras, 06, 11, 28 e 49. Do grupo 1 foram selecionadas as amostras 11 e 28, do grupo 2 a amostra 06 e do grupo 3 a amostra 49. As imagens dos grãos de quartzo foram feitas com uma câmera acoplada ao microscópio. Na FIG. 18 apresentam-se as micrografias tiradas das 04 amostras de grãos de quartzo estudadas por TL.
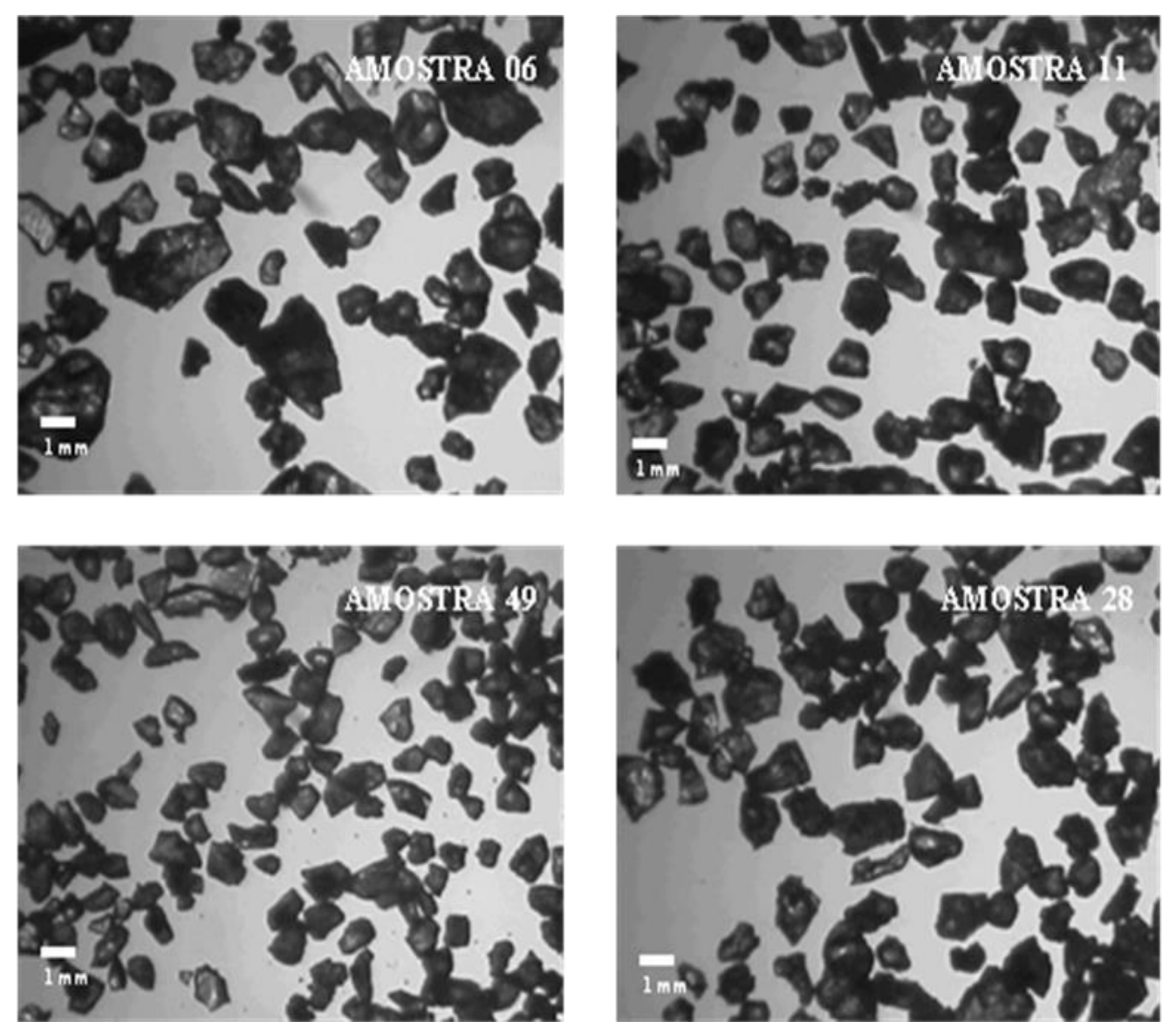

FIGURA 18 - Grãos de quartzos encontrados nas amostras de cerâmicas utilizadas para datação por TL. 
Após a minuciosa análise por micrografia óptica, não foi encontrado o material conhecido como espícula, nas amostras de quartzo. Desta forma, as 04 amostras (06, 11, 28 e 49) foram utilizadas para o estudo de datação.

Nas FIGs. 19, 20, 21 e 22 apresenta-se a curva de emissão TL do quartzo das respectivas amostras já com as radiações adicionais. Podem-se observar, claramente, em cada gráfico, três picos de maior intensidade de TL, considerados os principais picos na curva de emissão. O primeiro pico em $120{ }^{\circ} \mathrm{C}$ de vida média muito curta e altura pequena, o segundo em $200{ }^{\circ} \mathrm{C}$ e um terceiro pico largo centrado em $320^{\circ} \mathrm{C}$, que se desloca para temperatura mais baixa com maior dose de radiação. Para o cálculo da dose acumulada $\left(\mathrm{D}_{\mathrm{ac}}\right)$, utilizou-se o pico de $320{ }^{\circ} \mathrm{C}$, pois, apresenta estabilidade com a temperatura ambiente (Aitken, 1985).

Além disso, para a determinação da $\mathrm{D}_{\mathrm{ac}}$ foi utilizado o método de dose aditiva. Esse método fundamenta-se no fato de que a intensidade da TL é proporcional à dose de radiação.

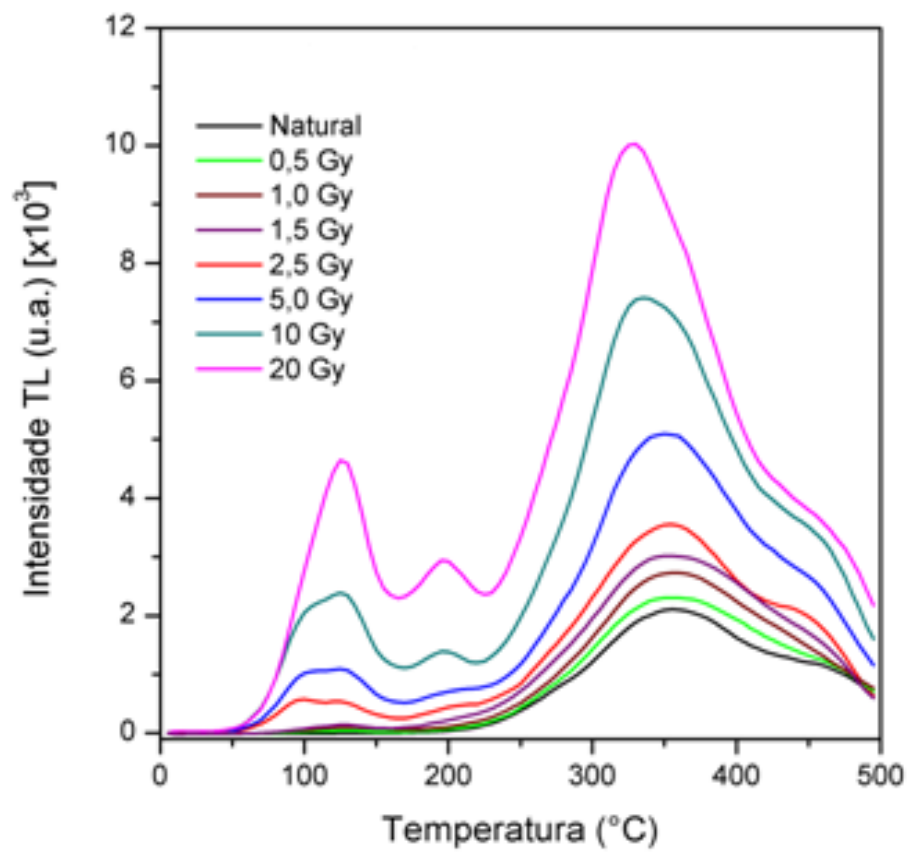

FIGURA 19 - Curva de emissão TL para a amostra 06, natural e adicional entre 0,5 Gy e $20 \mathrm{~Gy}$. 


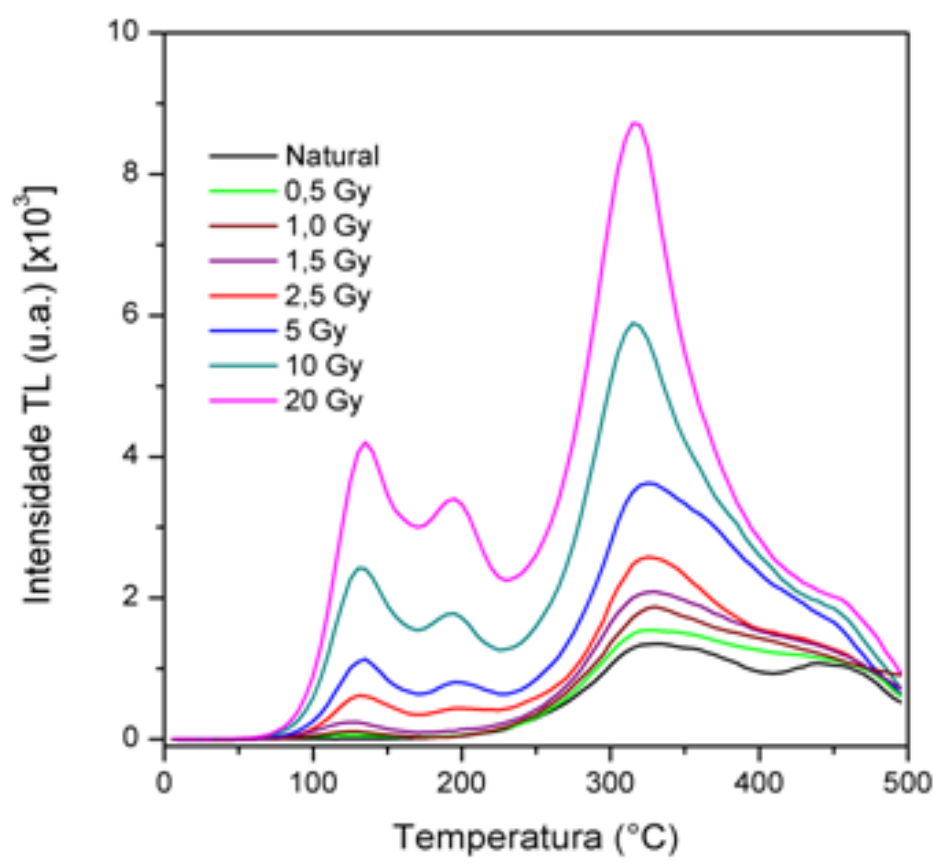

FIGURA 20 - Curva de emissão TL para a amostra 11, natural e adicional entre 0,5 Gy e $20 \mathrm{~Gy}$.

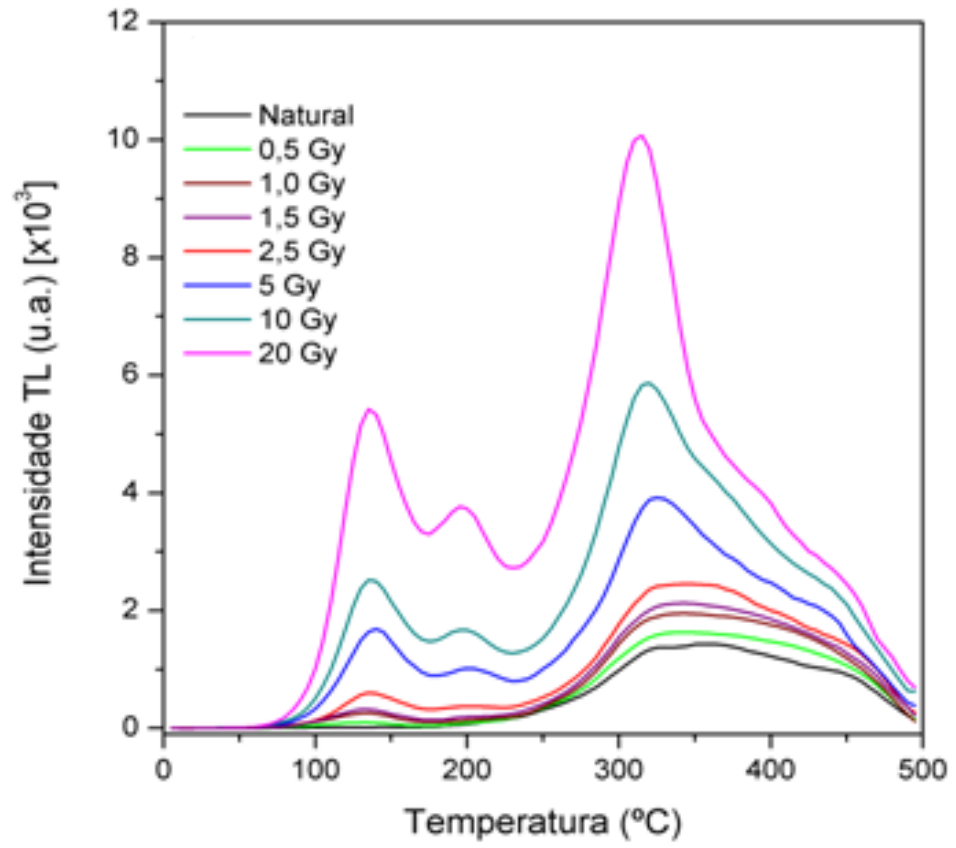

FIGURA 21 - Curva de emissão TL para a amostra 28, natural e adicional entre 0,5 Gy e $20 \mathrm{~Gy}$. 


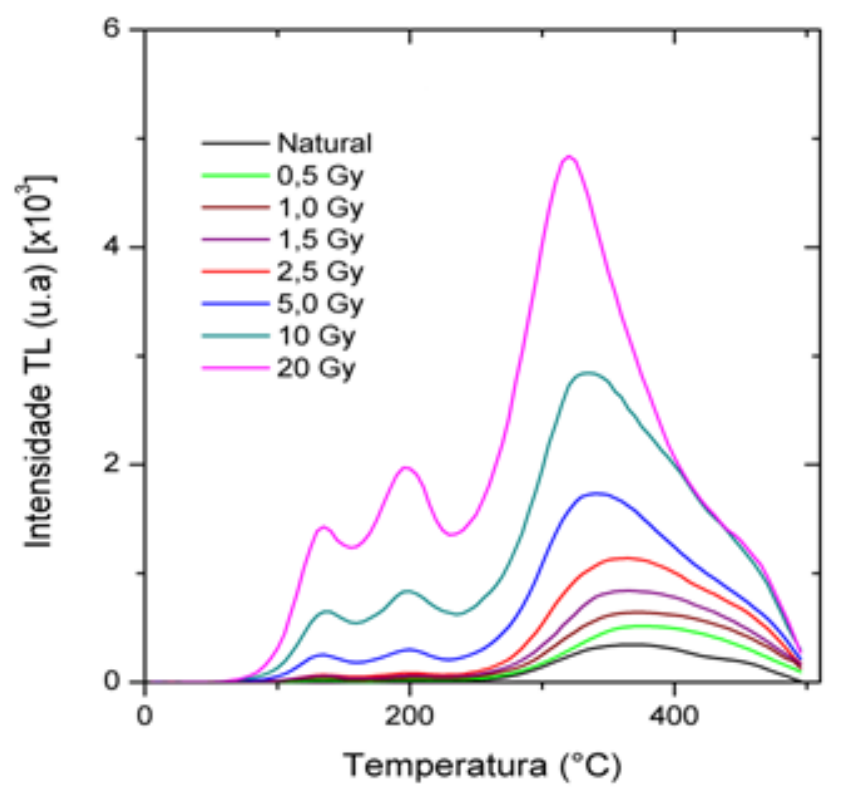

FIGURA 22 - Curva de emissão TL para a amostra 49, natural e adicional entre 0,5 Gy e $20 \mathrm{~Gy}$.

As intensidades médias das emissões TL para todas as amostras foram dispostas em um gráfico da intensidade de TL contra doses adicionadas (FIGs. 23, 24, 25 e 26). A extrapolação do ajuste da curva no gráfico contra o eixo das abscissas fornece a $D_{a c}$ ao longo dos anos, ou seja, a dose arqueológica para a datação por TL.

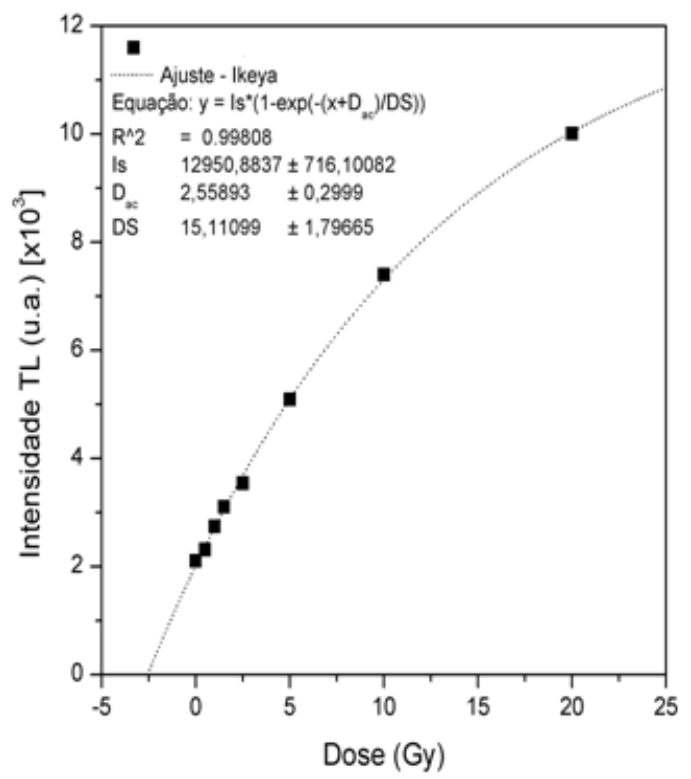

FIGURA 23 - Intensidade TL contra doses adicionais entre 0,5 Gy e 20 Gy para a amostra 06. 


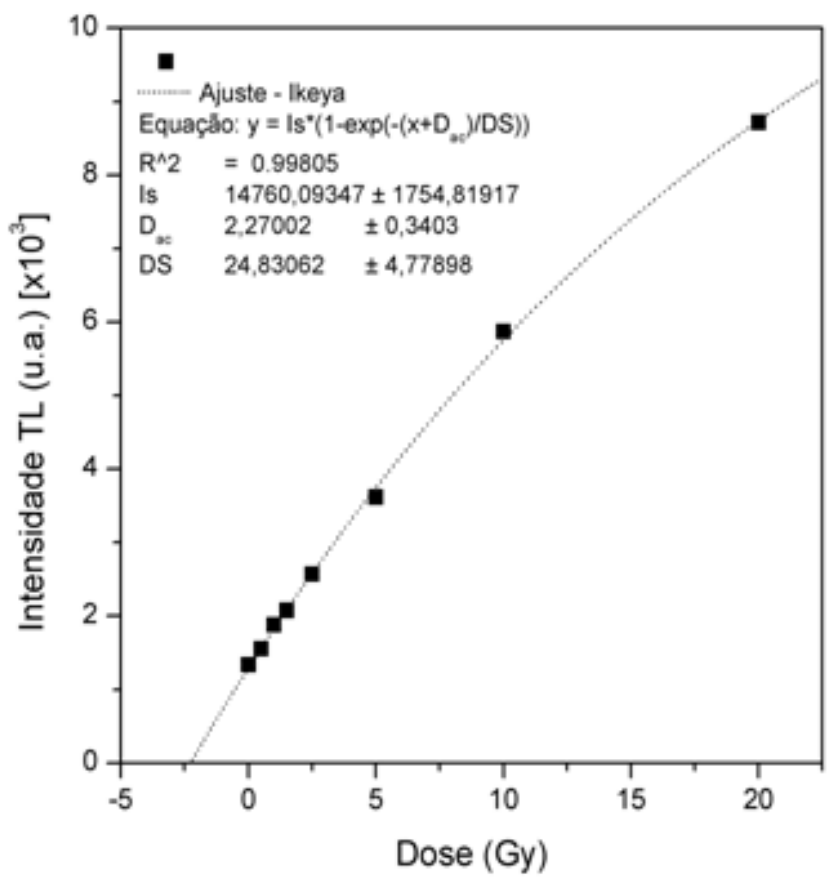

FIGURA 24 - Intensidade TL contra doses adicionais entre 0,5 Gy e 20 Gy para a amostra 11.

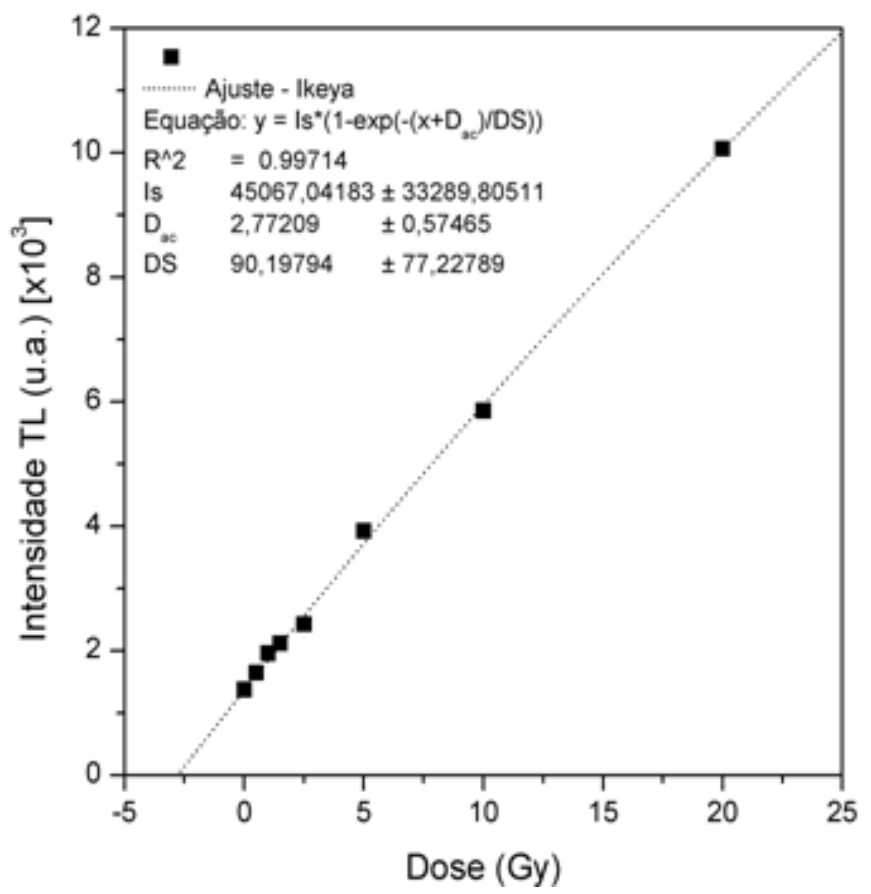

FIGURA 25 - Intensidade TL contra doses adicionais entre 0,5 Gy e 20 Gy para a amostra 28. 


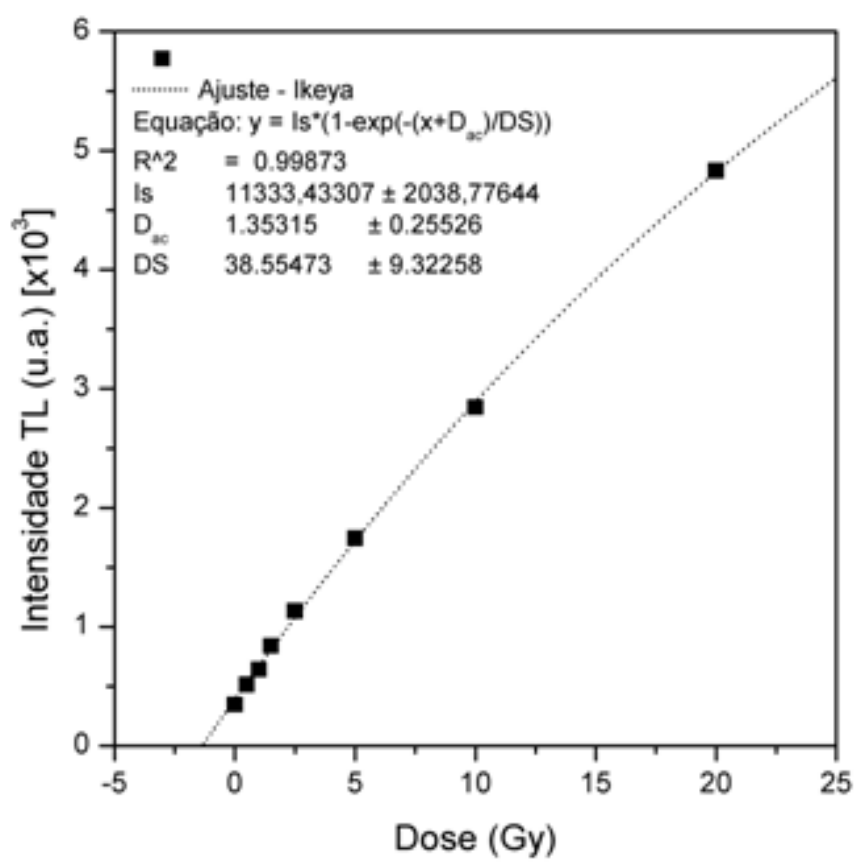

FIGURA 26 - Intensidade TL contra doses adicionais entre 0,5 Gy e 20 Gy para a amostra 49.

Utilizaram-se, para determinar dose anual $\left(D_{a n}\right)$, os resultados das concentrações de $U$, Th e K, obtidas por NAA e a taxa anual de radiação cósmica (contribuição dos raios cósmicos). Usou-se o procedimento proposto por Ikeya (1993) para determinar a idade das cerâmicas. Na TAB. 11, apresenta-se o resultado da concentração dos elementos, $\mathrm{U}, \mathrm{Th}, \mathrm{K}, \mathrm{D}_{\mathrm{an}}, \mathrm{D}_{\mathrm{ac}}$ e a idade (I) das amostras investigadas por TL.

TABELA 11 - Dose acumulada $\left(D_{a c}\right)$, Dose anual $\left(D_{a n}\right)$ e Idade (I) das amostras, obtidas por TL.

\begin{tabular}{cccccccc}
\hline Amostra & $\begin{array}{c}\mathbf{U} \pm \mathbf{D P} \\
(\mathbf{p p m})\end{array}$ & $\begin{array}{c}\mathbf{T h} \pm \mathbf{D P} \\
(\mathbf{p p m})\end{array}$ & $\begin{array}{c}\mathbf{K} \pm \mathbf{D P} \\
(\boldsymbol{\%})\end{array}$ & $\begin{array}{c}\mathbf{D}_{\mathbf{a n}} \\
(\mathbf{m G y} / \mathbf{a n o})\end{array}$ & $\begin{array}{c}\mathbf{D}_{\mathbf{a c}} \\
(\mathbf{G y})\end{array}$ & $\begin{array}{c}\mathbf{I} \\
(\mathbf{a n o s} \mathbf{d} . \mathbf{C})\end{array}$ & Grupo \\
\hline 06 & $2,988 \pm 0,252$ & $14,447 \pm 0,930$ & $1,488 \pm 0,567$ & $2,58 \pm 0,12$ & $2,54 \pm 0,16$ & $1027 \pm 78$ & 02 \\
11 & $3,143 \pm 0,252$ & $11,669 \pm 0,643$ & $1,026 \pm 0,19$ & $2,06 \pm 0,08$ & $2,30 \pm 0,17$ & $895 \pm 92$ & 02 \\
28 & $4,429 \pm 0,276$ & $8,114 \pm 0,520$ & $2,501 \pm 1,309$ & $3,35 \pm 0,17$ & $2,91 \pm 0,30$ & $1142 \pm 100$ & 01 \\
49 & $2,653 \pm 0,484$ & $9,967 \pm 0,725$ & $0,299 \pm 0,040$ & $1,286 \pm 0,126$ & $1,33 \pm 0,13$ & $978 \pm 141$ & 03 \\
\hline
\end{tabular}

Como apresentado na TAB. 11, os resultados da datação por TL mostram que a idade das amostras selecionadas variou entre 895 e 1142 anos d.C. 
Para datação por EPR foram selecionadas, após o processo de agrupamento, amostras do grupo 1 e 3. Do grupo 1 foram selecionadas as amostras 30 e 56 e do grupo 3 amostra 05 .

O fenômeno de EPR ocorre devido aos centros paramagnéticos, átomos que apresentam na camada de valência elétrons desemparelhados e momento angular diferente de zero; mas, com grande frequência, temos elétrons ou buracos desemparelhados associados a um defeito; um exemplo muito conhecido é o chamado centro de alumínio, que se forma quando $\mathrm{Al}^{3+}$ substitui $\mathrm{Si}^{4+}$ no tetraedro $\mathrm{SiO}_{4}$, na forma $\left[\mathrm{AlO}_{4} / \mathrm{h}\right]$ onde h é um buraco. O sinal EPR deste centro, registrado em $77 \mathrm{~K}$ ou abaixo é muito conhecido. Já o centro E' ${ }_{1}$, outro centro muito conhecido, forma-se na vacância do oxigênio. Sabe-se que, a vacância de oxigênio se forma e é estável na temperatura ambiente.

Quando o cristal é irradiado, elétrons são liberados na ionização e, depois são capturados pela vacância de oxigênio. Em aquecimentos acima de cerca de $120^{\circ} \mathrm{C}$, um elétron é liberado e a vacância de oxigênio com um elétron recebe o nome de centro ${ }^{\prime}{ }_{1}$. Todo esse processo depende da irradiação, por isso, o numero de centros $\mathrm{E}_{1}{ }_{1}$ é proporcional à dose de irradiação. Este fato é básico para a datação.

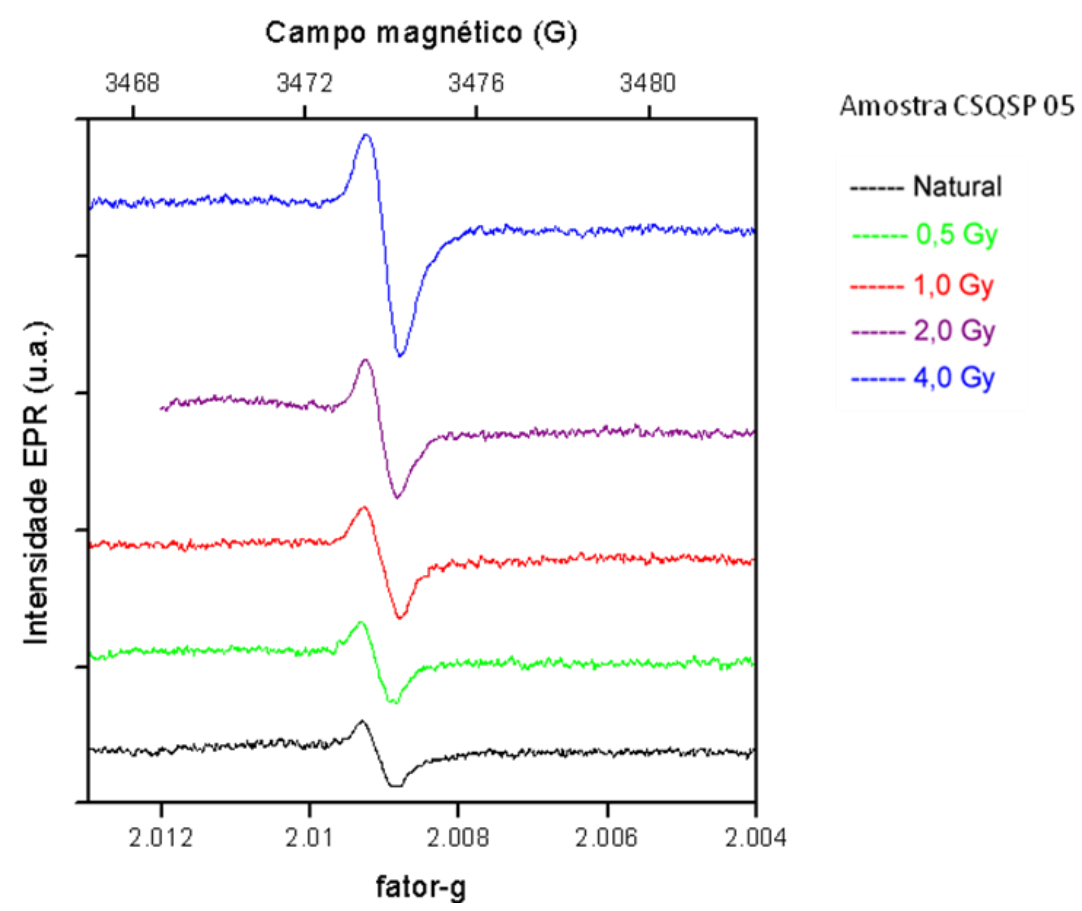

FIGURA 27 - Curva de comportamento das linhas de EPR em g=2.0092 para a amostra 05 . 


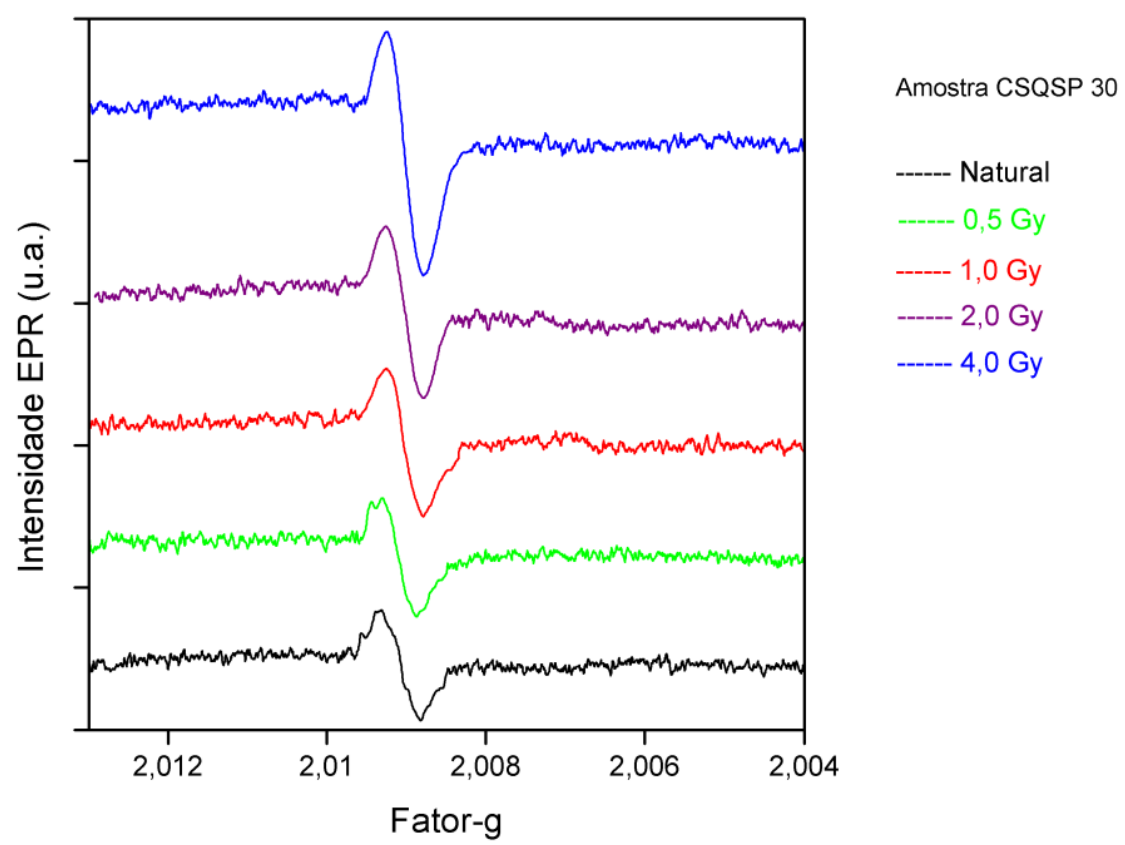

FIGURA 28 - Curva de comportamento das linhas de EPR em g=2.0092 para a amostra 30.

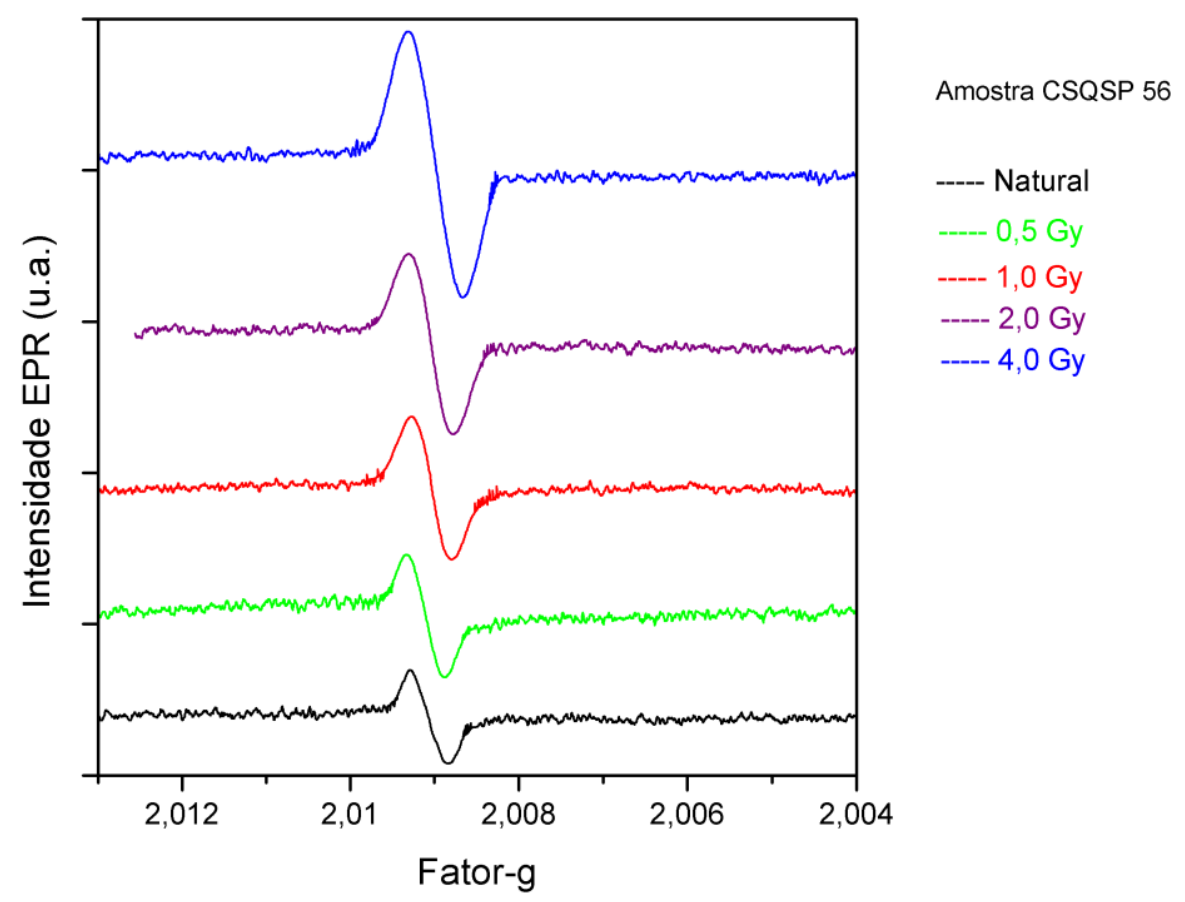

FIGURA 29 - Curva de comportamento das linhas de EPR em g=2.0092 para a amostra 56. 
O centro E' ${ }_{1}$ aparece após a irradiação das amostras e cresce com a irradiação $\gamma$, indicando que este sinal pode ser usado para análises por EPR na datação das amostras. Foi construído o gráfico da intensidade pico-pico do sinal de E' ${ }_{1}$ com g = 2,0092 em função da dose natural e das doses adicionais (FIGs. 27, 28 e 29).

As intensidades médias do sinal E' ${ }_{1}$ para todas as amostras foram dispostas em um gráfico da intensidade contra as doses. A extrapolação do ajuste da curva no gráfico até o eixo das abscissas fornece a dose acumulada $\left(\mathrm{D}_{\mathrm{ac}}\right)$ ao longo dos anos. Este procedimento foi repetido para todas as amostras, nas quais foi possível observar o centro E' ${ }_{1}$. Nas FIGs. 30, 31 e 32 apresenta-se a determinação da dose acumulada para as amostras selecionadas. A determinação da dose anual $\left(\mathrm{D}_{\mathrm{an}}\right)$ foi feita por meio da soma das contribuições das concentrações de $\mathrm{U}$, Th e $\mathrm{K}$ e da radiação cósmica.

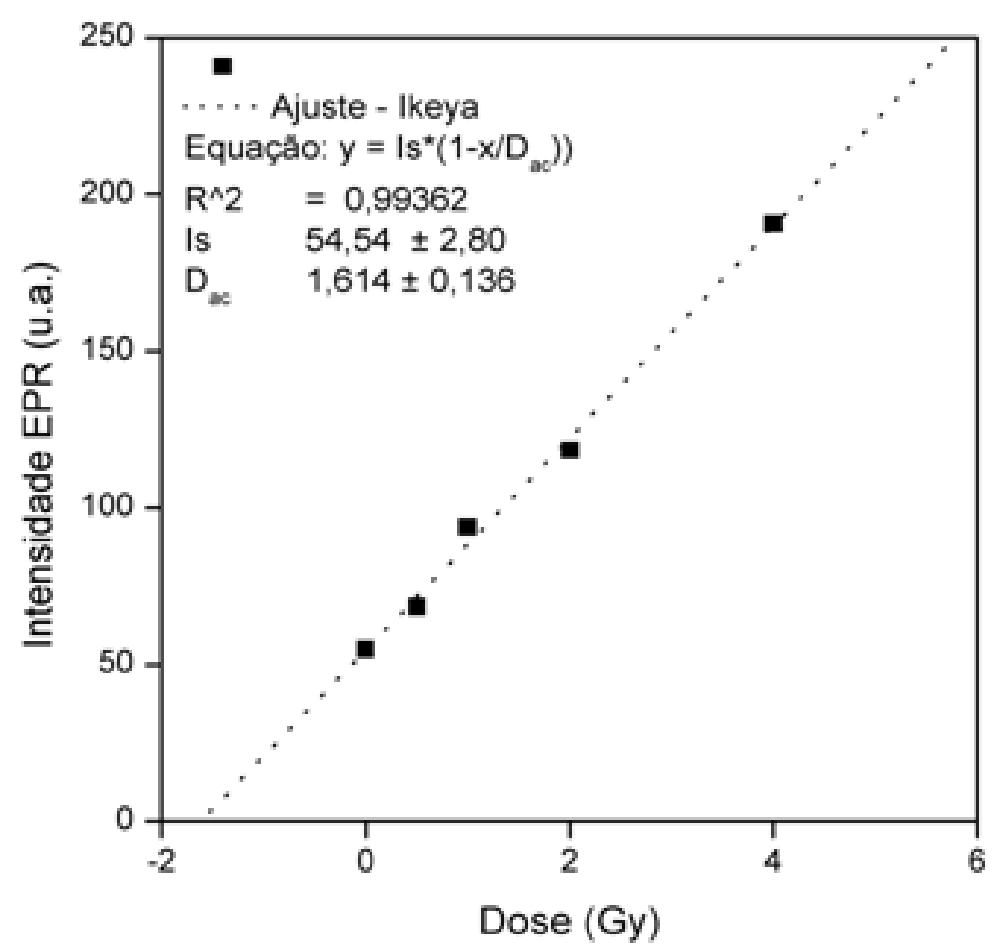

FIGURA 30 - Curva de calibração pelo método de dose aditiva para a amostra 05 . 


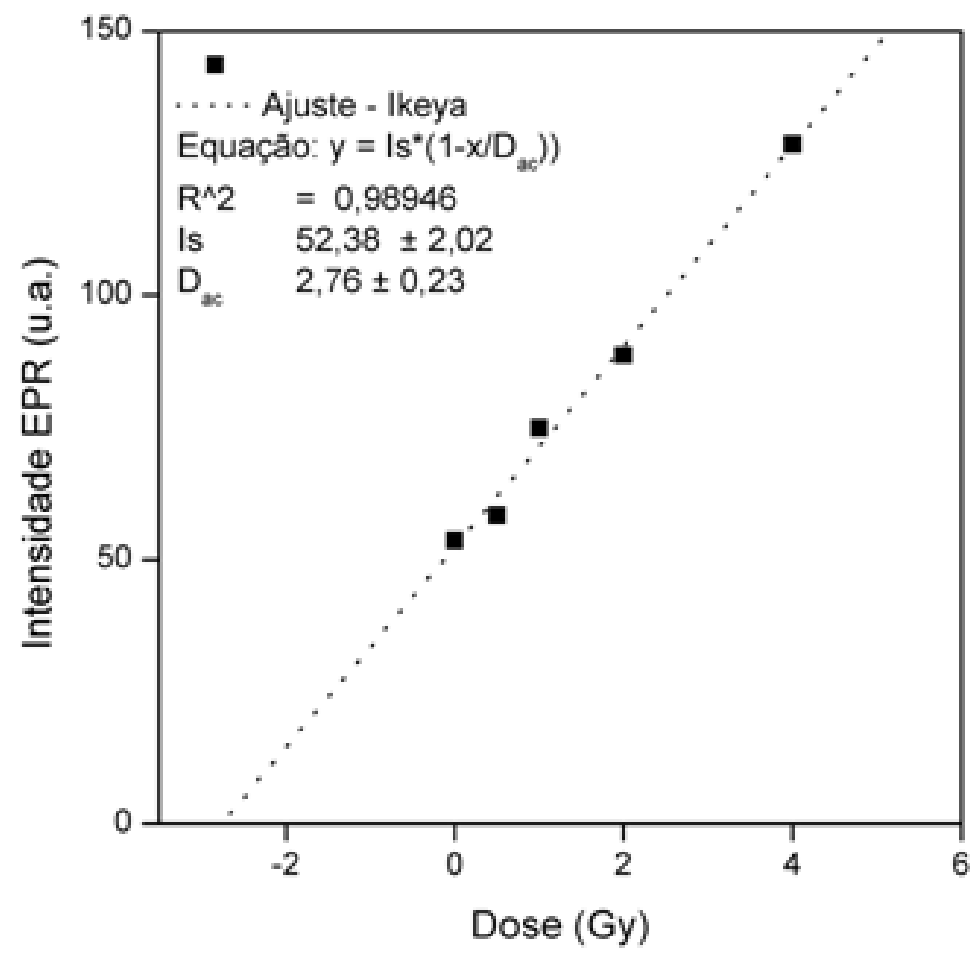

FIGURA 31 - Curva de calibração usando o método de dose aditiva para a amostra 30.

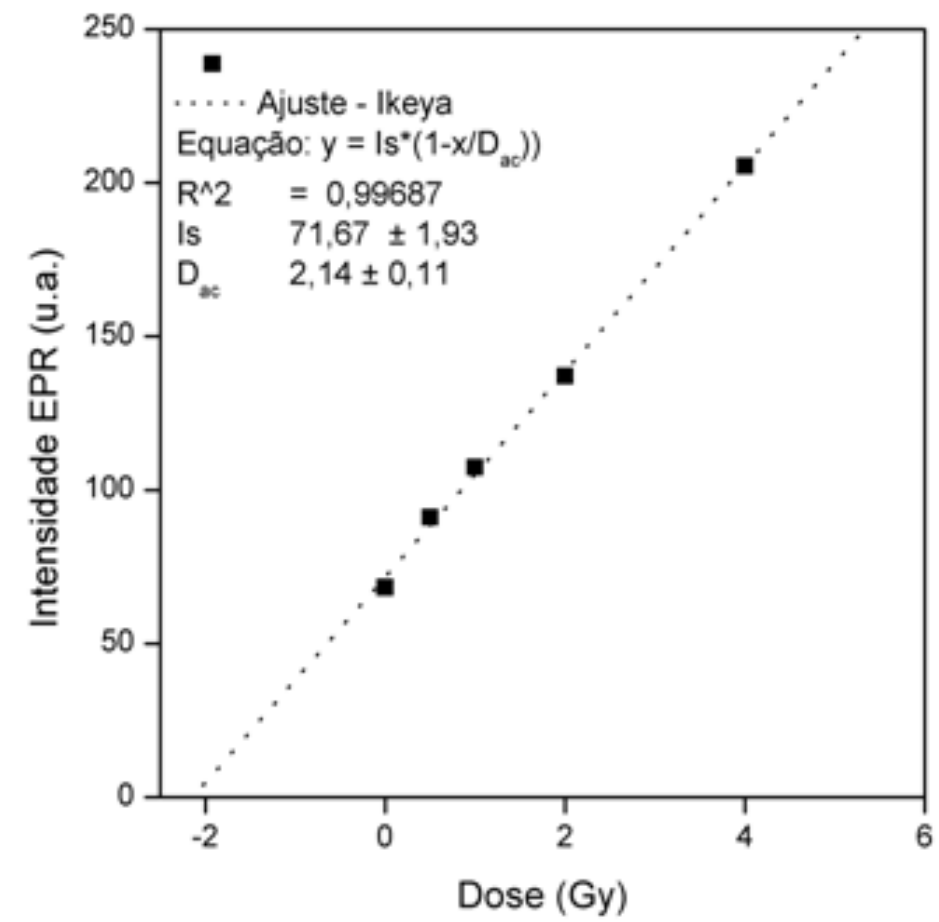

FIGURA 32 - Curva de calibração usando o método de dose aditiva para a amostra 56. 
Calculou-se a idade das cerâmicas por meio do procedimento proposto por Ikeya (1993). Na TAB. 12 apresentam-se as concentração dos elementos, U, Th, K, $\mathrm{D}_{\mathrm{an}}$, $\mathrm{D}_{\mathrm{ac}}$ e a idade (I) das amostras analisadas por EPR.

TABELA 12 - Dose acumulada $\left(\mathrm{D}_{\mathrm{ac}}\right)$, Dose anual $\left(\mathrm{D}_{\mathrm{an}}\right)$ e Idade (I) das amostras obtidas por EPR.

\begin{tabular}{cccccccc}
\hline Amostra & $\begin{array}{c}\mathbf{U} \pm \mathbf{D P} \\
(\mathbf{p p m})\end{array}$ & $\begin{array}{c}\mathbf{T h} \pm \mathbf{D P} \\
(\mathbf{p p m})\end{array}$ & $\mathbf{K} \pm \mathbf{D P}(\%)$ & $\begin{array}{c}\mathbf{D}_{\text {an }} \\
(\mathbf{m G y} / \mathbf{a n o})\end{array}$ & $\mathbf{D}_{\text {ac }}(\mathbf{G y})$ & $\begin{array}{c}\mathbf{I} \\
(\text { anos d.C })\end{array}$ & Grupo \\
\hline 05 & $2,28 \pm 0,17$ & $10,47 \pm 0,56$ & $0,75 \pm 0,15$ & $1,66 \pm 0,17$ & $1,61 \pm 0,136$ & $1041 \pm 132$ & 03 \\
& & & & & & & \\
30 & $3,18 \pm 0,23$ & $14,15 \pm 0,80$ & $1,77 \pm 0,14$ & $2,83 \pm 0,18$ & $2,76 \pm 0,23$ & $1037 \pm 103$ & 01 \\
& & & & & & & \\
56 & $2,42 \pm 0,58$ & $13,59 \pm 0,76$ & $1,13 \pm 0,11$ & $2,15 \pm 0,20$ & $2,14 \pm 0,11$ & $1017 \pm 106$ & 01 \\
\hline
\end{tabular}

Como mostrado na TAB. 12, os resultados da datação por EPR, indicam que as idades variaram muito pouco, entre 1017 e 1041 anos d.C.

Nos últimos anos, um grande numero de pesquisadores têm utilizado técnicas físicas para estudar as propriedades de queima de cerâmicas. Determinar a temperatura a qual a cerâmica foi queimada pode fornecer um respaldo para o entendimento de muitos aspectos da fabricação das cerâmicas.

A temperatura de queima pode ser obtida efetuando sucessivos aquecimentos dos materiais a diferentes temperaturas, monitorada por EPR. Um total de 06 amostras (02, 06, 11, 28, 47 e 49) foi estudado. As amostras 02, 06 e 47 do grupo 2, a amostra 49 do grupo 3 as amostras 11 e 28 do grupo 1. Nas FIGs. 33, 34, 35, 36, 37 e 38 apresenta-se o gráfico do fator g contra a temperatura experimental para cada amostra investigada. Podese observar nos espectros a variação, brusca, nos valores de g entre $600{ }^{\circ} \mathrm{C}$ e $650{ }^{\circ} \mathrm{C}$ indicando esta faixa de temperatura, como sendo a temperatura de queima das cerâmicas analisadas, no processo de manufatura. 


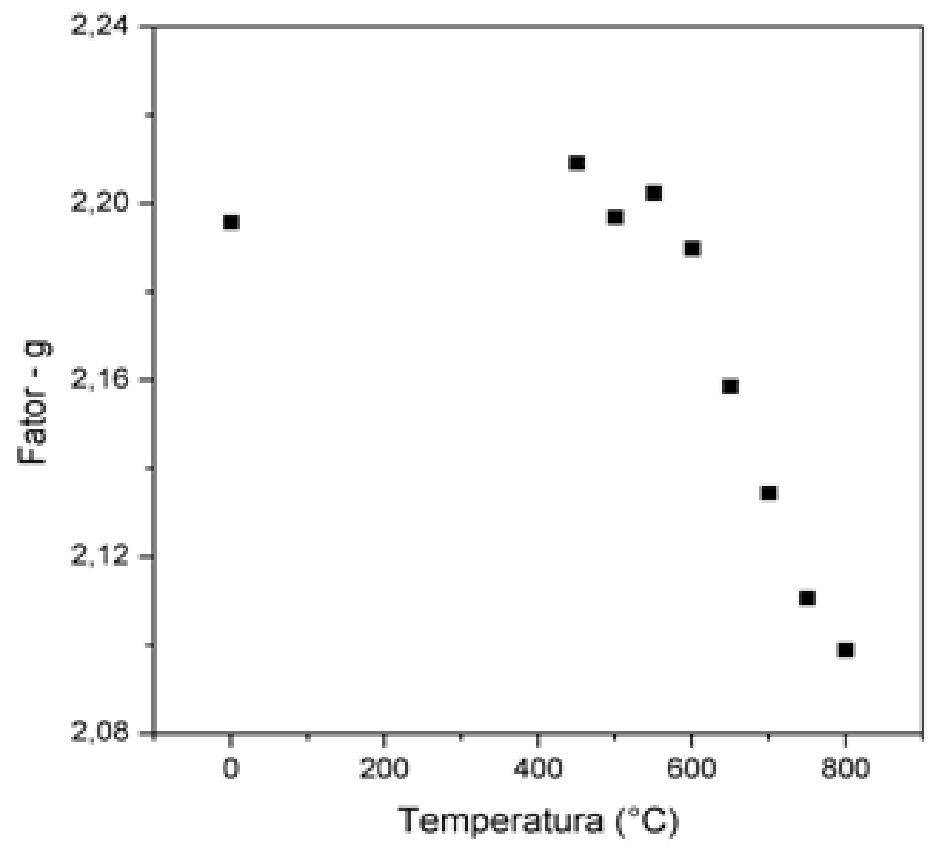

FIGURA 33 - Variação do fator g para o $\mathrm{Fe}^{3+}$ com a temperatura experimental realizada na amostra 02 .

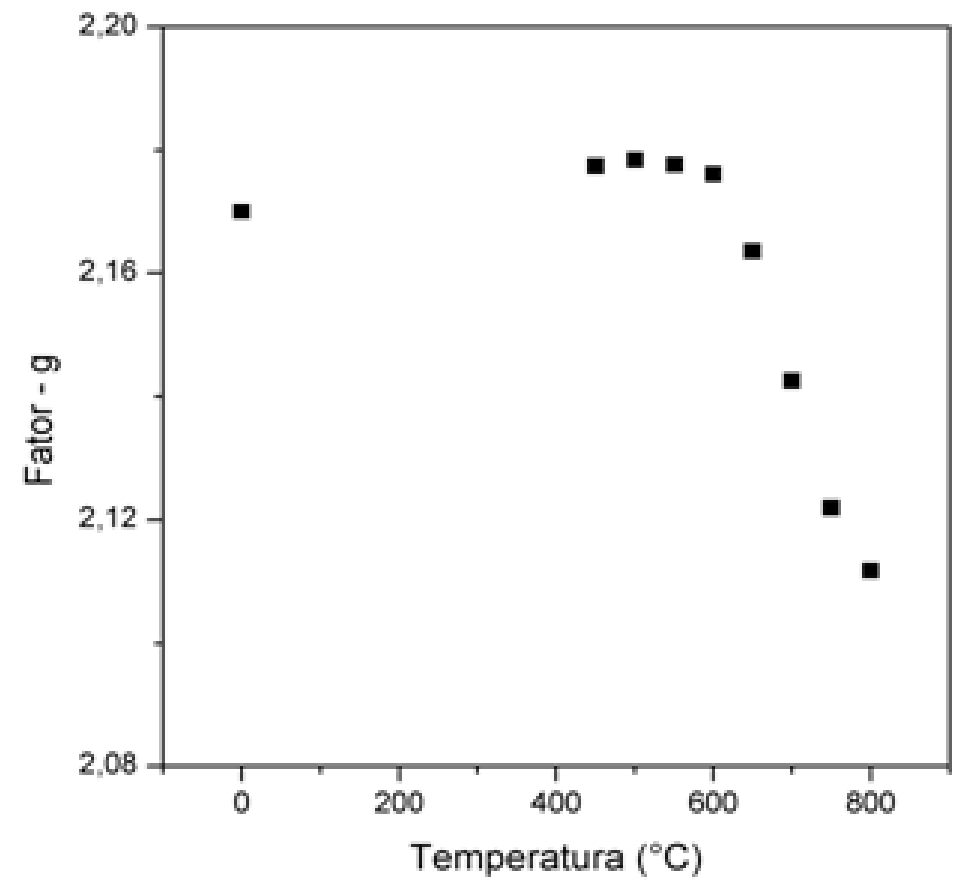

FIGURA 34 - Variação do fator g para o $\mathrm{Fe}^{3+}$ com a temperatura experimental realizada na amostra 06. 


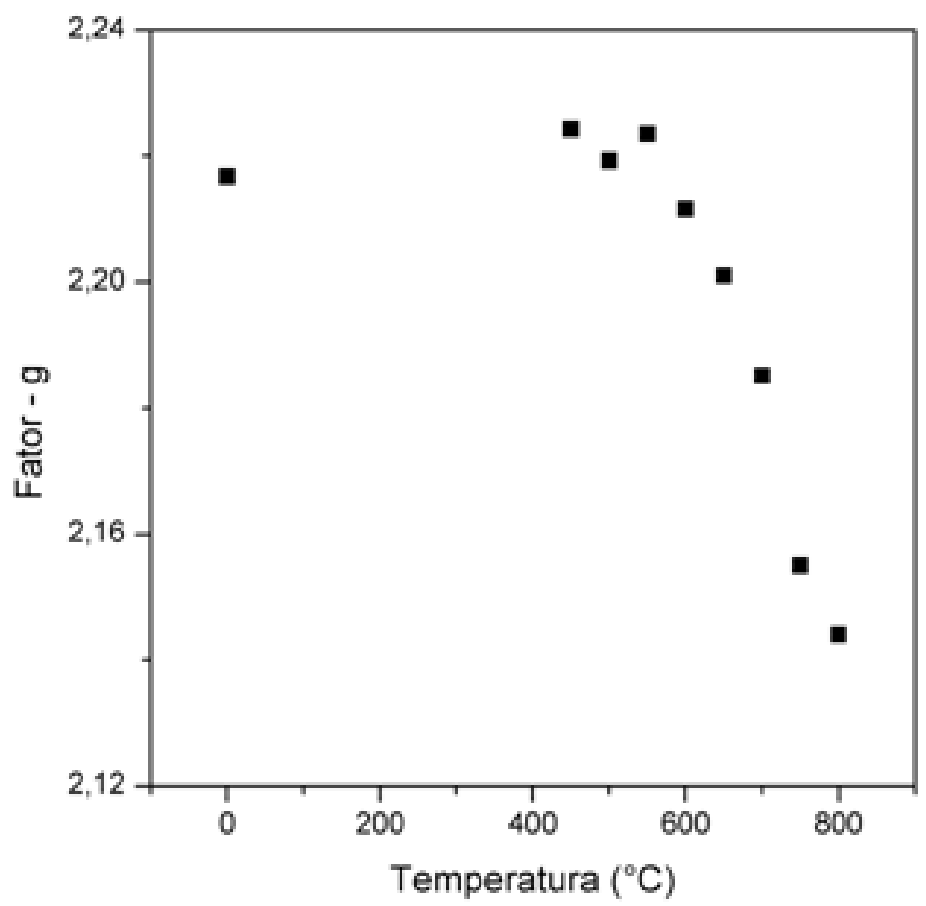

FIGURA 35 - Variação do fator g para o $\mathrm{Fe}^{3+}$ com a temperatura experimental realizada na amostra 11 .

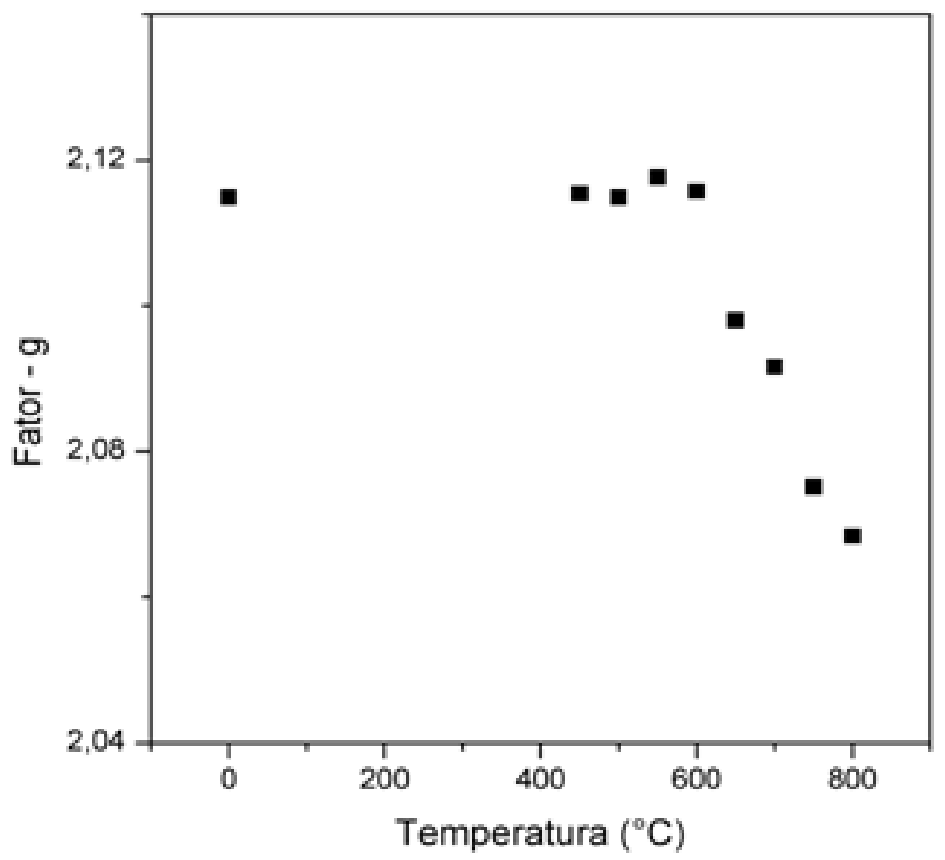

FIGURA 36 - Variação do fator g para o $\mathrm{Fe}^{3+}$ com a temperatura experimental realizada na amostra 47 . 


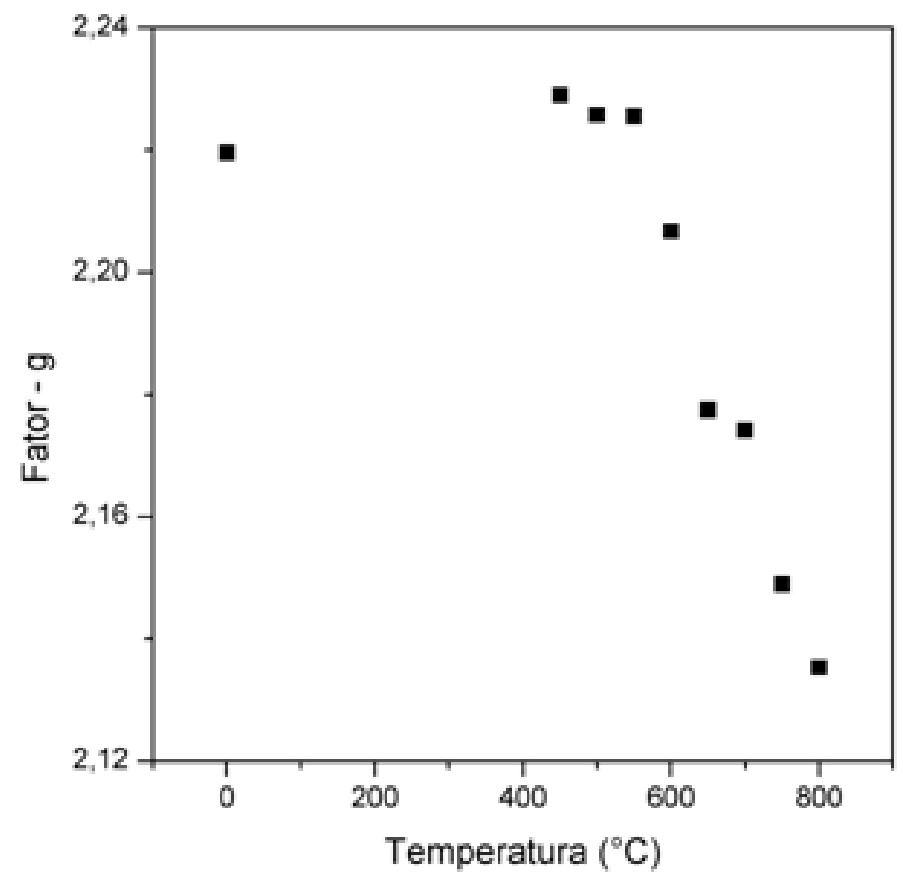

FIGURA 37 - Variação do fator g para o $\mathrm{Fe}^{3+}$ com a temperatura experimental realizada na amostra 28 .

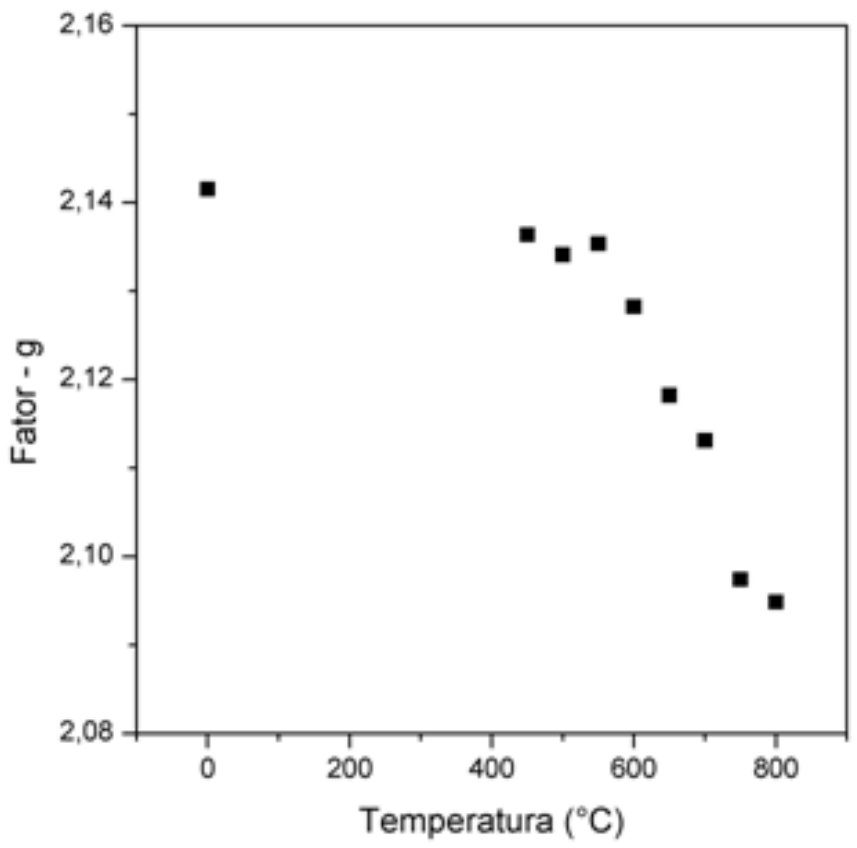

FIGURA 38 - Variação do fator g para o $\mathrm{Fe}^{3+}$ com a temperatura experimental realizada na amostra 49 . 
Na TAB. 13 apresentam-se os valores das temperaturas de queima para as seis amostras estudadas. Como pode ser visto os valores para temperaturas de queima dos fragmentos cerâmicos são muito próximos, entre a faixa de 600 e $650{ }^{\circ} \mathrm{C}$, indicando uma faixa de temperatura relativamente alta para a queima das cerâmicas Guaritas encontradas no sítio São Paulo II.

TABELA 13 - Resultado da temperatura de queima para as amostras analisadas.

\begin{tabular}{ccc}
\hline Amostra & Temperatura de queima $\left({ }^{\circ} \mathrm{C}\right)$ & Grupo \\
\hline 02 & $650 \pm 50$ & 02 \\
06 & $650 \pm 50$ & 02 \\
11 & $600 \pm 50$ & 01 \\
28 & $600 \pm 50$ & 01 \\
47 & $650 \pm 50$ & 02 \\
49 & $600 \pm 50$ & 03 \\
\hline
\end{tabular}




\section{CONCLUSÕES}

Neste trabalho, foram analisados 70 fragmentos cerâmicos coletados no sítio São Paulo II, localizado na Amazônia Central. As amostras foram estudadas por análise por ativação por nêutrons (NAA), microscopia óptica (OM), termoluminescência (TL) e espectroscopia paramagnética eletrônica (EPR).

A precisão do método analítico foi estudada, por meio do desvio padrão relativo (DPR). Os elementos que apresentaram um DPR menor que $10 \%$ foram $\mathrm{Na}, \mathrm{La}, \mathrm{Yb}, \mathrm{Lu}$, $\mathrm{Sc}, \mathrm{Cr}, \mathrm{Fe}, \mathrm{Co}, \mathrm{Zn}, \mathrm{Ce}, \mathrm{Eu}, \mathrm{Hf}$ e Th. O Co foi eliminado por que interferem devido a contaminação da broca de carbeto de tungstênio usada na preparação das amostras. O Zn foi eliminado devido à interferência espectral.

A presença de outliers foi estudada por meio da distância de Mahalanobis, utilizando como valor crítico o valor de Lambda Wilks. Os resultados mostraram que 3 amostras foram consideradas discrepantes e essas foram excluídas da base de dados. A base de dados formada por 67 amostras foi estudada por meio de análise de agrupamento, análise de componentes principais e análise discriminante. Os métodos estatísticos utilizados mostraram a existência de 3 grupos de amostras, indicando que na cerâmica do sítio São Paulo II foi utilizada nó mínimo mais de uma fonte de argila de composição química diferente. Os resultados mostraram também que, no mesmo grupo, existe uma dispersão relativamente acentuada, o que poderia indicar que não há uma boa homogeneidade na pasta usada por ceramistas para manufatura da cerâmica.

O resultado da datação realizado por meio de TL e EPR foram similares variando de $895 \pm 92$ a $1142 \pm 132$ d.C. Os resultados são da mesma ordem da datação obtida por carbono-14 (Lima et. al., 2006; Lima, 2008). Podemos supor que a idade do sítio está em torno de $1000 \pm 100$ anos d.C. A temperatura de queima determinada por EPR foi de $600 \pm$ $50{ }^{\circ} \mathrm{C}$. Os estudos arqueométricos realizados na cerâmica do sítio São Paulo II são concordantes com os estudos arqueológicos realizados por Tamanaha (2012). 


\section{SUGESTÕES PARA TRABALHOS FUTUROS}

- Aumentar o número de amostras analisadas por NAA. Aumentar o espaço amostral no sítio e incluir amostras de sítios próximos do São Paulo II, bem como outros sítios localizados na calha do rio Solimões. Isso reforçará as hipóteses levantadas neste trabalho e auxiliará os arqueólogos no entendimento do contexto de ocupação da região;

- Aplicar o filtro modificador de Mahalanobis para estudar o efeito do tempero na cerâmica;

- Avaliar os parâmetros de incerteza que influenciam as datações por TL e EPR e prever possíveis melhorias nos resultados das idades das cerâmicas;

- Estudar os argilominerais presentes na cerâmica arqueológica e na argila queimada e não queimada, por difração de raios-X, DRX. Esse estudo contribuirá para diferenciar as cerâmicas que compõem os diferentes grupos;

- Estudar o quartzo das amostras por DRX. Verificar o alo centrado em 23 graus das espículas no espectro de raios-X. 


\section{BIBLIOGRAFIA}

AHRENS, L.H. The lognormal distribution of the elements. Geochimica et Cosmochimica Acta, v. 6, n. 2/3, p. 121-131, 1954.

AITKEN, M.J. Thermoluminescence dating. London, Ingl.: Academic Press, 1985.

AITKEN, M.J. Archaeological involvements of physics. Physics Reports (Section C of Physics Letters), v. 40, n.5, p. 277-351, 1978.

ALMEIDA-FILHO, R.; MIRANDA, P.F. Mega capture of the Rio Negro and formation of the Anavilhanas Archipelago, Central Amazônia, Brazil: Evidences in an SRTM digital elevation model. Remote Sensing of Environment, v. 110, n. 3, p. 387-392, 2007.

ATHERTON, N.M. Principles of Electron spin resonance. New York: PTR Prentice Hall, 1993.

ATTAS, M.J. Magnetic prospecting. 1 - The water newton survey. Achaeometry, v. 1, n. 1, p. 24-26, 1958.

BALLA, M.; MOLNAR, Z.; KOROS, A. Uncertainly budget and validation of NAA using reference materials. Journal of Radioanalytical and Nuclear Chemistry, v. 259, n. 3, p. 395-400, 2004.

BECKMAN, R.J.; COOK, R.D. Outlier. Technometrics, v. 25, n. 2, p. 119-163, 1983.

BEIER, T.; MOMMSEN, H. Modified Mahalanobis filters for grouping pottery by chemical composition. Archaeometry, v. 36, n. 2, p. 287-306, 1994.

BENEDETTO, G.E.; CATALANO, F.; SABBATINI, L.; ZAMBONIN, P.G. Analytical characterisation of pigments on pre-Roman pottery by means of spectroscopic techniques part I: white coloured shards. Fresenius Journal of Analytical Chemistry, v. 362, n. 1, p. 170-175, 1998.

BENSIMON, Y.; DEROIDE, B.; CLAVEL, S.; ZANCHIETTA, J. Electron spin resonance and dilatometric studies of ancient ceramics applied to the determination of firing temperature. Japanese Journal of Applied Physics, v. 37, n. 8, p. 4367-4372, 1998.

BEZZERA, P.E.L. Compartimentação Morfotectônica do Interflúvio Solimões-Negro. 2003. Tese (Doutorado) - Centro de Geociências da UFPA, Belém. 
BISHOP, R.L.; CANOUTS, V.; CROWN, P.L.; ATLEY, S.P. Sensitivity, precision and accuracy: Their roles in ceramic compositional data bases. American Antiquity, v. 55, n. 2, p. 537-546, 1990.

BODE, P.; COEIJ, J.J. M. Activation analysis. In: Meyers, R.A., (Ed.). Encyclopedia of environmental analysis and remediation. New York: John Wiley \& Sons, 1998. v. 3, p. 68-84.

BORCARD, D.; GILLET, F.; LEGENDRE, P. Numerical ecology with R. New York, N.Y.; Springer, 2011.

BOUROCHE, J. M.; SAPORTA, G. Análise de dados. Rio de Janeiro: Zahar Editores, 1982.

BROWN, H.; GOLDBERG, E. US Atomic Energy Commission, AECD-2296, 1948.

CALEY, E. R. Klaproth as a pioneer in the chemical investigation of antiquities. Journal of Chemical Education, v. 26, n. 5, p. 242-247, 1949.

CALEY, E. R. The early history of chemistry in the service of archaeology. Journal of Chemical Education, n. 28, p. 64-66, 1951.

CHANG, H. Is Water, $\mathbf{H}_{2} \mathbf{O}$ ? Evidence, Realism and Pluralism. Boston: Springer, 2012.

COSTA, B.J.; BEMERGUY, L.R.; HASUI, Y.; BORGES, S.M.; JÚNIOR, F.C.; BEZERRA, L.P.; COSTA, L.M.; FERNANDES, G.M.J. Neotectônica da região amazônica: aspectos tectônicos, geomorfológicos e deposicionais. Revista Geonomos, v. 4, n. 2, p. 23-44, 1996.

DAMS, R. Nuclear Analytical Methods in the Life Sciences, In: KUCERA, J.; OBRUSNIK, J.; SABBIONI, E. (Ed.). Humana Press. New Jersey, 1994, p. 539-548.

DAVIS, J.C. Statistics and Data Analysis in Geology. New York: John Wiley \& Sons, 1986.

EATON, S.S.; EATON, G.R. The world as viewed by and with unpaired electrons. Journal of Magnetic Resonance, v. 223, p. 151-163, 2012.

FARIAS, T.M.B.; WATANABE, S.A. Comparative study of the thermoluminescence properties of several varieties of Brazilian natural quartz. Journal of Luminescence, $v$. 132, n. 10, p. 2684-2692, 2012.

FRONTASYEVA, V.M. Neutron Activation Analysis in the Life Sciences. Physics of Particles and Nuclei, v. 42, n. 2, p. 332-378, 2011.

GLASCOCK, M.D., Characterization of archaeological ceramics at MURR by neutron activation analysis and multivariate statistics, In: NEFF, H. (Ed.). Chemical Characterization of Ceramic Pastes in Archaeology, Prehistory Press. Madison, 1992, p. 11-26. 
GLASCOCK, M.D., NEFF, H. Neutron activation analysis and provenance research in archaeology. Measurement Science \& Technology, v. 14, n. 9, p.1516-1526, 2003.

GLASCOCK, M.D.; NEFF, H.; VAUGHN, K.J. Instrumental neutron activation analysis and multivariate statistics for pottery provenance. Hyperfine Interactions, v. 154, n. 1, p. 95-105, 2004.

GREENBERG, R.R.; BODE, P.; FERNANDES, P.E.A.N. Neutron activation analysis: A primary method of measurement. Spectrochimica Acta, v. 66, n. 3, p. 193-241, 2011.

HAIR, J.F.; ANDERSON, R.E.; TATHAM, R.L.; BLACK, W. C. Análise multivariada de dados. Trad. Adonai, S. Sant'Anna e Anselmo, C. Neto. 5 ed. Porto Alegre, RS: Bookman, 2006.

HANCOCK, R.G.V.; CARTER, T. How reliable are our published archaeometric analyses? Effects of analytical techniques through time on the elemental analysis of obsidians. Journal of Archaeological Science, v. 37, n. 2, p. 243-250, 2010.

IKEYA, M. New Applications of Electron Spin Resonance: Dating, Dosimetry and Microscopy. New Jersey: Scientific World, 1993.

JENSEN, M.; KEDIN, R.; YUE, Y. Microscopic features of biologically formed amorphous silica. On Biomimetrica, Shanghai, Ago. 2011. Disponível em: <http://www.intechopen.com/books/on-biomimetcs/microscopic-features-of biologically formed amorphous-silica>. Acesso em 17 de jan. 2012.

JOBSON, J.D. Applied multivariate analysis: Categorical and multivariate methods. New York: Springer-Verlag, 1992.

JOHNSON, A.J. e NICHERN, D.W. Applied Multivariate Statistical Analysis. New Jersey: Prentice Hill, 2002.

JOLLIFFE, I.T.; JONES, B.; MORGAN, J.T. Identifying influential observations in hierarchical cluster analysis. Journal of Applied Statistics, v. 22, n.1, p. 61-80, 1995.

JOLLIFFE, I.T. Rotation of ill-defined principal components. Applied Statistics-Journal of the Royal Statistical Society, v. 38, n. 1, p. 139-147, 1989.

KAUFMAN, L.; ROUSSEEEUW, P.J. Finding groups in data: An introduction to cluster analysis. New Jersey: John Wiley \& Sons, 1990.

KNAPPETT, C.; PIRRIE, D.; POWER, M.R.; NIKOLAKOPOULOU, I.; HILDITCH, J.; ROLLINSON, G.K. Mineralogical analysis and provenancing of ancient ceramics using automated SEM-EDS analysis (QEMSCAN): a pilot study on LB I pottery from Akrotiri, Thera. Journal of Archaeological Science, v. 38, n. 2, p. 219-232, 2011.

KIRSH, Y. Kinetic Analysis of Thermoluminescence; theoretical and pratical aspects. Physica Statu Solidi, v. 129, n. 15, p. 16-48, 1992.

LATINI, R.M.; BELLIDO, A.V.; VASCONCELLOS, M.B.A. Classification of 
archaeological ceramics from the brazilian amazon basin. Química Nova, v. 24, n. 6, p.724-729, 2001.

LEGENDRE, P. \& LEGENDRE, L. Numerical ecology. Amsterdam, Hol.: Elsevier, 1998.

LIMA, H.P.; NEVES, E.G.; PETERSEN, J.B. La fase Açutuba: Um novo complexo cerâmico na Amazônia Central. Arqueologia Suramericana, v.2, n. 1, p. 26-52, 2006.

LIMA, H.P. História das Caretas: a tradição borda incisa na Amazônia Central. 2008. Tese (Doutorado) - Museu de Arqueologia e Etnologia da USP, São Paulo.

LOMBARDI, G. The casting core composition and provenance of the Goljamata Kosmatka (Bulgaria) bronze head. Journal of Archaeological Science. v.36, n. 2, p. 520-527, 2009.

MAHALANOBIS, P.C. On the generalised distance in statistics. Proceedings of the National Institute of Science of India. v.2, n. 1, p. 49-55, 1936.

MAJOR, J.; DITOMMASO, A.; LEHMANN, J.; FALCÃO, S.P.N. Weed dynamics on Amazonian Dark Earth and adjacent soils of Brazil. Agriculture, Ecosystems and Environment, v. 11, n. 1-4, p. 1-12, 2005.

MACKEEVER, S.W.S. Thermoluminescence of solids. Cambridge: Cambridge University Press, 1985.

MANGUEIRA, G.M.; TOLEDO, R.; TEIXEIRA, S.; FRANCO, R.W.A. A study of the firing temperature of archeological pottery by X-ray diffraction and electron paramagnetic resonance. Journal of Physics and Chemistry of Solids, v. 72, n. 2, p. 90-96, 2011.

MANLY, B.F.J. Multivariate statistical methods. London: Chapman and Hall, 1986.

MARTINI M. Physics Methods in Archaeometry. Varenna: IOS Press, 2004.

MOITA, B.M. Proveniência da formação icá e de sedimentos do rio Solimões, entre os municípios de Tefé e Manacapuru - Amazonas. 2008. Dissertação (Mestrado) - Instituto de Ciências Exatas da UFA, Manaus.

MORRISON, D.F. Multivariate statistical methods. NewYourk: McGraw-Hill Company, 1976.

MUNITA, C.S.; PAIVA, R.P.; ALVES, M.A., OLIVEIRA, P.M.S.; MOMOSE, E.F. Provenance study of archaeological ceramics. Journal of Trace and Microprobe Techniques, v. 21, n. 4, p. 697-706, 2003.

MUNITA, C.S. Contribuición de la química a la arqueología. In Jiménez, E.N., (Ed.). Las técnicas analíticas nucleares y el patrimonio cultural. Quito: Ediecuatorial, 2010, p. 23.

NALIMOV, V.V. The application of mathematical statistics to chemical analysis. Oxford: Pergamom Press, 1963.

NETO, P.L.O.C. Estatística. São Paulo: Edgard Blücher, 2002. 
NUNES, P.K. Estudos arqueométricos do sítio arqueológico hatahara. 2009. Dissertação (Mestrado) - Instituto de pesquisas Energéticas e Nucleares, São Paulo.

OAKLEY, K.P. Fluorine, uranium and nitrogen dating of bones. In: Pyddoke, E. (Ed.). The Scientist and Archaeology. New York: Roy Publishers, 1963, v. 3, p. 111-119.

OLIVEIRA, L.C.; BOMFIM, A.P.S.; SOUZA, S.O. Estudo do tempo de vida dos picos termoluminescentes do quartzo de Xingó. Revista Canindé, v. 8, p.139-149, 2006.

PARRY, J.S. Activation Spectrometry in Chemical Analysis. New York: WileyInterscience, 1990.

PAVIA S. The determination of brick provenance and technology using analytical techniques from the physical sciences. Archaeometry, v. 48, n. 2, p. 201-218, 2006.

PEACOCK, D.P.S. Scientific analysis of ancient ceramics: Review. World Archaeology, v. 1, n. 3, p. 375-389, 1970.

PENNY, K.I. Appropriate critical values when testing for a single multivariate outlier by using the Mahalanobis distance. Applied Statistical, v. 45, n. 1, p. 73-81, 1996.

PERLMAN, I.; ASARO, F. Pottery analysis by neutron activation. Archaeometry, v. 11, n. 1, p. 21-38, 1969

QUEIROZ, M.M.A.; HORBE, A.M.C.; SEYLER, MOURA, P.C.A.V. Hidroquímica do rio Solimões na região entre Manacapuru e Alvarães - Amazonas - Brasil. Revista Acta Amazônica, v. 39, n. 4, p. 943-952, 2009.

RASMUSSEN, K.L.; LA FUENTE, G.A.; BOND, A.D.; MATHIESEN, K.K.; VERA, S.D. Pottery firing temperatures: a new method for determining the firing temperature of ceramics and burnt clay. Journal of Archaeological Science, v. 39, n. 6, p. 1705-1716, 2012.

R Development Core Team, version 2.15.1. R: A language and environment for statistical computing. R Foundation for Statistical Computing, Vienna, Austria, 2012. ISBN 3900051-07-0, Disponível em: <http://www.R-project.org/>. Acesso em: 02 Nov. 2012.

REIS, E. Estatística Multivariada Aplicada. Lisboa, Por.: Edições Sílabo, 1997.

ROELANDTS, I. Advances in radiogeochemistry. Journal of Radioanalytical and Nuclear Chemistry, v. 243, n. 1, p. 209-218, 2000.

ROSSETTI, D.F.; TOLEDO, P.M.; GÓES, A.M. New geological framework for Western Amazonia (Brazil) and implications for biogeography and evolution. Quaternary Research, v. 63, n. 1, p. 78-89, 2005.

SEABORG, G.T. LIVINGOOD, J.J. Artificial Radioactivity as a Test for Minute Traces of Elements. Journal American Chemistry Society. v. 60, n. 8, p. 1784-1795, 1938. 
SHEPARD, O.A. Ceramics for the archaeologist. Washington, D.C.: Braun-Brumfeld, 1985.

SOETE, D.; GIJELS, R.; HOSTE, J. Neutron activation analysis. London: Wiley Interscience, 1972.

SPEAKMAN, R.J.; GLASCOCK M.D. Acknowledging fifty years of neutron activation analysis in Archaelogy. Archaeometry, Oxford, v. 49, n. 2, p. 179-183, 2007.

STEARNS, T.M.; BEEVER, J.E.; SOUTHEY, B.R.; ELLIS, M.; MICKEITH, F.K.; RODRIGUEZ-ZAS, S.L. Evaluation of approaches to detect quantitative trait loci for growth, carcasss, and meat quality on swine chromosomes 2, 6, 13, and 18. II. Multivariate and principal component analysis. American Society of Animal Science. v. 83, n. 11, p. 2471-2481, 2005.

STEINNES, E. Neutron activation analysis in the geosciences: Lost territory, or New Deal? Journal of Radioanalytical and Nuclear Chemistry, v. 261, p. 701-708, 2004.

STOLTMAN, B.J. New petrographic evidence pertaining to ceramic production and importation at the olmec site of San Lorenzo. Archaeometry, v. 53, n. 3, p.510-527, 2011.

SZMUK, P.E., WATANABE, S. Dating of Brazilian Indian pottery. TLD Publication IEA, $\mathrm{n}^{\circ} 231,1971$.

TAMANAHA, E. Ocupação polícroma no baixo e médio rio Solimões, Estado do Amazonas. 2012. Dissertação (Mestrado) - Museu de Arqueologia e Etnologia da USP, São Paulo.

TANDOH, J.B.; NYARKO, B.J.B.; DAMPARE, S.B.; BREDWA-MENSAH, Y.; GYAMPO, O.; AHIAMADJIE, $\mathrm{H}$. The use of INAA technique in provenance studies of ancient pottery from the Greater Accra region of Ghana. Journal Radioanal Nuclear Chemistry, v. 284, n. 3, p. 567-573, 2010.

THORN, J.; GLASCOCK, M.D. New evidence for apulian red-figure production centres. Archaeometry, v. 52, n. 5, p. 777-795, 2010.

TITE M.S. Ceramic production, provenance and use - a review. Archaeometry, v. 50, n. 2, p. 216-231, 2008.

TOYOTA, G.R. Caracterização química da cerâmica Marajoara. 2009. Dissertação (Mestrado) - Instituto de pesquisas Energéticas e Nucleares, São Paulo.

VELDE B.; DRUC I.C. Archaeological ceramic materials: origin and utilization. Berlim: Springer, 1999.

WEIL, J.A.; BOLTON, J. Electron paramagnetic resonance. New Jersey: John Wiley \& Sons, 2007.

WILKS, S.S. Multivariate statistical outliers. The Indian Journal of Statistics, v. 25, n. 4, p. 407-426, 1963. 
WINTLE, A.G. Fifty years of luminescence dating. Archaeometry. v. 50, n.2, p.276-312, 2008 .

WINTLE A.G. Luminescence Dating: Laboratory Procedures and Protocols. Radiation Measurements, v. 27, n. 5-6, p. 769-817, 1997. 